NUCLEAR ENERGY RESEARCH INITIATIVE (NERI)

FINAL REPORT

\title{
Advanced Extraction Methods for Actinide/Lanthanide Separations
}

Grant No. DE-FG07-02SF22614 SF 269A

Project Number 02-098

Final Report

September 2002 - September 2005

Submitted by:

Lead Organization: University of Florida

PI: Michael J. Scott - Associate Professor of Chemistry

Collaborating Organization: Argonne National Laboratory

Process Chemistry and Engineering Department

Chemical Technology Division

Submitted on:

November 28, 2005 


\section{Technical Objectives}

Separation chemistry has always played a crucial role in the preparation of reactor fuels for both nuclear energy and nuclear weapons production. It is now assuming a central position in strategies for the clean up of decommissioned nuclear facilities, and potentially in the disposal of high-level radioactive waste. Although the United States does not currently allow spent fuel to be recycled, ${ }^{1}$ as it is practiced around the world, it has taken an active role in the development of nuclear waste reprocessing technologies.

Nuclear fuel reprocessing is based on the dissolution of irradiated material in a nitric acid solution. The reprocessing operations produce high and medium level liquid wastes (HLLW and MLLW, respectively) containing different long-lived radioactive elements as $\beta / \gamma$ emitters (Tc, I, $\mathrm{Zr}, \mathrm{Se}, \mathrm{Cs}$, etc.) and $\alpha$ emitters (transuranium actinides: $\mathrm{Np}, \mathrm{Pu}, \mathrm{Am}, \mathrm{Cm}$, etc.) (Figure 1). In order to simplify the conditioning of such wastes, it would be highly desirable to separate the different radioactive components with respect to their lifetime., ${ }^{2,3}$ Their separation would decrease the volume of waste intended for disposal in deep geological repositories, as intended for Yucca Mountain, and instead utilizing subsurface repositories, which are easier to manage. ${ }^{4}$ Furthermore, these nuclides once isolated, could be turned into short-lived or non-radioactive elements, thereby eliminating the radiological hazards and waste disposal problems.

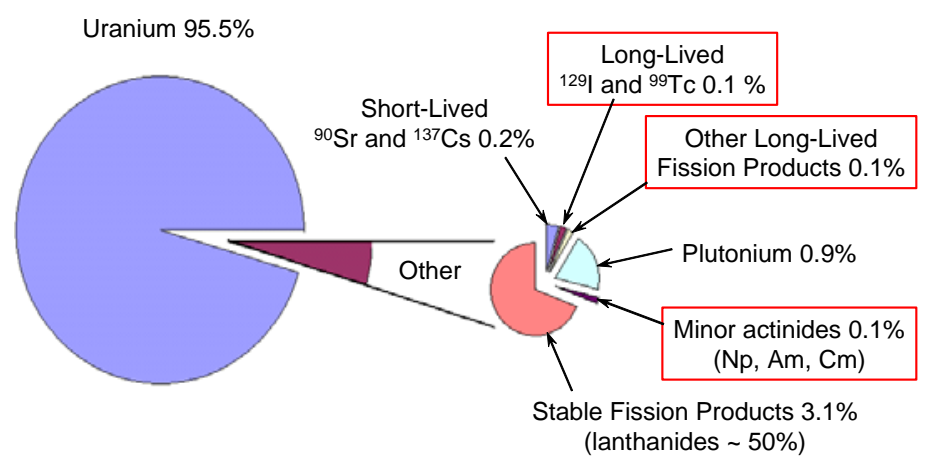

Figure 1: Composition of nuclear fuel rod after it has been removed from a reactor for disposal 
One of the most promising scenarios for successful nuclear reprocessing is the transmutation of long-lived actinides, such as americium, into short-lived nuclides by irradiation with neutrons. This process, however, yields significant amounts of lanthanides. Some of the lanthanides have very high neutron absorption, and they act as neutron poisons, reducing the efficiency and yield of the transmutation process. Therefore, to reach the goal of actinide transmutation the efficient separation of the lanthanides from the actinides is critical. ${ }^{5-8}$

During the last few decades, a number of processes for the removal of actinides from nitric acid waste streams have been reported. ${ }^{9-22}$ With few exceptions, ${ }^{13,15}$ these processes are based on liquid-liquid extraction procedures. Initially, a number of acidic organophosphorous extractants have been employed in the waste processing flowsheets. The studies have focused on bis(2-ethylhexyl) phosphoric acid, ${ }^{14-16}$ diisodecyl phosphoric acid, ${ }^{17}$ and bis(hexylethyl) phosphoric acid. ${ }^{18}$ Procedures involving these acidic extractants, however, suffer from major drawbacks. For instance, they require very low acidity to efficiently extract trivalent actinides, and exhibit poor selectivity for trivalent actinides over a number of fission products and inert constituents like $\mathrm{Zr}$ or Mo.

Along with acidic extractants, a neutral organophosphorous compounds have also been actively studied as actinides extractants included tributyl phosphate (TBP), ${ }^{15}$ a mixed trialkylphosphine oxides, ${ }^{21}$ dihexyl- $N, N$-diethylcarbamoylmethyl phosphonate (DHDECMP), ${ }^{10-13,19}$ or octyl(phenyl)- $N, N$-diisobutylcarbamoylmethyl phosphine oxide (1) (CMPO). ${ }^{20,22}$ The studies have shown that the monofunctional extractants are effective only at low acidities and occasionally require a salting-out agent to achieve efficient extraction of trivalent actinides. $^{15,21}$ On the other hand, the bifunctional neutral extractants like DHDECMP and CMPO can easily operate at much higher acidities relative to the monofunctional ligands. 
Actually, the bifunctional species behave more as monodentate extractants, rather than chelating agents, and the presence of the carbamoyl portion is important not only for coordination to the metal as had been previously proposed, ${ }^{11,23}$ but for ability to buffer the extractant against the effect of $\mathrm{HNO}_{3}{ }^{24}$ Since the acidity of waste solutions is generally in the range of 1 to $3 \mathrm{M}$ $\mathrm{HNO}_{3}$, the built in buffering effect of compound $\mathbf{1}$ makes the extraction process easier to control and prior acidity adjustment is not needed.

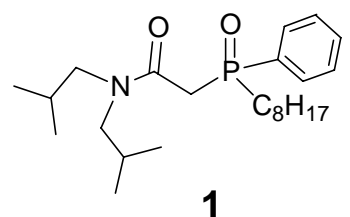

Figure 2. CMPO - (N,N-diisobutylcarbamoylmethyl) octylphenylphosphineoxide.

The extraction of uranium and plutonium form nitric acid solution can be performed quantitatively by the extraction with the monofunctional organophosphorous compound TBP. ${ }^{25,26}$ Commercially this process has found wide use in the PUREX (plutonium uranium extraction) reprocessing method. The TRUEX (transuranium extraction) process, is further used to coextract the trivalent lanthanides and actinides ions from high-level liquid waste (HLLW) generated during PUREX extraction. This method uses the neutral bifunctional CMPO $[(\mathrm{N}, \mathrm{N}-$ diisobutylcarbamoylmethyl) octylphenylphosphineoxide] (Figure 2) intermixed with TBP as a synergistic agent. ${ }^{27,28}$ However, the final separation of trivalent actinides from trivalent lanthanides still remains a challenging task.

Through the last decades the general structure of the classical CMPO has been modified in various ways, in order to develop a new extractant system that would compensate for the lack of selectivity for trivalent actinides over lanthanides in the TRUEX process. Compounds bearing numerous residues at the nitrogen and phosphorus, in a variety of combinations, has been 
synthesized. ${ }^{24,29}$ Horwitz et. al. investigated the solution structure of the Am(III) complex formed with CMPO under the technical conditions for the above mentioned TRUEX process. Their results show that Am(III) ion is coordinated by three CMPO molecules and three nitrate anions in an overall neutral complex as illustrated in Figure 3. A further $\mathrm{HNO}_{3}$ molecule is hydrogen bound to each of the carbamoyl oxygens. ${ }^{30,31}$ Furthermore, two to four molecules of CMPO have been suggested to be included in the complex formed with plutonium(IV) and more than one molecule of CMPO to be involve in the CMPO complexes of trivalent lanthanides. ${ }^{30}$
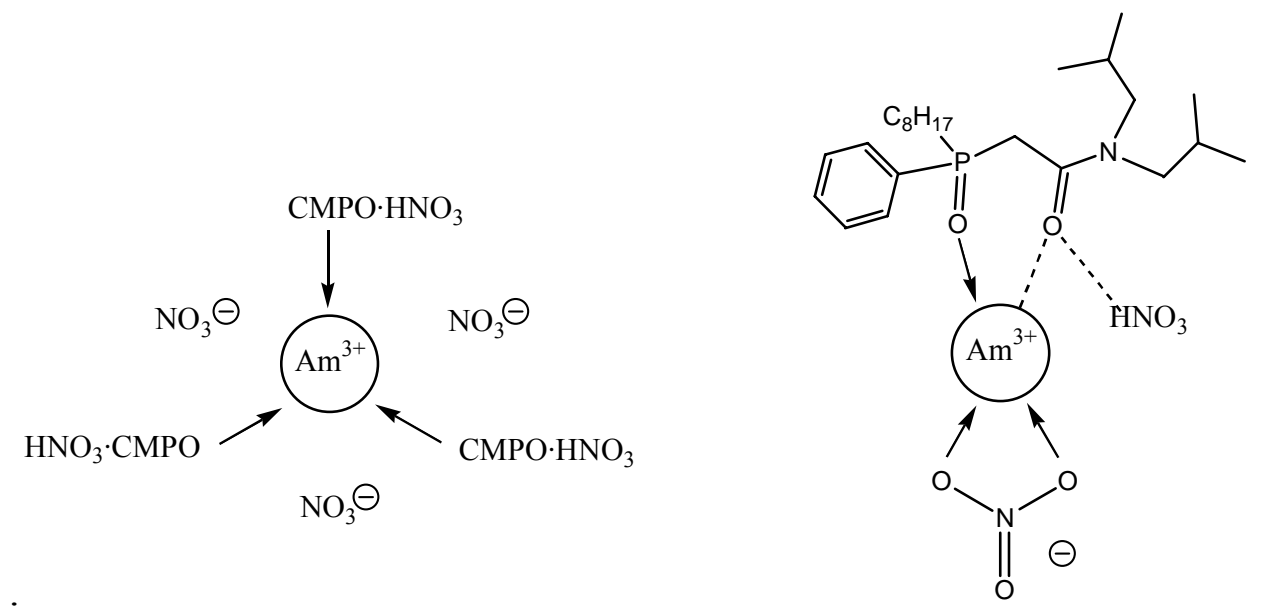

Figure 3. Possible solution structure (schematic) of the americium (III) nitrato-CMPO complex at high $\mathrm{HNO}_{3}$ concentration. ${ }^{32}$

It seems reasonable to construct molecules, in which several (three or four) CMPO functions are combined in a suitable mutual arrangement. This may not only lead to new ligands which show improved extraction properties on the basis of chelate effects (favorable entropic factors) but also to ligands which show selectivity in extraction due to the different stoichiometry (or composition) of complexes and to differences in the steric requirements. Inspired by this fact, groups in the 1990s attached multiple CMPO moieties to a variety of calixarene and calixarene-like platforms and were able to extract actinides at higher selectivities than seen in 
comparable experiments with mono-CMPO extractants. ${ }^{32-36}$ The most extensively studied group of these ligand systems contained four CMPO moieties tethered to the narrow and wide rims of calix[4]arenes (Figure 4). These ligand systems have shown increased actinide affinity relative to the mono-CMPO ligands, but their lanthanide selectivity has proved to be less predictable.

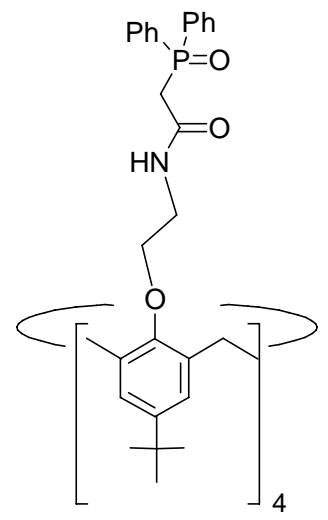

2

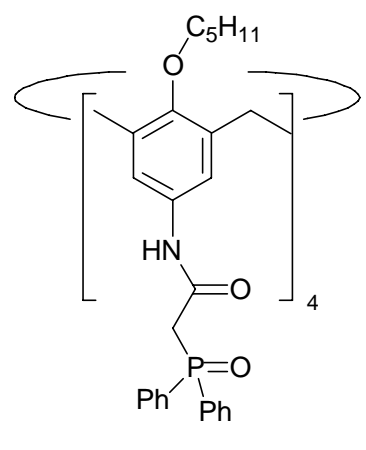

3

Figure 4. Calix[4]arenes with CMPO functions at the narrow and wide rims.

The affinity for lanthanides in these systems varied widely across the series, with the selectivity toward some lanthanides equaling that of the actinides. ${ }^{34}$ Additionally, the multiCMPO ligand systems presented in the literature have thus far lacked definitive characterizations of the ligand-metal complexes formed during the extraction experiments. Such a detailed understanding of the chemical basis for the metal selectivities of these ligands is essential for creating improved metal extracting systems.

Taking inspiration from the suggested coordination environment of the extracted species in the TRUEX process and the calix[4]arene work, we have developed a $C_{3}$-symmetric trisCMPO ligand system (Figure 5). The new extractants exhibit much higher selectivity for the actinide thorium over all of the lanthanides in comparison to other multi-CMPO systems such as presented in Figure $3 .{ }^{37}$ It shows considerable promise as improved extractants for actinide 
recoveries from high level liquid waste and for general clean-up operations. The design and synthesis of that tris-CMPO ligand system has focused on combining high distribution coefficients for the selected metal ions, high ion selectivity, and great stability toward hydrolysis in acidic media.

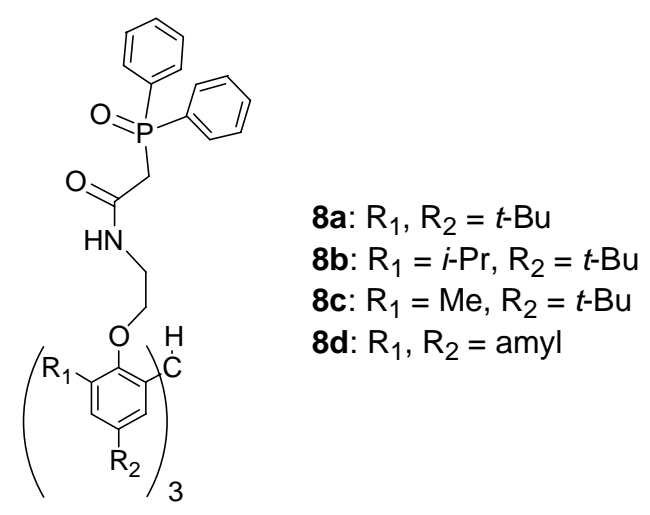

Figure 5. $C_{3}$-symmetric tris-CMPO ligand system.

The CMPO bifunctional neutral ligand was chosen as the extraction moiety for two important reasons: the ability to act as a bidentate ligand and the capability of the amide group to behave as an intramolecular buffer. The buffering effect protects the metal-phosphoryl bond from direct attack by hydronium ions in highly acidic media. ${ }^{24}$

Overall, basicity of the phosphoryl oxygen increases in the order: phosphonate (RO) ${ }_{2} \mathrm{PO}$ $<$ phosphinate $\mathrm{RO}(\mathrm{R}) \mathrm{PO}<$ phosphine oxide $\mathrm{R}_{2} \mathrm{PO}$; were $\mathrm{R}=$ alkyl. As a role, an increase in basicity increase the extraction efficiency while decrease ion selectivity. ${ }^{29}$ Therefore, choice of substituents should be very careful to afford high extraction efficiency and high ion selectivity at the same time. The tris-CMPO ligand system was designed to have a lower $\mathrm{P}=\mathrm{O}$ basicity than any dialkyl phosphine oxide, through the replacement of the alkyl with a phenyl groups. The decrease in basicity of oxygen is due to the greater inductive effect of the benzene ring. This way the decrease of basicity is achieved without introducing a P-O-C bond, which is subject to 
hydrolysis. Moreover, the phenyl groups adjacent to the $\mathrm{P}=\mathrm{O}$ group provide the steric hindrance that was found to be one of the factors responsible for higher selectivity for Am(III) over $\mathrm{Eu}(\mathrm{III})$ for some CMPO derivatives. ${ }^{29}$

The $\mathrm{An}(\mathrm{III}) / \mathrm{Ln}(\mathrm{III})$ separation, is still one of the key problems facing any new partitioning and transmutation nuclear waste management strategy. Problems are particularly posed by the identical oxidation states and the approximately equal ionic radii of the metals. During the period of the proposal, the binding attributes of the ligand systems with An(III) in addition to several other actinides including $\mathrm{Pu}(\mathrm{IV})$ and $\mathrm{U}(\mathrm{III})$ will be tested at Argonne and the information gained from these studies will be used to develop new, more sophisticated ligands. Ligands secured to the $C_{3}$-symmetric platform described herein afford ligands adept at selectively sequestering actinide and lanthanide ions from acidic nuclear waste streams.

\section{Research Progress}

\section{Synthesis of Tris-CMPO and Tris-CMPS Ligand Systems}

To develop a functional tris-CMPO/tris-CMPS ligand systems, three ligating groups can be attached to a platform capable of preorganizing these moieties for cooperative metal binding. Previous work with the triphenoxymethane platform 4, has shown that when all three phenol oxygens are substituted an "all up" conformation is observed. This conformer forces all oxygens on the same site relative to the central methine hydrogen of the platform both in the solid state and in solution. ${ }^{38}$ The attachment of three CMPO moieties to this platform through the

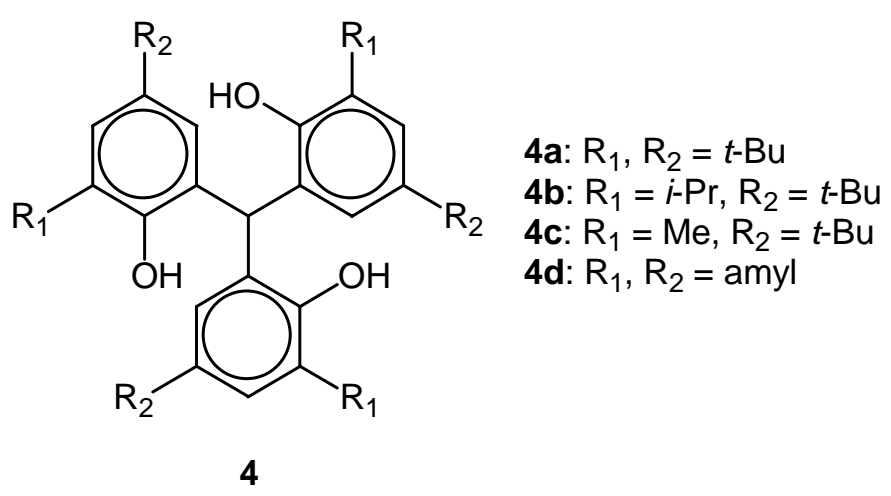

Figure 5. Triphenoxymethane platform with different substituents at 3 and 5 
phenol oxygens satisfies the requirement for proximate metal binding. The aliphatic substituents on the platform $\left(\mathrm{R}^{1}\right.$ and $\mathrm{R}^{2}$ ) alter the solubility of the final complexes in organic solvents (Figure 5).

Scheme 1 illustrates two synthetic paths that have been previously developed in our group to synthesize the triphenoxymethane scaffold. ${ }^{38}$ Isolation and purification of products in both routs are quite simple; the triphenoxymethane compounds are filtered away and any of starting materials or by-products are removed with washing of the solid with methanol.

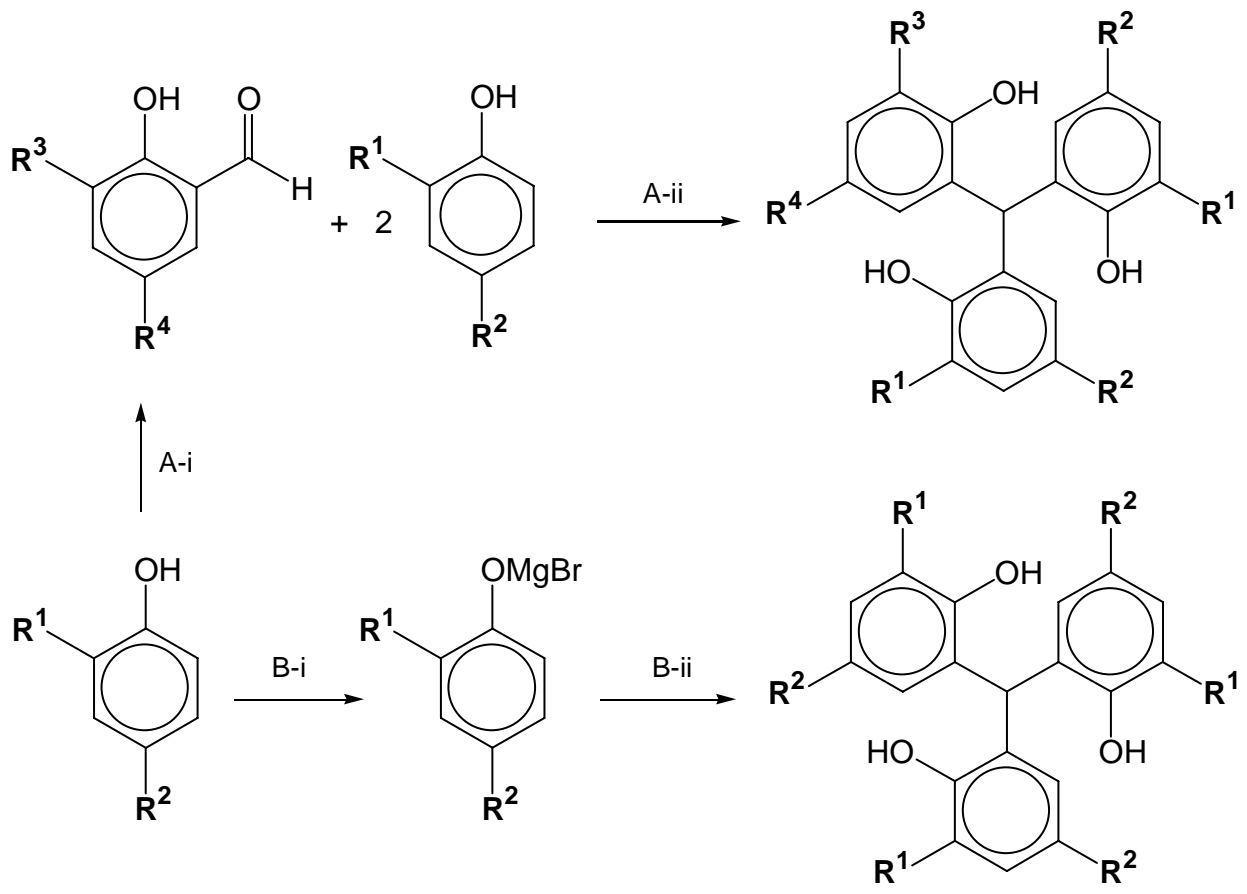

Scheme 1. The two synthetic routs to prepare the triphenoxymethane platform starting with 2,4-dialkyl phenol. Route A: (i) paraformaldehyde, $\mathrm{SnCl}_{4}$, toluene; (ii) $\mathrm{SOCl}_{2}$, MeOH. Route B: (i) EtMgBr, $\mathrm{Et}_{2} \mathrm{O}$; (ii) triethylorthoformate. $\mathrm{R}^{1}$ and $\mathrm{R}^{2}$ can be any alkyl. 


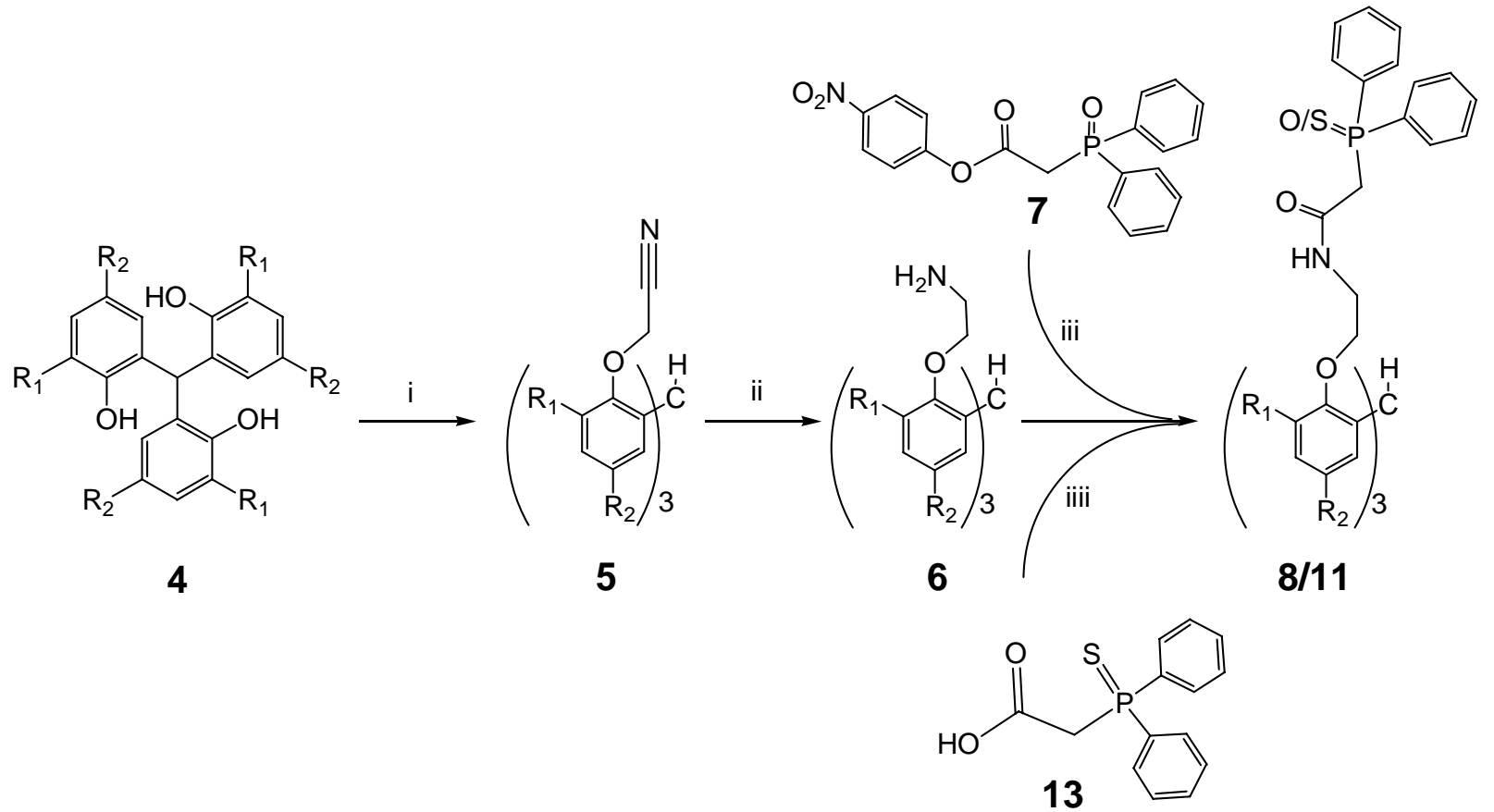

Scheme 2. 8: $\mathrm{R}_{1}, \mathrm{R}_{2}=\mathrm{t}-\mathrm{Bu}$ : (i) $\mathrm{K}_{2} \mathrm{CO}_{3}, \mathrm{NaI}, \mathrm{ClCH}_{2} \mathrm{CN}$, refluxing acetone, 2 days, $75 \%$;

(ii) $\mathrm{LiAlH}_{4}, \mathrm{Et}_{2} \mathrm{O}$, rt overnight, $80 \%$; (iii) $7, \mathrm{CHCl}_{3}, 45^{\circ} \mathrm{C}, 3$ days, $95 \%$; 11: $\mathrm{R}_{1}, \mathrm{R}_{2}=$ amyl:

(iiii) 13, Mercaptothiazoline, DCC, DMAP, $\mathrm{CH}_{2} \mathrm{Cl}_{2}$, rt overnight, $70 \%$.

The CMPO moieties were tethered to the platform using well-established derivatization method developed for the CMPO-calixarene systems (Scheme 2). ${ }^{32,33}$ The attachment of the CMPS moieties was facilitated using synthetic methodology developed for preparation of the hydroxypyridinones. ${ }^{39}$ Since all steps of these syntheses are high yielded, multi-gram quantities of ligands were produced with little synthetic effort

\section{Lanthanide and Actinide Extraction with the Tris-CMPO/CMPS Ligand Systems}

Lanthanides are often used as models for actinides in extraction and complexation studies owing to the similarity of their ionic radii and their coordination behavior. Thus, first extraction experiments were carried out with series of these trivalent ions as a models for actinides(III). 
Thorium(IV) was studied for similar reasons as a model of plutonium(IV). The conditions of the extraction experiments were chosen both to mimic the acidic environment of the TRUEX process, and allow a direct comparison between the extraction properties of our tris-CMPO ligands with other published multiple-CMPO ligand systems presented in Figure 3. The lanthanides, lanthanum, cerium, neodymium, europium, and ytterbium while the actinide thorium as nitrate salts $\left(1 \mathrm{M}\right.$ nitric acid solution) were extracted with an equal volume of a $10^{-3}$ M methylene chloride ligands solution. The extractability of the metal ion in all cases was determined by measuring the metal concentration in the nitric acid phase before and after extraction.

Chart 1 and Table 1 give the percentage of thorium(IV) and series of lanthanides(III) extracted into methylene chloride by the tris-CMPO ligand 8a, classical mono-CMPO extractant $\mathbf{1}$, and the most fully studied the tetra-CMPO calixarene systems, 2 and 3 , for comparison. Results of the extraction experiments reveal that $\mathbf{8 a}$ is a highly efficient extractant for Th(IV) similar in magnitude to the CMPO-calixarene systems, but unlike these other systems, 8a has a low and constant affinity for trivalent lanthanides across the series. Surprisingly, the monoCMPO molecule was found to have very low affinity for both Th(IV) and entire series of lanthanides in presented extraction conditions. For a decent extraction level, mono-CMPO 1 must be present at $10^{-2} \mathrm{M}$ concentration [for example $\% \mathrm{E}$ Th(IV) $=12.2$ for $10^{-2} \mathrm{M}$ of $\mathbf{1} ; \% \mathrm{E}$ $\mathrm{Eu}(\mathrm{III})=69.6$ for $0.25 \mathrm{M}$ of $\mathbf{1}] .^{32}$ Presumably, the single CMPO moieties are not basic enough to remove the nitrate counterions of the metal ions, limiting their effectiveness and metal ion extractability. The calix[4]arene CMPO systems show an increase in Th(IV) selectivity due to the participation of two or more CMPO arms in metal binding, but the variability in the lanthanide extraction results using these systems suggest that these arms may be too far apart to 
force the complexes into rigid structural arrangements. Therefore, the selectivity of tris-CMPO ligands for thorium(IV) over the lanthanides(III) may be attributed to the higher intrinsic stability of the thorium complex created by the combined effects of its increased Lewis acidity relative to the trivalent lanthanides and the increased ability of the actinide metals to accommodate the coordination environment presented by the ligand. Similar metal complex stability effects were shown to influence the alkali-metal extraction

$$
\text { properties of } \mathbf{8 a} .^{37}
$$

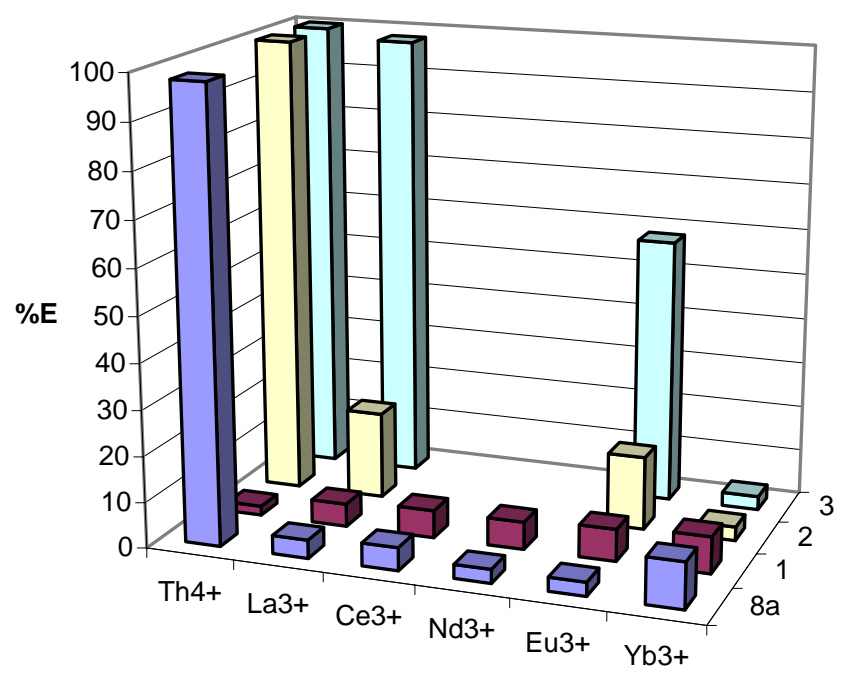

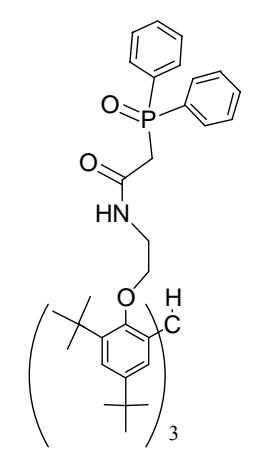

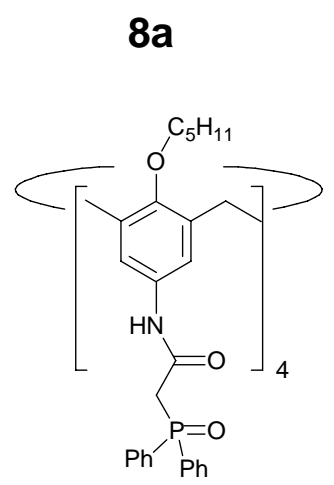

3

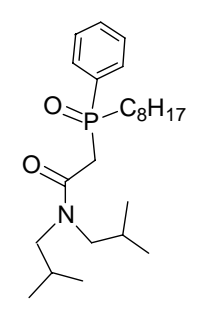

1

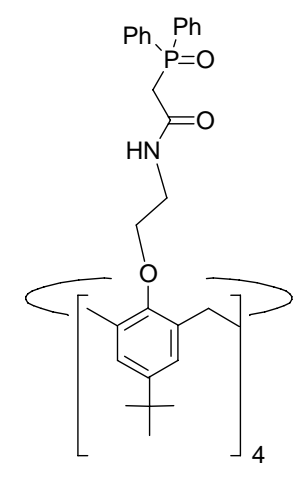

2

Chart 1. Metal Extraction Percentage (\%E) for the ligands 1, 2, 3, and 8a using equal volumes of $10^{-4} \mathrm{M}$ metal nitrate in $1 \mathrm{M} \mathrm{HNO}_{3}$ and $10^{-3} \mathrm{M}$ ligand in $\mathrm{CH}_{2} \mathrm{Cl}_{2}$. 
Table 1. Extraction percentage $(\% \mathrm{E})^{a}$ for $\mathbf{1}-\mathbf{3}$ and $\mathbf{8 a}$.

\begin{tabular}{|c|c|c|c|c|c|}
\hline $\begin{array}{c}\text { Cation } \\
\left(10^{-4} \mathrm{M}\right) \text { in } \\
1 \mathrm{M} \mathrm{HNO}_{3}\end{array}$ & $\begin{array}{c}\text { Equivs of } \\
\text { ligand in } \\
\text { organic } \\
\text { phase }\end{array}$ & $\begin{array}{c}\mathbf{8 a} \\
(\% \mathrm{E})\end{array}$ & $\begin{array}{c}1 \\
(\% \mathrm{E})\end{array}$ & $\begin{array}{c}2 \\
(\% \mathrm{E})\end{array}$ & $\begin{array}{c}3 \\
(\% \mathrm{E})\end{array}$ \\
\hline $\mathrm{Th}^{4+}$ & 10 & $98 \pm 1$ & $2 \pm 1$ & $>90$ & $>90$ \\
\hline $\mathrm{La}^{3+}$ & 10 & $4 \pm 1$ & $5 \pm 1$ & $19 \pm 1$ & $98 \pm 1$ \\
\hline $\mathrm{Ce}^{3+}$ & 10 & $5 \pm 1$ & $6 \pm 1$ & - & - \\
\hline $\mathrm{Nd}^{3+}$ & 10 & $3 \pm 1$ & $6 \pm 1$ & - & - \\
\hline $\mathrm{Eu}^{3+}$ & 10 & $3 \pm 1$ & $7 \pm 1$ & $16 \pm 1$ & $58 \pm 1$ \\
\hline $\mathrm{Yb}^{3+}$ & 10 & $10 \pm 1$ & $8 \pm 1$ & $3 \pm 1$ & $3 \pm 1$ \\
\hline
\end{tabular}

Modification of the tris-CMPO ligand system by introducing different substituents in ortho- and para- positions of the aryl rings of triphenoxymethane platform slightly alters its solubility in non-polar solvents $(\mathrm{Me}<i-\operatorname{Pr}<t-\mathrm{Bu}<\mathrm{Amyl})$, although do not affect significantly its extraction properties as presented in Chart 2 or Table 2. The trend for selective extraction of Th(IV) over entire series of lanthanides(III) has not been changed. 


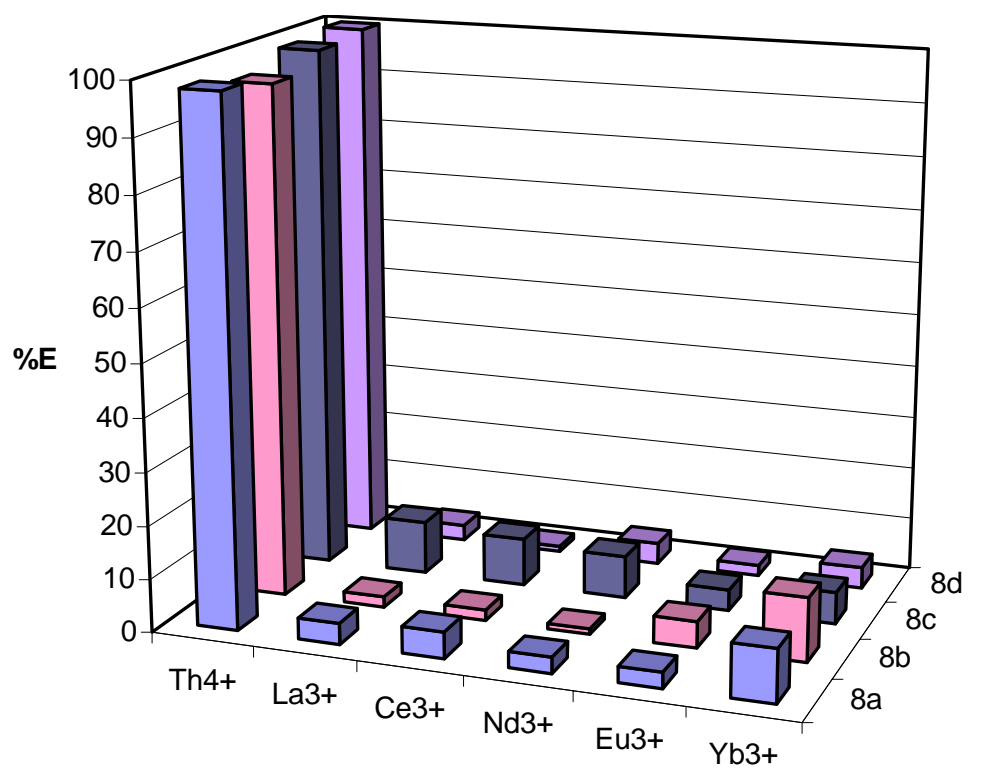

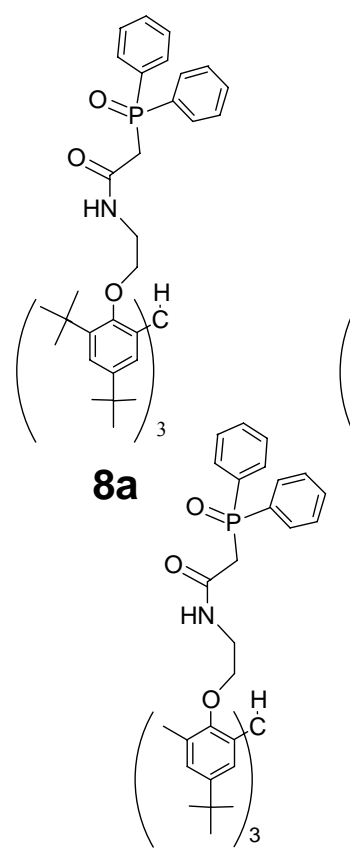

8c

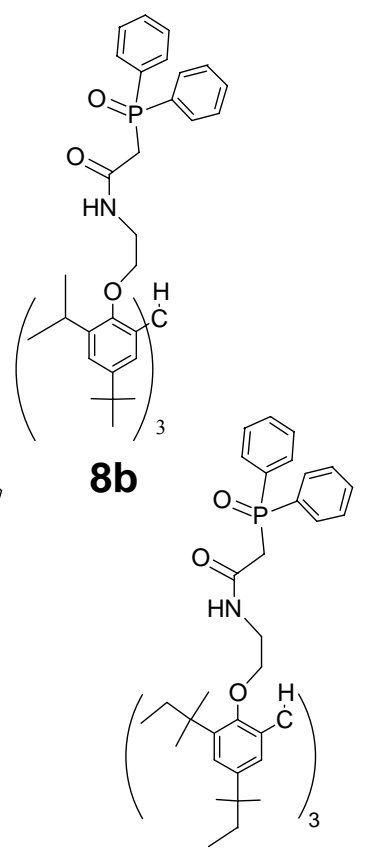

8d

Chart 2. Metal extraction percentage $(\% \mathrm{E})$ for the ligands $\mathbf{8 a}-\mathbf{8 d}$ using equal volumes of $10^{-4} \mathrm{M}$ metal nitrate in $1 \mathrm{M} \mathrm{HNO}_{3}$ and $10^{-3} \mathrm{M}$ ligand in $\mathrm{CH}_{2} \mathrm{Cl}_{2}$.

Table 2. Extraction percentage $(\% \mathrm{E})$ for $\mathbf{8 a}-\mathbf{8 d}$.

\begin{tabular}{c|c|c|c|c|c}
\hline Cation & Equivs of & $\mathbf{8 a}$ & $\mathbf{8 b}$ & $\mathbf{8 c}$ & $\mathbf{8 d}$ \\
$\left(10^{-4} \mathrm{M}\right)$ in & ligand in & $(\% \mathrm{E})$ & $(\% \mathrm{E})$ & $(\% \mathrm{E})$ & $(\% \mathrm{E})$ \\
$1 \mathrm{M} \mathrm{HNO}_{3}$ & organic phase & & & & \\
\hline $\mathrm{Th}^{4+}$ & 10 & $98 \pm 1$ & $96 \pm 1$ & $99 \pm 2$ & $100 \pm 1$ \\
$\mathrm{La}^{3+}$ & 10 & $4 \pm 1$ & $2 \pm 1$ & $10 \pm 2$ & $3 \pm 2$ \\
$\mathrm{Ce}^{3+}$ & 10 & $5 \pm 1$ & $2 \pm 1$ & $9 \pm 1$ & $1 \pm 1$ \\
$\mathrm{Nd}^{3+}$ & 10 & $3 \pm 1$ & $5 \pm 1$ & $4 \pm 1$ & $2 \pm 1$ \\
$\mathrm{Eu}^{3+}$ & 10 & $10 \pm 1$ & $12 \pm 1$ & $6 \pm 1$ & $4 \pm 1$ \\
$\mathrm{Yb}^{3+}$ & 10 & $3 \pm 1$ & $8 \pm 1$ & $4 \pm 1$ \\
\hline
\end{tabular}


To understand the difference between the lanthanides and actinide thorium, as well as compare the structure with complex of $\mathbf{8 a}\left(\mathrm{R}_{1}, \mathrm{R}_{2}=t\right.$-Bu) obtained previously, ${ }^{37}$ the thorium nitrate complex of $\mathbf{8 c}\left(\mathrm{R}_{1}=\mathrm{Me}, \mathrm{R}_{2}=t-\mathrm{Bu}\right)$ has been synthesized and characterized. The fully hydrated nitrate salts of these metals were utilized in the preparation of these complexes to provide the exogenous water ligands and nitrate counterions available when dissolved in $1 \mathrm{M}$ nitric acid. The crystal structure (Figure 7) of the thorium nitrate complex 14c (ligand scaffold 8c) was found to be isostructural with previously published structure of thorium nitrate complex 14a (using ligand moiety $\mathbf{8 a}, \mathrm{R}_{1}, \mathrm{R}_{2}=t-\mathrm{Bu}$ ). ${ }^{37}$

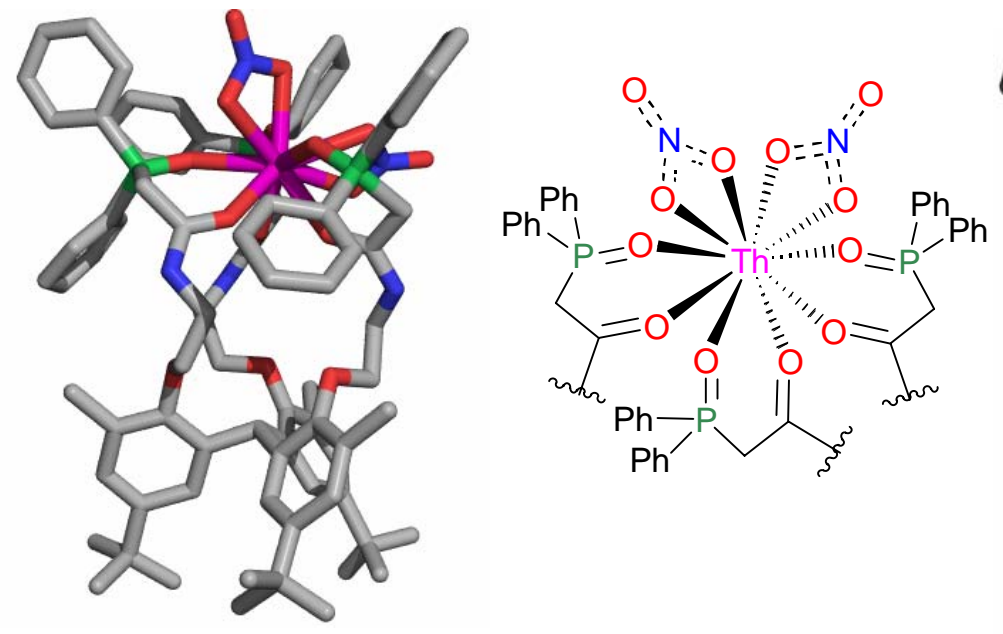

Ligand 8c

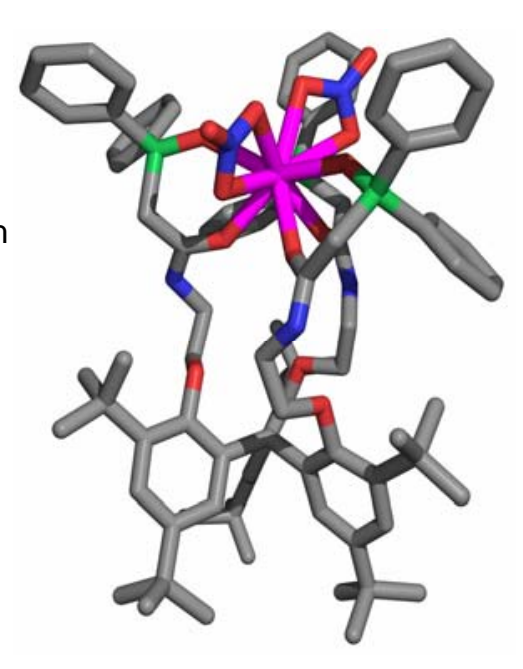

Ligand 8a

Figure 7. Crystal structures of the 10 coordinate +2 cationic thorium(IV) nitrate complexes with ligands $8 \mathbf{c}$ and 8 a respectively with two coordinated $\mathrm{NO}_{3}{ }^{2-}$ counterions.

Figure 7 presents the crystal structures of the thorium nitrate complexes of $\mathbf{8 c}$ and $\mathbf{8 a}$ were all three CMPO arms cooperatively bind the metal center through their six oxygen donor atoms. The tight binding of the tetravalent metal by these three bulky ligand moieties allows 
only enough space for two of its four nitrate counterions generating a $2+$ cationic complexes. In fact, the cooperative binding of the thorium ion by all three CMPO moieties in $\mathbf{8 c}$, in solution, has been verified by the ${ }^{31} \mathrm{P}$ NMR spectrum. The complex exhibits a single phosphorus resonance shifted $9 \mathrm{ppm}$ downfield in comparison to the spectrum for the unbound ligand, in agreement with all three CMPO moieties binding the metal simultaneously in solution. For the FT-ICR-MS spectrum, the complex was acidified with nitric acid prior to injection. The spectrum contains predominantly the $2+$ cationic species: $\left[8 \mathrm{c} \bullet \mathrm{Th}\left(\mathrm{NO}_{3}\right)_{2}\right]^{2+}$ that agrees with the crystal structure and $\left[\mathbf{8 c} \bullet \mathrm{Th}\left(\mathrm{NO}_{3}\right)(\mathrm{H})\right]^{2+}$ which can be easily form in $1 \% \mathrm{HNO}_{3}$ in $\mathrm{MeOH}$ solution used for MS analysis. The ${ }^{1} \mathrm{H}$ NMR spectrum in $\mathrm{CDCl}_{3}$ clearly demonstrated the loss of the $C_{3}$-symmetric environment induced by the ligand upon thorium coordination. The resonances associated with analogous linker moiety hydrogens located near this asymmetry differentiate relative to the ${ }^{1} \mathrm{H}$ NMR spectrum of $\mathbf{8 a}$, while resonances associated with the less affected triphenoxymethane portion of the complex retain their symmetry.

Although the crystal structures of lanthanum and neodymium complexes with $\mathbf{8 c}$ have not been determined yet, the presence of the single phosphorous resonance ${ }^{31} \mathrm{P}$ NMR spectrum of their complexes clearly indicates equal participation of all three ligand arms in metal ion binding. For the Nd(III) complex, the signal is shifted $31 \mathrm{ppm}$ downfield, while for the $\mathrm{La}(\mathrm{III}) 3 \mathrm{ppm}$ with respect to the ligand itself. Based on characterization of the lanthanide complexes of $\mathbf{8 a}$ and similarity with the thorium complexes of $\mathbf{8 a}$ and $\mathbf{8 c}$ can be expected that upon complexation by $\mathbf{8 c}$, the $\mathrm{Nd}$ and $\mathrm{La}$ will form $2+$ cationic complexes. Indeed, the FT-ICR-MS analysis confirmed presence of similar 2+ cationic complexes as were previously found upon complexation with $\mathbf{8 a}{ }^{37}$ In addition to the presence of $\left[\mathbf{8} \mathbf{c} \bullet \operatorname{Ln}\left(\mathrm{NO}_{3}\right)\right]^{2+}$ 
species $(\mathrm{Ln}=\mathrm{Nd}, \mathrm{La})$, the $[\mathbf{8} \mathrm{c} \bullet \mathrm{Ln}(\mathrm{H})]^{2+}$ along with $1+$ cationic $\left[\mathbf{8 c} \bullet \operatorname{Ln}\left(\mathrm{NO}_{3}\right)_{2}\right]^{+}$complexes has been observed.

In general, the solvent extraction separation process is based on the transfer of a charged metal ion, from a polar aqueous phase to an immiscible phase with simultaneous charge neutralization. As published previously, ${ }^{37}$ the crystal structure of thorium and neodymium nitrates of 8a showed three CMPO arms tightly binding the metal center allowing space on the metals for only one (in case of $\operatorname{Ln}(\mathrm{III})$ ) and two (in case of $\mathrm{Th}(\mathrm{IV})$ ) nitrate ions, generating a $2+$ cationic complexes. In view of the fact that ${ }^{31} \mathrm{P}$ NMR and FT-ICR-MS have confirmed the existence of these species in solution the affinity of the organic phase for these charged complexes might be limited. Therefore, the bis-CMPO ligand 9 was synthesized in order to open up the coordination sphere of the metal and allow one or two more nitrates to coordinate to metal center. Additionally bound nitrates would reduce the positive charge of the complex to $1+$ or even completely neutralize it, and possibly enhance its solubility in the organic phase.

The extraction results reveled, however, that the extraction potential of bis-CMPO ligand 9 is very similar to the mono-CMPO compound (Chart 3). Extractant 9 shows very low affinity for Th(IV) as well as the entire series of lanthanides. Apparently, three preorganized CMPO arms are essential to fulfill the geometry requirements around metal center, affording appreciable extraction percentage. 

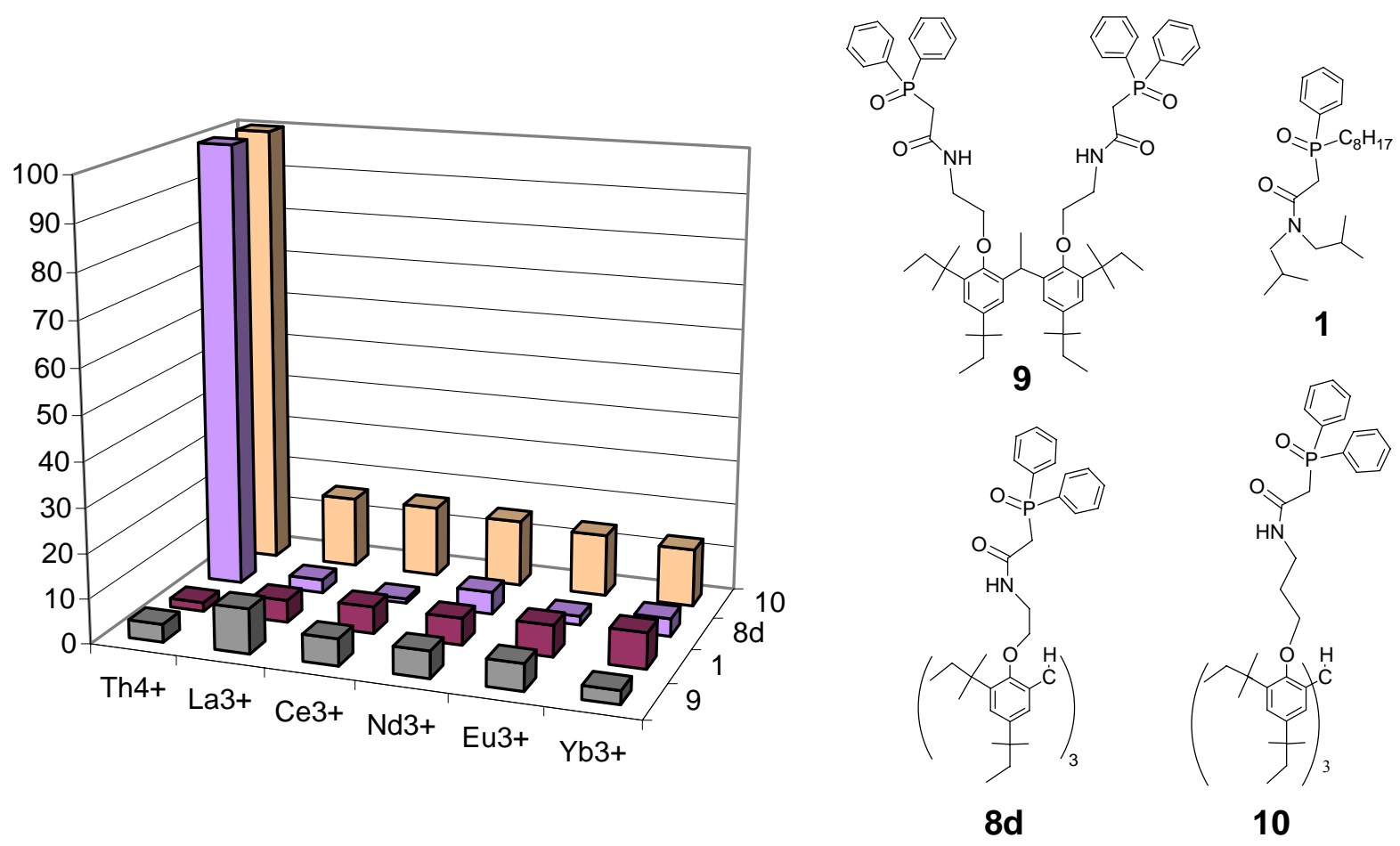

Chart 3. Metal extraction percentage (\%E) for the ligands 9, 1, 8a,and 10.

Table 3. Extraction percentage (\%E) for 1, 9, 8d and 10.

\begin{tabular}{c|c|c|c|c|c}
\hline Cation & $\begin{array}{c}\text { Equivs of } \\
\text { ligand in }\end{array}$ & $\mathbf{9}$ & $\mathbf{1}$ & $\mathbf{8 d}$ & $\mathbf{1 0}$ \\
$1 \mathrm{M} \mathrm{HNO}_{3}$ & organic & $(\% \mathrm{E})$ & $(\% \mathrm{E})$ & $(\% \mathrm{E})$ & $(\% \mathrm{E})$ \\
\hline $\mathrm{Th}^{4+}$ in & 10 & $4 \pm 2$ & $2 \pm 1$ & $98 \pm 1$ & $100 \pm 1$ \\
$\mathrm{La}^{3+}$ & 10 & $10 \pm 2$ & $5 \pm 1$ & $4 \pm 1$ & $16 \pm 1$ \\
$\mathrm{Ce}^{3+}$ & 10 & $6 \pm 2$ & $6 \pm 1$ & $5 \pm 1$ & $16 \pm 2$ \\
$\mathrm{Nd}^{3+}$ & 10 & $6 \pm 1$ & $6 \pm 1$ & $3 \pm 1$ & $15 \pm 1$ \\
$\mathrm{Eu}^{3+}$ & 10 & $6 \pm 1$ & $7 \pm 1$ & $3 \pm 1$ & $14 \pm 2$ \\
$\mathrm{Yb}^{3+}$ & 10 & $3 \pm 2$ & $8 \pm 1$ & $10 \pm 1$ & $13 \pm 2$ \\
\hline
\end{tabular}


The combination of three ligating functions of the CMPO type is not the only factor that determines the complexation effectiveness. Evidently their mutual orientation and flexibility of their arms also has an important influence. It can be assumed that an appropriate balance between rigidity and flexibility of the basic skeleton may also be crucial for an effective coordination. For example, CMPO like calix[4]arene extractants show a strong increase of the extraction percentage with increasing length of the spacer between $\mathrm{P}=\mathrm{O}$ and $\mathrm{C}=\mathrm{O}$ groups. ${ }^{34}$ It can thus be proposed, that extraction of a particular cation depends on the size of the cavity and on flexibility of the ligand. It seems reasonable that the more flexible molecule is able to form a cavity of an appropriate size to accommodate metal ions. The same dependence is apparent in case of compound 10 (Chart 3). The extractability increased with flexibility, but at the expense of selectivity. However, the preorganization is still an overriding factor in enhancing extraction in comparison to the simple ligand $\mathbf{1 .}$

It is well known that the separation of the light actinides (thorium, uranium, plutonium, and neptunium) can be achieved by exploiting the greater oxidation states of these $5 \mathrm{f}$ elements. Since results of the extraction experiments have proven the ability of ligand $\mathbf{8}$ to take advantage of differences in oxidation states of tetravalent thorium and a series of trivalent lanthanides, we were prompted to study the extraction of radioactive metal ions. The $\mathrm{Pu}(\mathrm{IV})$ extraction experiment was performed at Argonne National Laboratory by Dr. Artem Guelis, to verify ability the of the tri-CMPO scaffold to preferentially extract other tetravalent light actinides. All tests were performed using $\mathbf{8 a}$ extractant representing similarly behaving 8 molecules. Ligand 8a was found to be very effective in extracting $\mathrm{Pu}(\mathrm{IV})$ at the earlier presented conditions, significantly more effective than commercially used mixture of mono-CMPO and TBP in transuranium elements extraction process (TRUEX). In fact, much lower concentrations of 
ligand 8a were required to achieve approximately the same distribution ratio $(D)$ of $\mathrm{Pu}(\mathrm{IV})$ as the mono-CMPO extractant, with synergistic agent, can attain. After 24 hours of extraction, the $97.76 \%(D=43.60)$ of $\mathrm{Pu}(\mathrm{IV})$ was removed from aqueous phase by our ligand (8a) at extractant concentration as low as $10^{-3} \mathrm{M}$ (Table 4). To reach similar $D$ value, the concentration of CMPO molecule 1 in organic phase needs to be two hundreds times higher then 8 a $(0.2 \mathrm{M})$, and accompany by 1.0 M TBP (Chart 4). Future optimalization of the conditions might bring even better results. In addition, efforts to fully characterize the plutonium with the ligands have been undertaken in collaboration with Dr. Mary Neu at Los Alamos National Laboratory. Large single crystals of the $\mathrm{Pu}(\mathrm{IV})$ species with ligand $\mathbf{8 b}$ have been obtained and they will be subjected to X-ray diffraction experiments during the first quarter of the $2^{\text {nd }}$ year.

Table 4. Extraction of $\mathrm{Pu}(\mathrm{IV})$ from $1 \mathrm{M} \mathrm{HNO}_{3}$ with $0.001 \mathrm{M}$ of $8 \mathbf{a}$ in $\mathrm{CH}_{2} \mathrm{Cl}_{2}$. Non-optimized conditions.
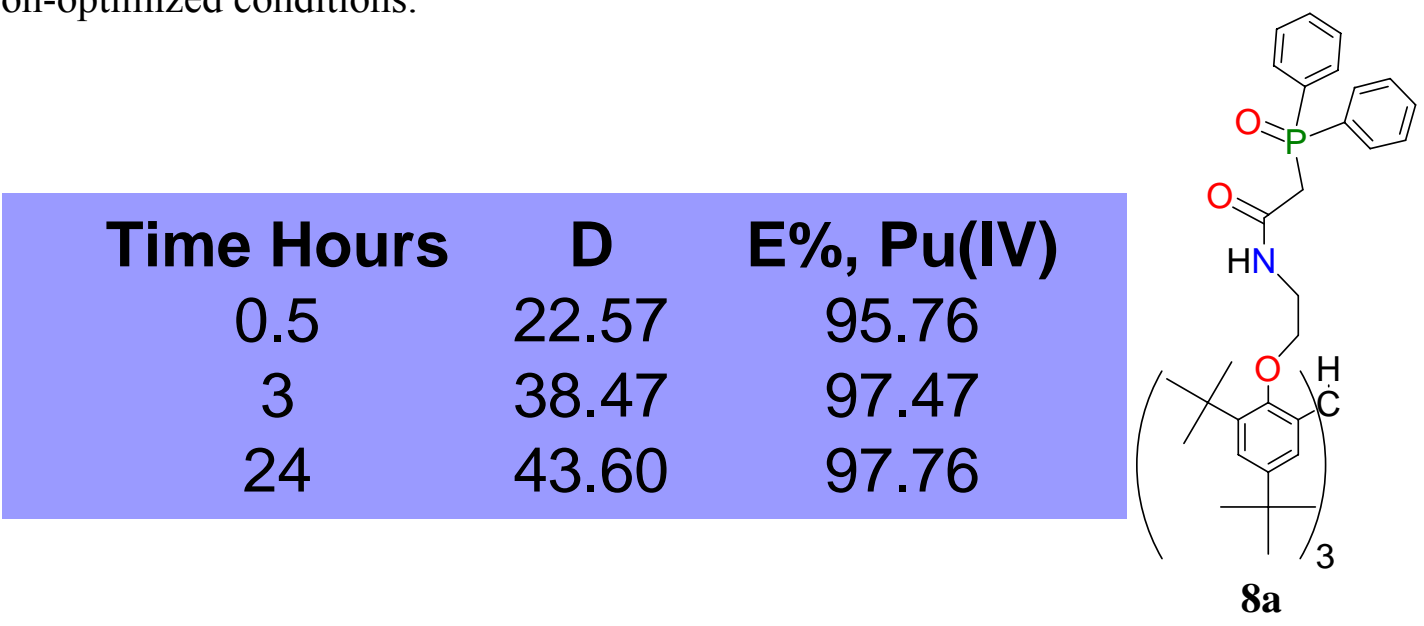


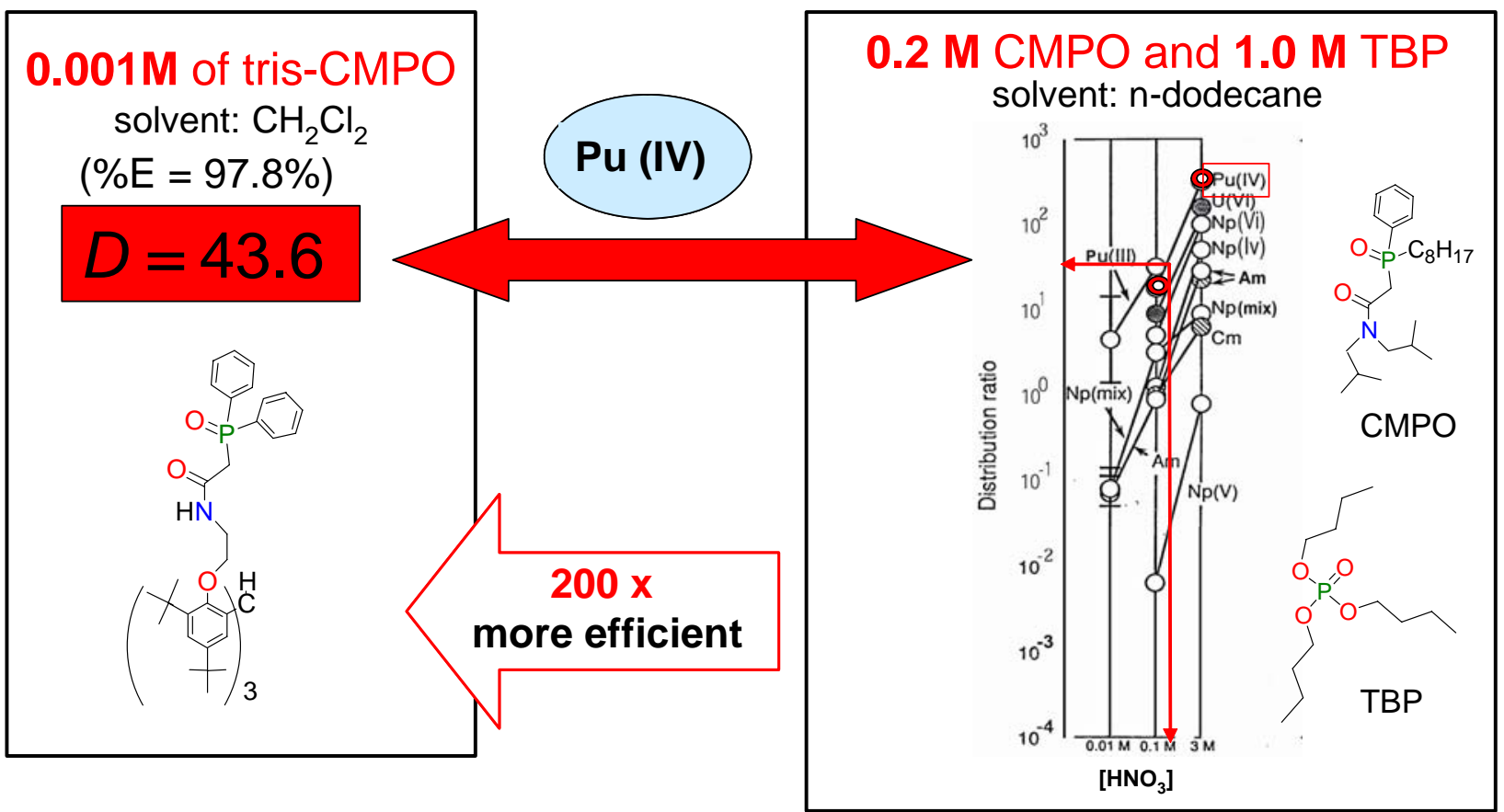

Chart 4. Acid dependency of distribution ratios of major components in HLLW. Extraction system: 0.2M CMPO (1) and 1.0 M TBP [tri-n-butyl-phosphate, $\left(\mathrm{H}_{9} \mathrm{C}_{4}-\mathrm{O}\right)_{3}{ }^{-}$ $\mathrm{P}=\mathrm{O})$ ] in n-dodecane (TRUEX) ${ }^{40}$ The distribution ratio, $D$ is given by the ratio of the concentration of metal ion in the organic phase to that in the aqueous phase.

In early fifties, Seaborg found, ${ }^{41}$ that trivalent lanthanides and actinides can be separated using cation-exchange resin columns presumably due the ability of the actinides to employ $5 f$ orbitals in bonding. The idea is based on similar spatial extensions of the $5 \mathrm{f}, 6 \mathrm{~d}, 7 \mathrm{~s}$ and $7 \mathrm{p}$ orbitals of the trivalent actinides, particularly the lightest members of the group. The orbital expansion promotes the possibility of direct orbital overlap, and therefore the $5 \mathrm{f}$ covalent contribution to the ionic bonding of actinides with suitable ligands. ${ }^{7}$ With that in mind, the $\mathrm{Am}(\mathrm{III}) / \mathrm{Eu}(\mathrm{III})$ extraction experiment was performed at Argonne National Laboratory to test if 8a can take advantage of such a difference between Am(III) and its electronic analogue $\mathrm{Eu}(\mathrm{III})$, and extract Am(III) in higher extend than Eu(III). It was found (Chart 5) that the ligand by itself 
has low affinity for both ions, and in fact is not able to distinguish between these two elements. However, the ligand combination with carefully selected coextractant, may improve selectivity and efficiency of the extraction.
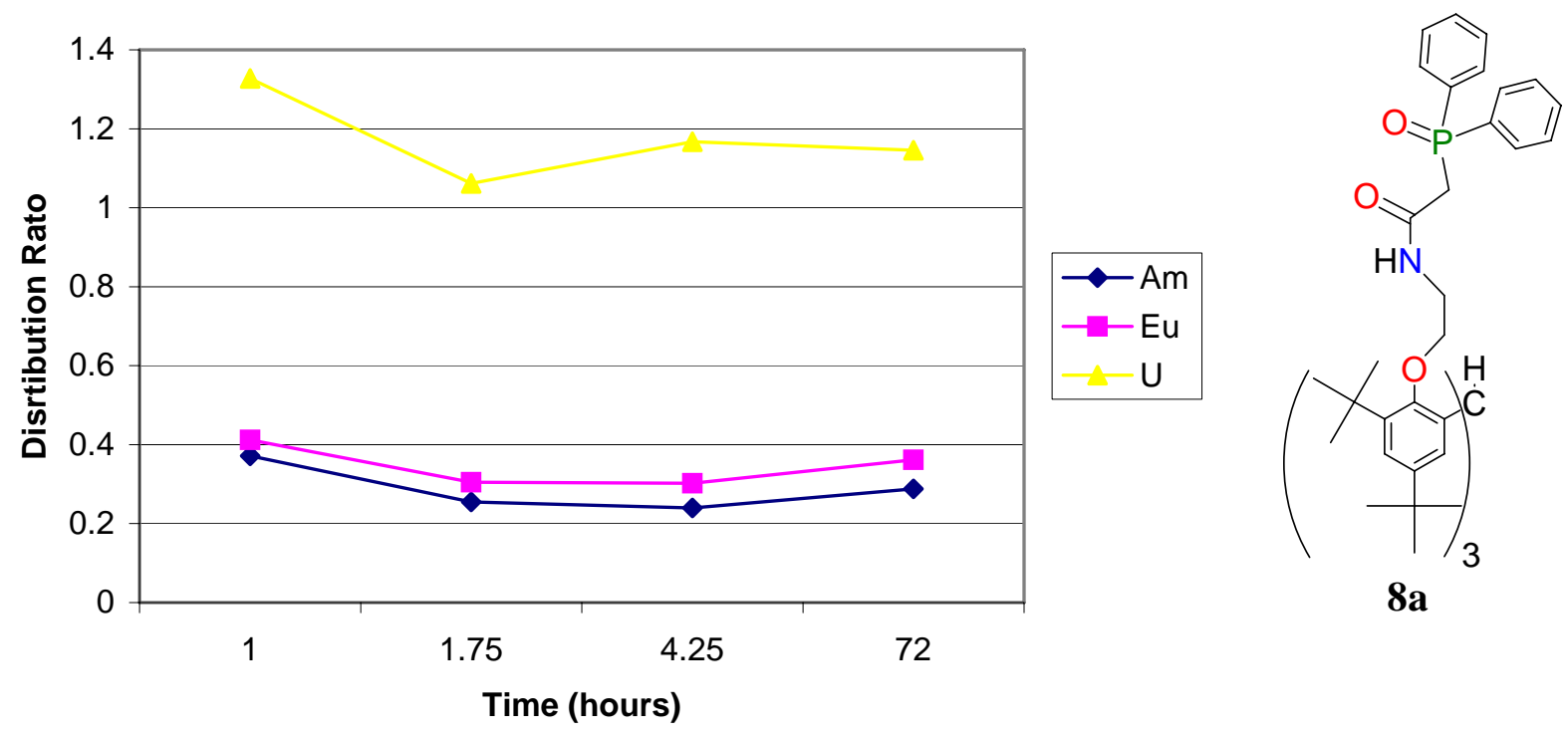

Chart 5. $\mathrm{Am} / \mathrm{Eu}$ and $\mathrm{U}^{\mathrm{a}}$ extraction from $1 \mathrm{M} \mathrm{HNO}_{3} / 5 \mathrm{M} \mathrm{NaNO}$ by $0.001 \mathrm{M}$ 8a in $\mathrm{CH}_{2} \mathrm{Cl}_{2}$. ${ }^{\mathrm{a}} \mathrm{U}-238$ included as a component of a purified Am stock's composition.

In the final step of extraction, the organic solvent rearranges to stabilize the new complex. The degree of rearrangement is a function of the structure of the hydrophobic complex and the solvating ability of the organic phase. ${ }^{7}$ If a solvating extractant (for instance TBP) is present simultaneously with a chelating extractant (for example CMPO), the free energy for increased extraction efficiency usually is generated in the solvation step of the overall reaction. By combining selected chelating molecules (CMPO) with solvating molecules (TBP) (synergistic system), total extraction percentage greater than the sum of the extraction for individual molecules is often achieved. Addition of the synergist (solvating molecule) may 
involve replacement of the remaining coordinated water molecules or expend the coordination sphere to accommodate the solvating molecule. ${ }^{42}$

The two slightly different neodymium complexes of $\mathbf{8 a}$ were previously found in the asymmetric unit of its X-ray crystal structure. ${ }^{37}$ In one of the neodymium complexes, the metal is coordinated by a water molecule while the neodymium in the other complex is anhydrous. Similar effect was found in case of Eu (III) complex with 8a. It seems reasonable, that one of the factors responsible for poor extractability of the trivalent lanthanides and americium by system $\mathbf{8}$, might be the incomplete dehydratation of the metal ion during extraction to the organic phase. The hydrate complex may effectively resist the phase transfer. Therefore, addition of synergist may help complete dehydratation process and improve phase transfer.

Significant modifications of the mono-CMPO 1 extractant properties has been achieved by addition of the synergist like TBP. ${ }^{31}$ Benefits reported by authors of mixed CMPO-TBP extractant system include an enhanced distribution ratio of $\mathrm{Am}(\mathrm{III})$ above $2 \mathrm{M} \mathrm{HNO}_{3}$, and suppressed distribution ratio of Am(III) at low acidity (used for stripping). and insensitivity of distribution ratio of $\mathrm{Am}(\mathrm{III})$ to acidity in the range of 2 to $6 \mathrm{M} \mathrm{HNO}_{3}$. However, the most significant benefit gained from addition of TBP to CMPO is the improved extractant compatibility with aliphatic diluent as reflected in the increased metal ion loading capacity without third phase formation. The enhancements produced by the TBP modification were inspiration for further extraction experiments using our ligand system. 

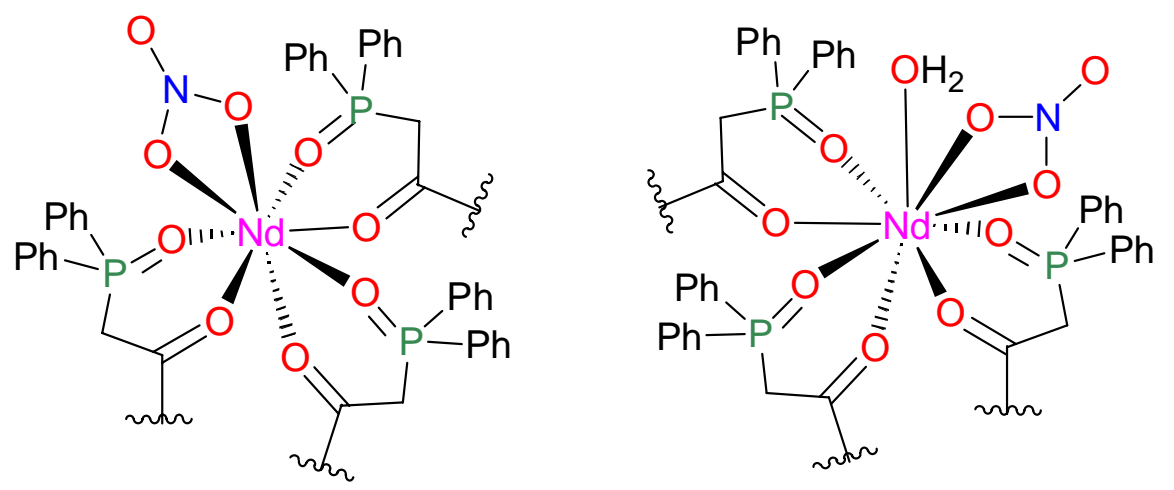

Figure 7. Diagrams of neodymium(III) complexes of 8a: anhydrous 8 coordinated +2 cationic complex (left) and water-containing 9 coordinated +2 cationic complex (right).

The extraction experiment with 8a and TBP revealed, that indeed the extraction strength of the synergistic mixture of $\mathbf{8 a}$ and TBP is greater than the sum of the two ligands separately (Chart 6 and Table 5). However, the effect on the distribution ratio of Am(III) and the separation factor of $\mathrm{Am}(\mathrm{III}) / \mathrm{Eu}(\mathrm{III})$ has been not been determined.

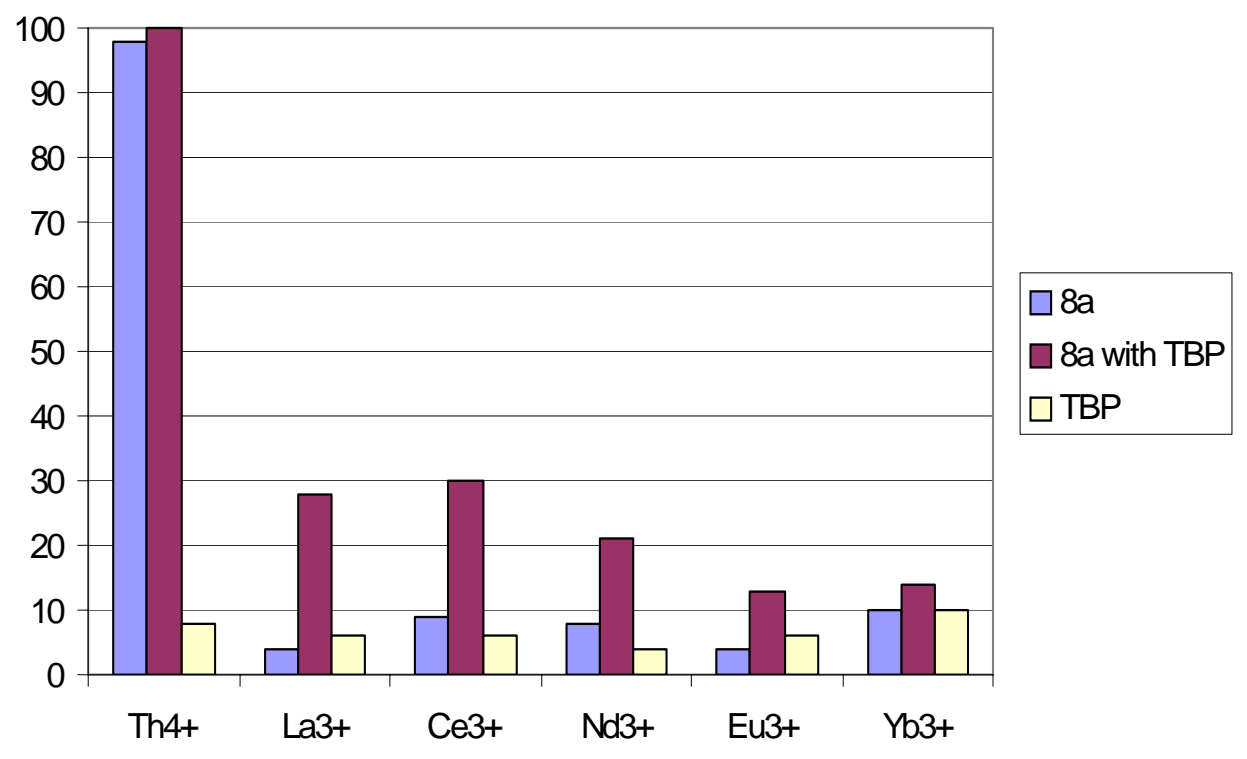

Chart 6. Metal extraction (\%E) for ligand 8a, TBP, and synergistic mixture 8a-TBP.

Table 5. Extraction percentage for ligand 8a, TBP, and synergistic mixture of $\mathbf{8 a - T B P}$. 


\begin{tabular}{|c|c|c|c|}
\hline $\begin{array}{c}\text { Cation } \\
\left(10^{-4} \mathrm{M}\right) \text { in } \\
1 \mathrm{M} \mathrm{HNO}_{3}\end{array}$ & $\begin{array}{l}10 \text { Equivs of } \mathbf{8 a} \text { in } \\
\mathrm{CH}_{2} \mathrm{Cl}_{2} \\
(\% \mathrm{E})\end{array}$ & $\begin{array}{c}10 \text { Equivs of } 8 \mathbf{a} \text { in } \\
\mathrm{CH}_{2} \mathrm{Cl}_{2} \text { with } \\
0.5 \mathrm{M} \text { TBP } \\
(\% \mathrm{E})\end{array}$ & $\begin{array}{c}0.5 \mathrm{M} \text { solution of } \\
\text { TBP in } \mathrm{CH}_{2} \mathrm{Cl}_{2} \\
(\% \mathrm{E})\end{array}$ \\
\hline $\mathrm{Th}^{4+}$ & $98 \pm 1$ & $100 \pm 2$ & $8 \pm 1$ \\
\hline $\mathrm{La}^{3+}$ & $4 \pm 1$ & $28 \pm 3$ & $6 \pm 2$ \\
\hline $\mathrm{Ce}^{3+}$ & $5 \pm 1$ & $30 \pm 1$ & $6 \pm 2$ \\
\hline $\mathrm{Nd}^{3+}$ & $3 \pm 1$ & $21 \pm 1$ & $4 \pm 1$ \\
\hline $\mathrm{Eu}^{3+}$ & $3 \pm 1$ & $13 \pm 1$ & $6 \pm 1$ \\
\hline $\mathrm{Yb}^{3+}$ & $10 \pm 1$ & $14 \pm 1$ & $10 \pm 2$ \\
\hline
\end{tabular}

The choice of the solvent represents one of the most important factors in liquid-liquid separation science. To achieve effective phase separation, non-polar solvents should be used. For safety reasons, however, the high boiling and flashing points, and low toxicity of the solvent are equally important as polarity for the waste clean-up operations. Therefore to find application in nuclear waste decontamination, the increase of compatibility of our ligand system with aliphatic solvents would be highly desirable. That can be achieved either by altering the structure of the ligand itself or addition of synergist. The solubility studies of 8a confirmed, that addition of TBP indeed induced an increase in solubility of the extractant in non-polar solvents. Unfortunately, effect is only temporary and tris-CMPO ligand eventually crashes out of the solution. The phenomenon most likely can be attributed to formation of hydrogen bonds within and between molecules over time. These interactions may rigidify the structure and give rise to precipitation. In the solid state structure of 8a (Figure 9), there are two strong hydrogen bonds 
between amides hydrogens and phosphoryl oxygens on adjacent arms (blue boxes), as well as the intermolecular hydrogen bonds between carbonyl oxygens on one ligand and remaining amides hydrogens on the other (red box). The aliphatic solvent may actually force these aromatic molecules to aggregate, therefore decreasing their solubility and resulting in precipitation.

Efforts to substitute the amide hydrogens with a simple methyl group were undertaken since this change in $\mathbf{8}$ would greatly enhance the solubility of the ligand. In addition, it was thought that the alkylation will increase the hardness of the carbonyl oxygen donor and enhance the binding affinity for actinides. Numerous strategies were designed to place an alkyl group on the amide nitrogen, and unfortunately, the steric constraints of the ligands seemed to hinder the majority of these reactions. In most instances, products with incomplete substitution of the three nitrogens were isolated. After many unsuccessful attempts, two separate synthetic pathways were developed, and they are presented in Scheme 3. With the smaller linker arms $(n=2)$, the compound must be prepared by route $\mathbf{B}$ while an increase in the length of the arms $(n=3)$ requires that pathway A be followed. Presumably, the steric bulk and the rigidity of the platform preclude the preparation of the shorter arms species by pathway $\mathbf{A}$. 
Scheme 3. Synthetic methodologies employed to place Alkyl groups on the amide nitrogens.

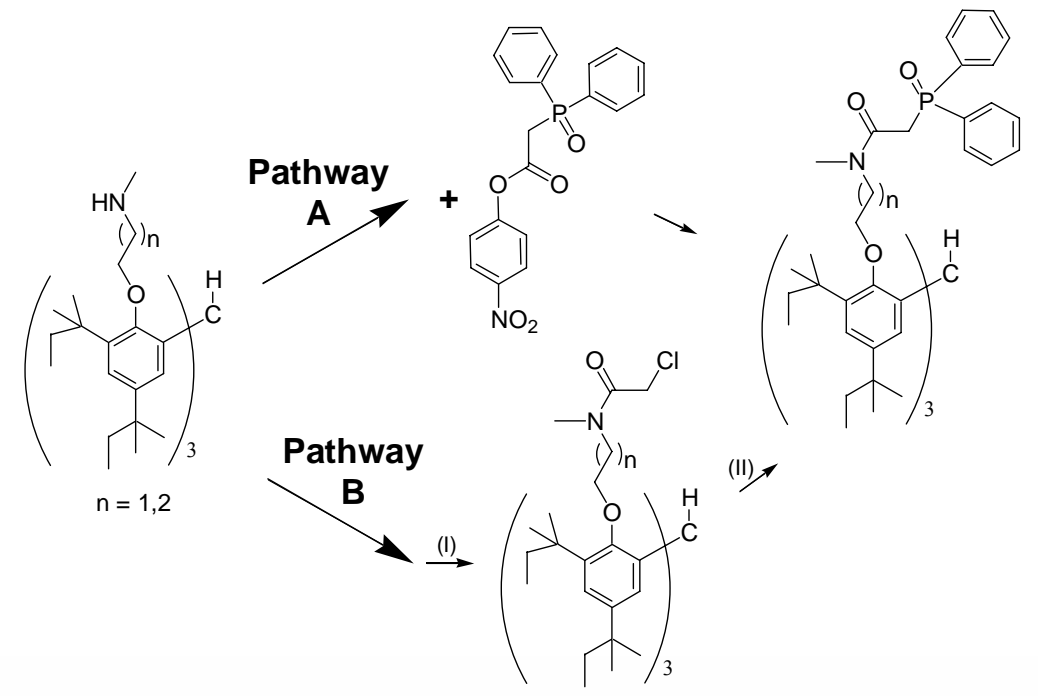

(I) chloroacetyl chloride, $\mathrm{K}_{2} \mathrm{CO}_{3}$; (II) ethyl diphenylphosphinite

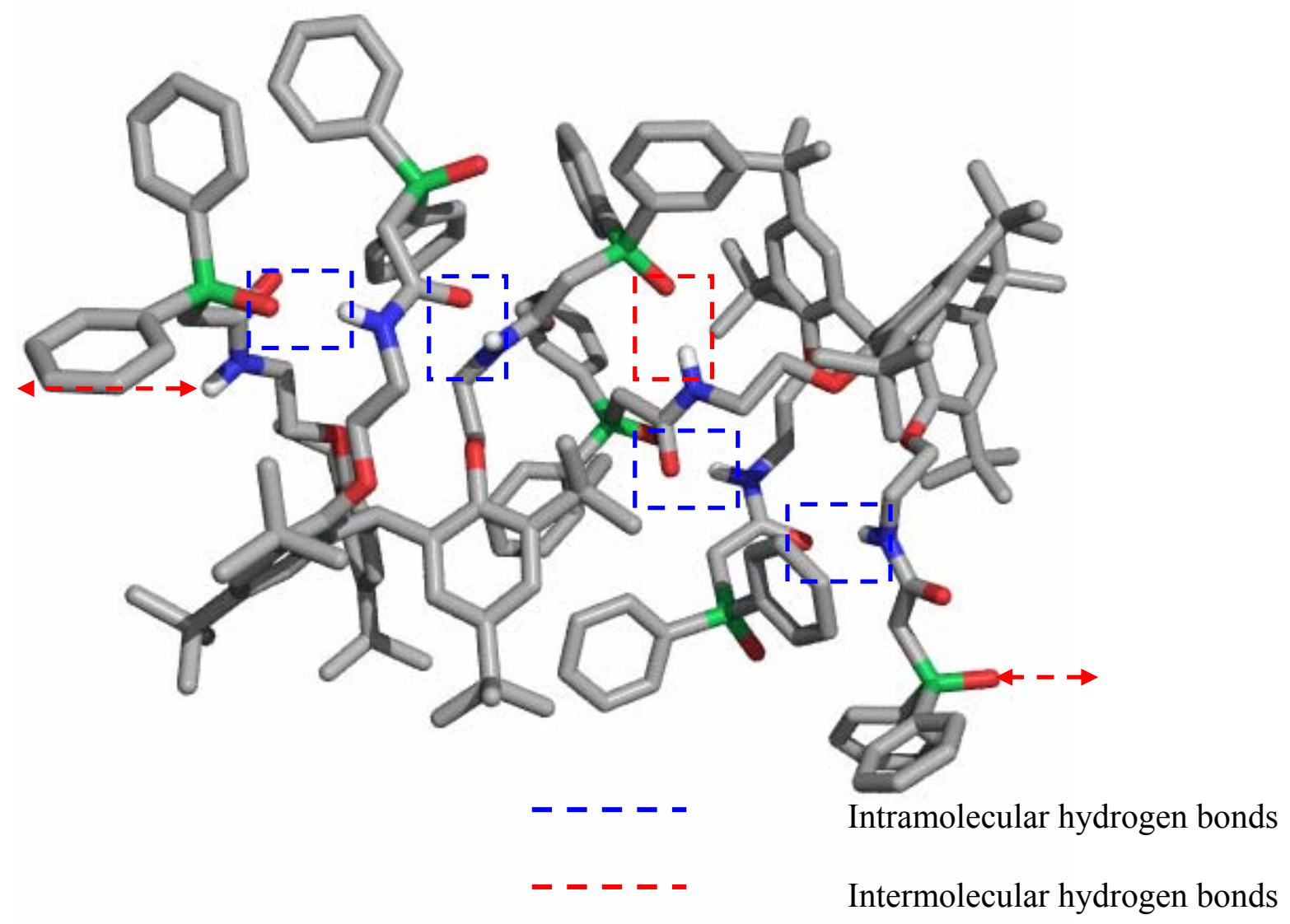

Figure 9. Fragment of the crystal structure of 8a molecules forming hydrogen bond connected network. (Crystals obtained by slow diffusion of pentane into saturated solution of $8 \mathrm{a}$ in $\mathrm{CH}_{2} \mathrm{Cl}_{2}$ ). 
As predicted by the elimination of the hydrogen bonding interactions, the compound with the three carbon $(n=3)$ linker arm is much more soluble in non-polar solvents in comparison to 8d, and the ligand will dissolve in solvents such as pentane, greatly facilitating its use in an "real world" liquid/liquid extraction process. Unfortunately, the two carbon species $(\mathrm{n}=2)$ is still poorly soluble in non-polar solvents such as dodecane.

With only a few atoms between the triphenoxymethane base and the methyl group on the nitrogen, the arms are held fairly rigidly, and in fact, there appears to be a beneficial hydrophobic interaction between the three methyl groups (highlighted by *) in the solid-state structure presented in Figure 10, and these groups are all oriented directly towards each other.

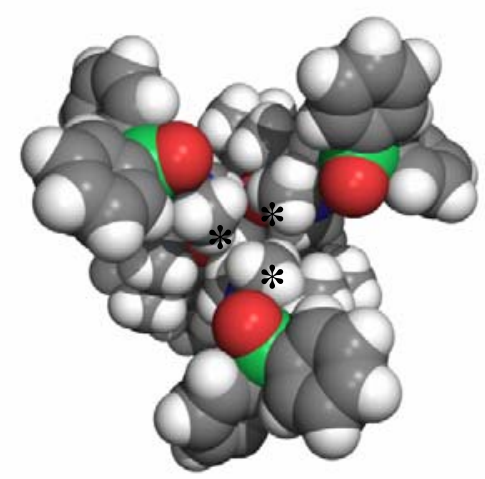

Figure 10. X-ray structure of compound $(\mathrm{n}=2)$ depicted in Scheme 2.

During the fourth quarter of year 2, the binding properties of the compounds with the alkylated nitrogens were fully studied at Florida and several grams of each derivative were sent to Argonne for analysis. Along with increasing the solubility, it was anticipated that the compounds would be more effective ligands for extraction of actinides in comparison to 8a and 8d since alkylation of the nitrogens should favour the resonance structure which places a negative charge on the oxygen. This increase in charge should make the carbonyl oxygens harder donor groups to the metal center. In previous work with $\mathbf{8 a}$ and $\mathbf{8 d}$, they have been shown to be a particularly effective binders of $\mathrm{Pu}(\mathrm{IV})$ from acidic solutions by the Argonne group. Although the alkylated ligands, compounds 11 and 12, are still selective towards the An(IV) metals, surprisingly, the alkyl groups on the nitrogen appear to decrease the affinity for the 4+ metals as illustrated in the plots presented in Figure 11. 

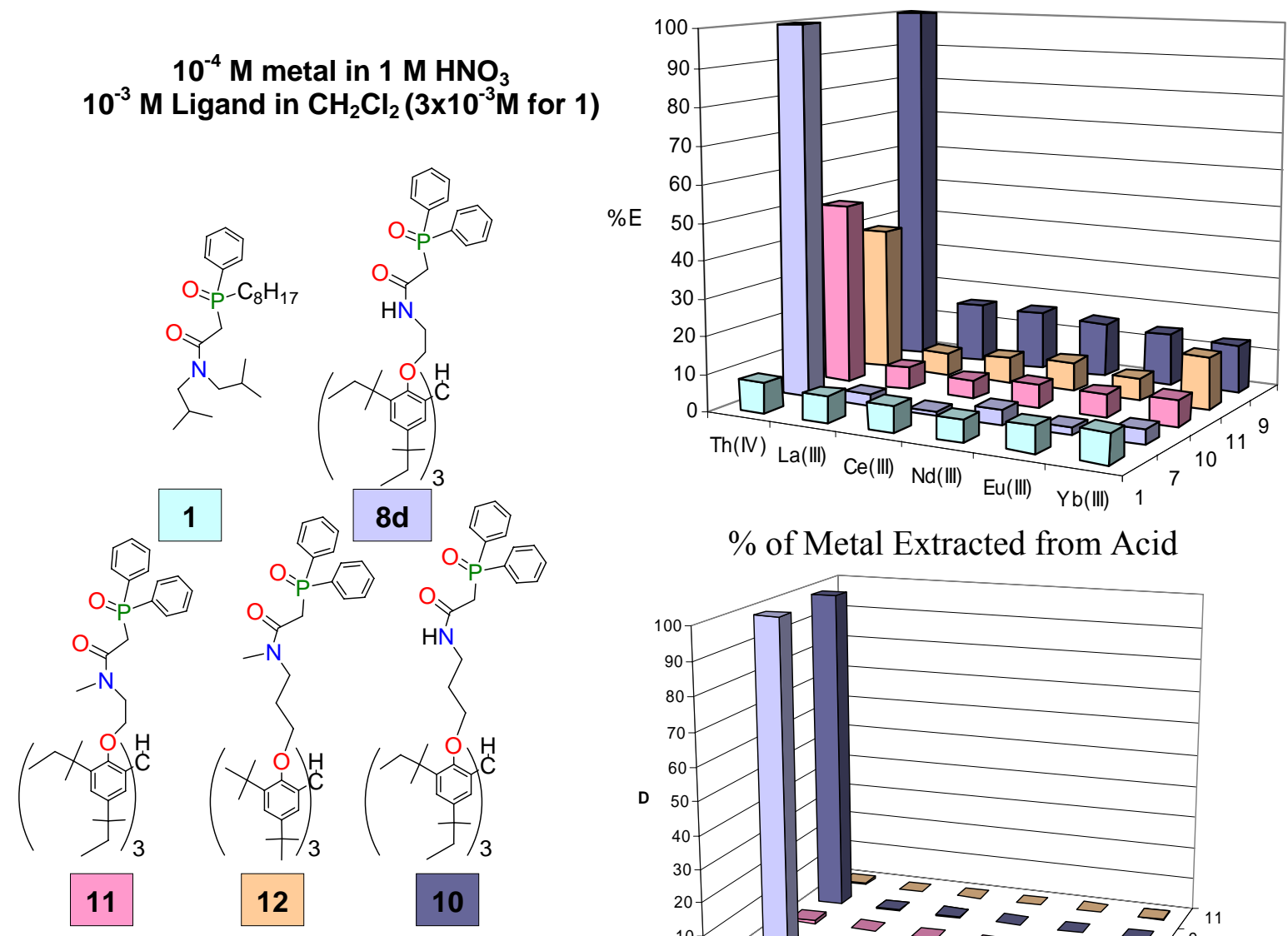

$\%$ of Metal Extracted from Acid

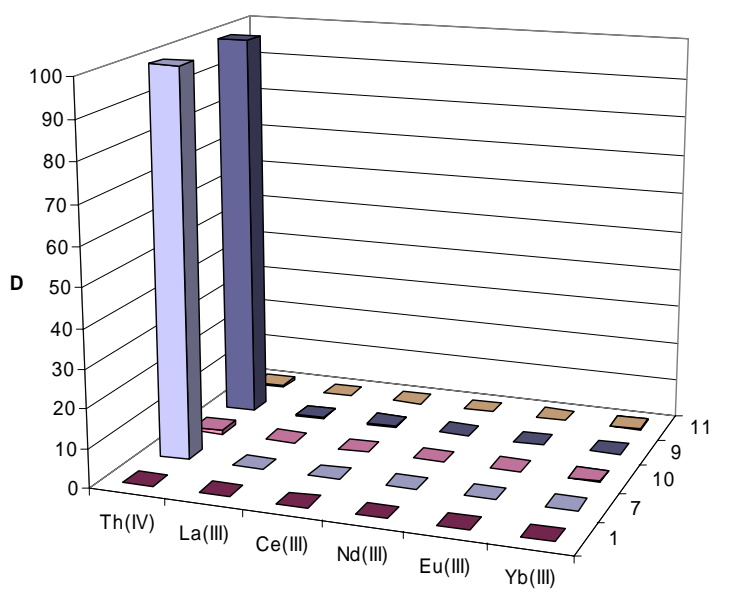

D-values for Extraction of Metal from Acid

Figure 11. Extraction plots for the alkylated and unalkylated ligands.

Although the affinity of $\mathbf{1 1}$ and $\mathbf{1 2}$ for An(IV) has decreased, both ligands are still selective for An(IV) over Ln(III) in comparison to CMPO. From this data, it appears that the N$\mathrm{H}$ functionality is very important for the enhanced extraction of the actinides ions in the 4+ oxidation state. Given that these amide groups should be adept at forming hydrogen bonds to the nitrate counterions, they may perhaps allow for the formation of more stable charged species in 
the organic layer. This interaction may prove important in the design of effective, selective reagents of the An(III) ions and will be exploited further in upcoming studies.

In view of the interesting trends witnessed for these ligands, several grams of each compound were sent to Argonne for analysis, and during the fourth quarter the alkylated ligands were studied in detail. The compounds exhibited enhanced solubility in comparison to 7, and the extraction experiments were performed in both dichloromethane and octanol at concentrations of $10^{-2} \mathrm{M}$ ligand and $1 \mathrm{M}$ nitric acid. The results are contained in Figure 12, and the ligands 8d, 10, 11, and 12 are all extremely selective for the An(IV) ions in both dichloromethane and octanol. Interestingly, although the D value is low, ligand $\mathbf{1 1}$ does show a enhanced affinity (2.2 times) for $\mathrm{Am}(\mathrm{III})$ or $\mathrm{Eu}(\mathrm{III})$ and these results are highlighted in Table 6. In the coming quarter work will continue with these ligands with a goal of understanding the binding mechanism in the acidic solutions by methods such as EXAFS. This information will be invaluable for the development of ligands with enhanced affinity for An(III) ions..

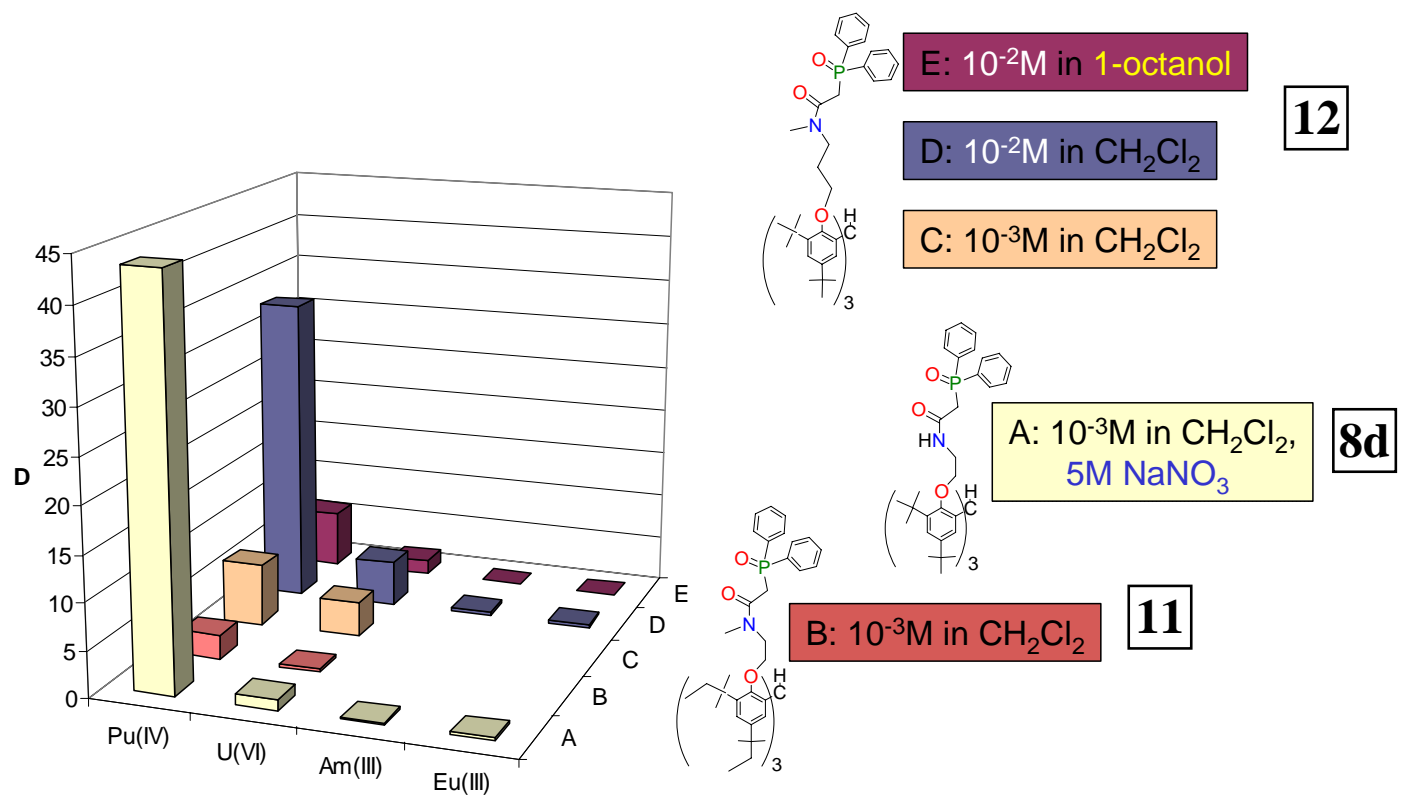

Figure 12. Plot of the D-values for the extraction of metal ions by $\mathbf{8 d}, \mathbf{1 1}$, and $\mathbf{1 2}$ 
Table 6. Extraction Data for 11.

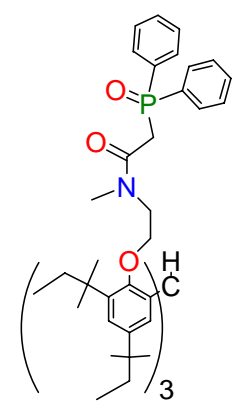

Solvent - dichloromethane
\begin{tabular}{|c|c|c|}
\hline An ion & D value & Extraction\% \\
\hline $\mathrm{Pu}(\mathrm{IV})$ & 33.1 & 97.1 \\
\hline $\mathrm{UO}_{2}{ }^{2+}$ & 4.85 & 82.9 \\
\hline $\mathrm{Am}(\mathrm{III})$ & 0.50 & 33.2 \\
\hline $\mathrm{Eu}(\mathrm{III})$ & 0.23 & 18.8 \\
\hline
\end{tabular}

Solvent - octanol
\begin{tabular}{|c|c|c|}
\hline An ion & D value & Extraction\% \\
\hline $\mathrm{Pu}(\mathrm{IV})$ & 33.1 & 85.9 \\
\hline $\mathrm{UO}_{2}{ }^{2+}$ & 4.85 & 60.6 \\
\hline $\mathrm{Am}(\mathrm{III})$ & 0.06 & 5.6 \\
\hline $\mathrm{Eu}(\mathrm{III})$ & 0.02 & 2.4 \\
\hline
\end{tabular}

As outlined in previous reports, we have isolated and fully characterized the solution structure of the Th(IV) compounds in the absence of acidic media, and in the third quarter of year 2, a new cell was constructed to characterize the structure of the $\mathrm{Pu}(\mathrm{IV})$ species obtained from the acidic solutions by EXAFS spectroscopy at the Advanced photon source at Argonne. The cell and the samples used for analysis are depicted in Figure 13. EXAFS data was collected at the Advanced Photon Source at Argonne National Lab during the fourth quarter of year 2. Unfortunately, the signal-to-noise ratio was too low to accurately analyze the data in the first attempt and the data was recollected in the first quarter of year 3.

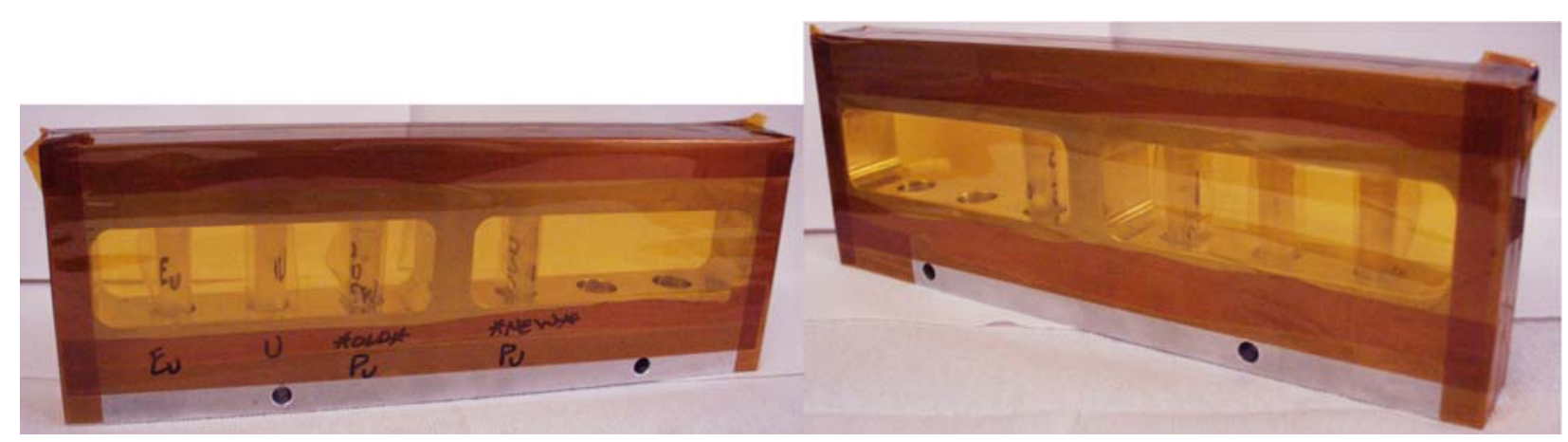

Figure 13. New cell for EXAFS measurements which contains ligand/actinide mixtures. 

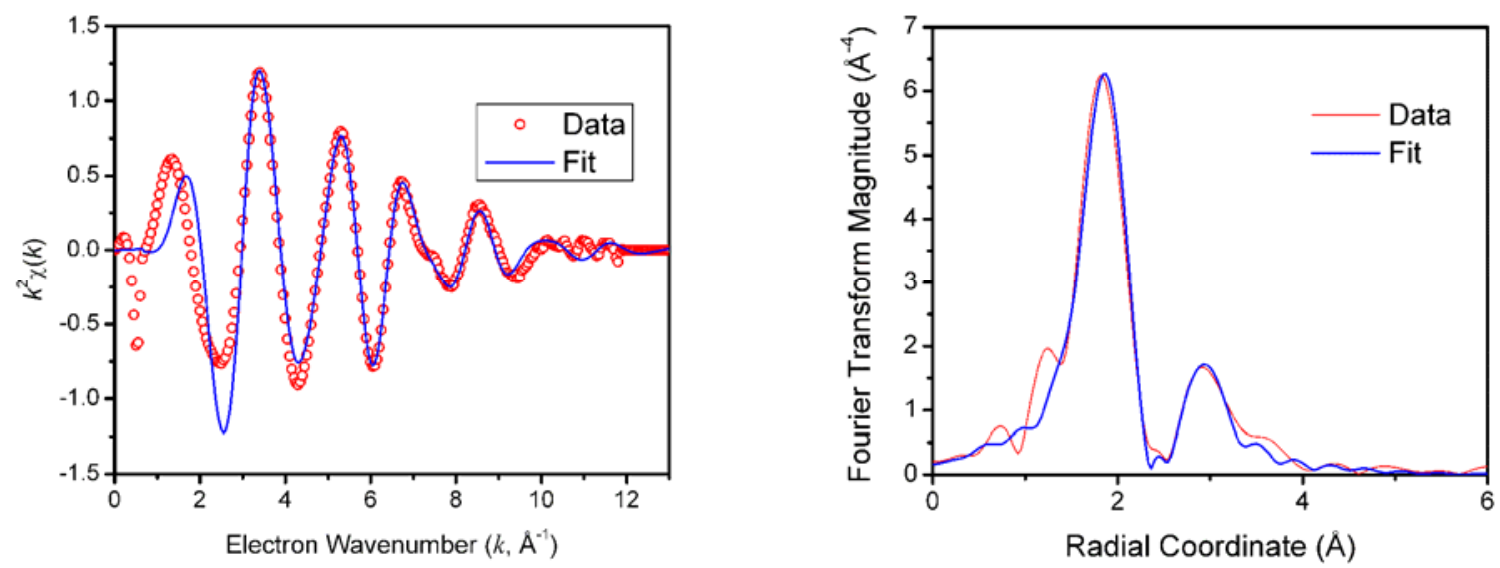

Figure 14. Acutal EXAFS data and fitting for the Pu(IV) ion extracted from acid by $\mathbf{8 d}$.

An initial, crude fit of this improved data is contained in Figure 14. In the first coordination shell of the $\mathrm{Pu}(\mathrm{IV})$ centre, there appears to be approximately $12+/-2 \mathrm{Pu}-\mathrm{O}$ bonds in the neighbourhood of $2.35 \AA$, with a somewhat greater disorder than a crystalline $\mathrm{PuO}_{2}$. If the next shell around the metal is fit exclusively using Pu-P interactions, the analysis suggests there is anywhere from 6-9 Pu-P bonds at 3.63 $\AA$. The EXAFS analysis for these molecules is quite complicated since the $\mathrm{Pu}-\mathrm{O}-\mathrm{P}$ and $\mathrm{Pu}-\mathrm{O}-\mathrm{C}$ angles are quite acute. A detailed examination of the 5 solid-state X-ray structures of the Th(IV), $\mathrm{Nd}(\mathrm{III})$, and $\mathrm{Eu}(\mathrm{III})$ complexes with ligand 7 characterized by the Florida group reveals that the angles for these bonds fall within the range of 134 to 146 degrees (Figure 15). Thus, one must consider the double scattering and triple scattering paths between the $\mathrm{Pu}(\mathrm{IV})$ and phosphorous atoms in the interpretation of the

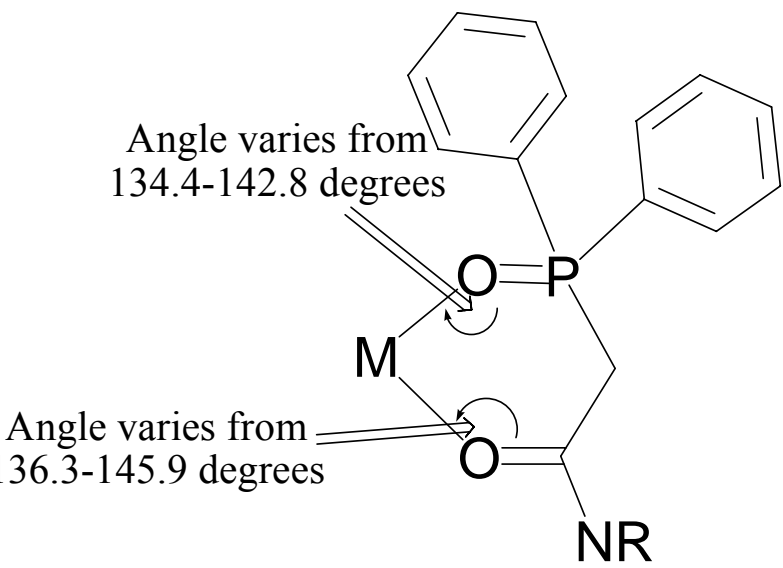

Figure 15: Range of bond angles found in a collection of $\mathrm{Ln}(\mathrm{III})$ and Th(IV) solid-state structures. 
EXAFS data, and the analysis of the data becomes somewhat more complicated. In addition, the scattering paths for $\mathrm{Pu}-\mathrm{C}$ and $\mathrm{Pu}-\mathrm{N}$ interactions have been excluded from the calculations up to this point. The inclusion of these atoms into the fitting should reduce the number of Pu-P distances to a more accurate number, and this information will help determine the number of CMPO arms bound to the metal centre during the extraction event. Unfortunately, the data suggests there is a very strong interaction at a distance 3.1-3.5 $\AA$ and we have been unable to deduce the identity of these speices. The staff member conducting these refinements thinks it might involve a Pu atom and due the success of the ${ }^{1} \mathrm{H}$ NMR experiments recently obtained with the diamide ligands (vide infra), the analysis was suspended until more data can be ascertained by solution chemistry using other techniques. If the ${ }^{1} \mathrm{H}$ NMR spectrum of the Th(IV) complex with $8 \mathrm{a}$ is identical to the isolated Th(IV) compound depicted in Figure 7, it would confirm the solution structure is identical to the solid-state structure.

\section{New Ligands for An(III) Binding}

The successful separation method for trivalent lanthanides and actinides must exploit the slight differences in ionic radii and covalency/polarizability of these metal ions. Materials with the greatest potential for increased covalent interactions provide the most significant opportunity for successful $\mathrm{Ln}(\mathrm{III}) / \mathrm{An}(\mathrm{III})$ separation, and therefore soft donor ligands containing $\mathrm{S}$ or $\mathrm{N}$ groups are often employed. ${ }^{43-45}$ For example, purified CYANEX 301 [bis(2,4,4-trimethylpentyl) phosphinic acid, $\left.\left[\left(\mathrm{H}_{3} \mathrm{C}\right)_{3} \mathrm{C}-\mathrm{CH}_{2}-\mathrm{CH}\left(\mathrm{CH}_{3}\right)-\mathrm{CH}_{2}\right]_{2} \mathrm{P}(\mathrm{S})-\mathrm{SH}\right]$ can strongly discriminate Am(III) form $\mathrm{Eu}(\mathrm{III})$ with separation factor as high as $\mathrm{SF}=5.9 \times 10^{3}$. Presumably the selectivity, arises from the greater covalent bonding tendency between sulfur donor atom and Am(III) in comparison with $\mathrm{Eu}(\mathrm{III}){ }^{46}$ Therefore, a new tris carbamoylmethylphosphine sulfide (tris-CMPS) 
ligand system was designed, with three phosphine sulfide donors rather than the phosphine oxide groups found in 8 (Figure 13). The three soft sulfur atoms were expected to increase interactions with Am(III) upon complex formation, and therefore significantly enhance ability of our ligand system to discriminate between $\mathrm{An}(\mathrm{III})$ and $\mathrm{Ln}(\mathrm{III})$ ions in acidic solutions. In order to determine the extraction potential of this newly synthesized molecule, several extraction experiments on the series of lanthanides and selected actinide has been performed. To allow a direct comparison between extraction properties of the tris-CMPS derivatives and the tris-CMPO compounds, identical extraction conditions were used.

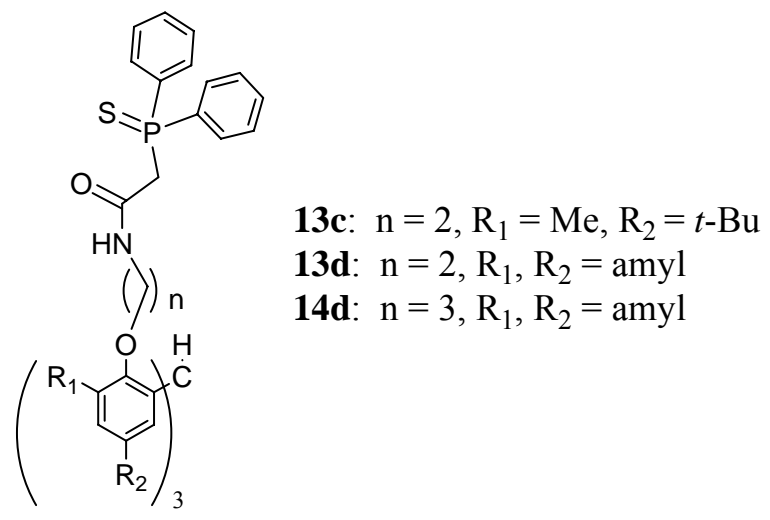

Figure 13. The tris-carbamoylmethylphosphine sulfide (tris-CMPS) derivatives.

The substitution of phosphine oxide with softer phosphine sulfide dramatically altered the extraction behavior of the ligand. Initial extraction experiment on trivalent lanthanides and tetravalent thorium with 13d has shown very low affinity for the entire series of studied metal ions. In general, the extraction percentage of $\operatorname{Ln}(\mathrm{III})$ with $\mathbf{1 3 d}$ increased slightly with respect to efficiency of the CMPO equivalent 8d. The selectivity for Th(IV) however, was absent (Chart 7), and due to their similarities, a similar effect is expected for Pu(IV). Apparently, the harder tris-phosphine oxide donor, preferentially interacts with harder than Ln(III) acids like Th(IV) and $\mathrm{Pu}(\mathrm{IV})$, while much softer tris-phosphine sulfide donor can no longer take advantage of such a metal acidity difference. Interestingly, in sharp contrast to this observation, addition of TBP to 
solutions of 13d (Chart 8) induced an antagonistic effect and the extraction percentage dropped in comparison to either free TBP or 13d. The reason for this decrease in binding affinity is currently under study.

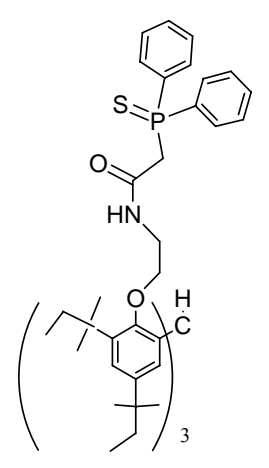

13d

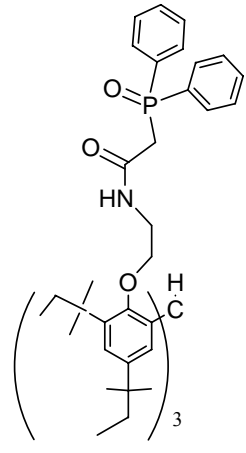

8d

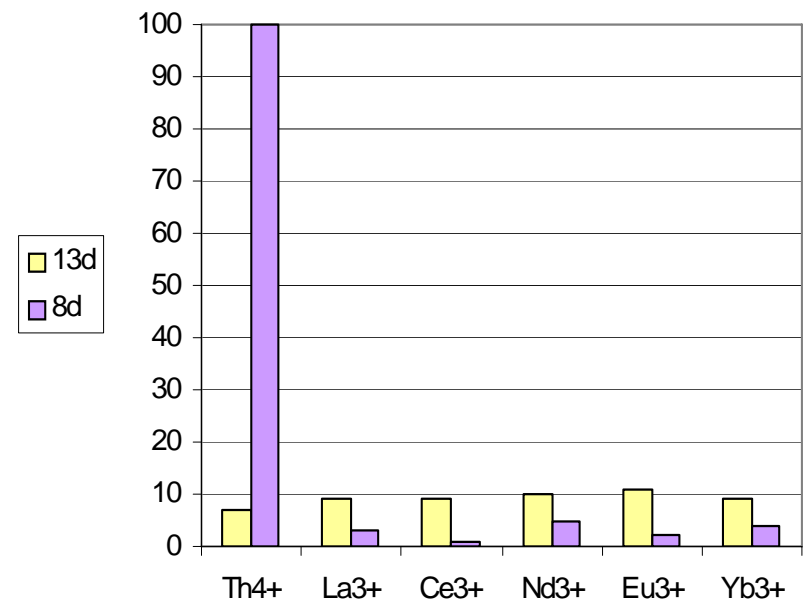

Chart 7. Comparison metal binding of 13d and 8d ligands (\%E).

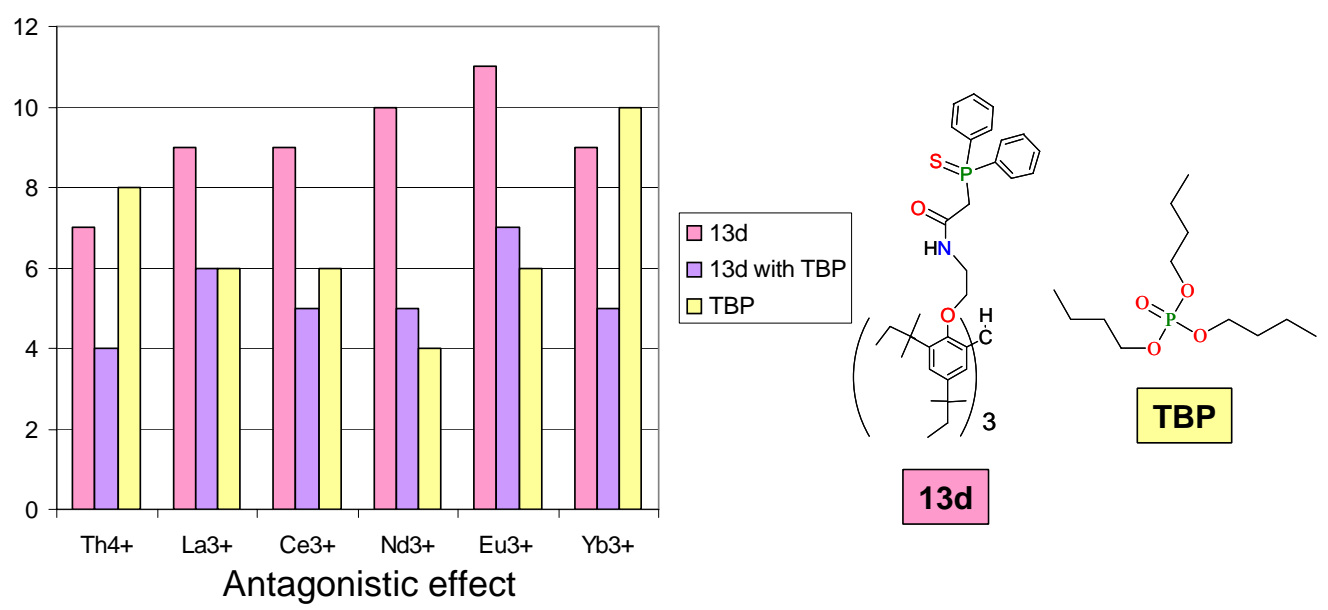

Chart 8. Comparison metal binding of Metal Extraction Percentage (\%E) for Ligand $0.001 \mathrm{M}$ 13d, $0.5 \mathrm{M}$ TBP, and Mixture 0.001 M 13d and 0.5 M TBP).

In order to test the influence of the length on the arm in the extractant with CMPS derivative, a new ligand, 14, with an additional carbon atom spacer has been synthesized (Chart 
9). Unlike the tris-CMPO system, extraction percentage of all tested metal ions with two and three carbon linker tris-CMPS derivatives were found to be the same.
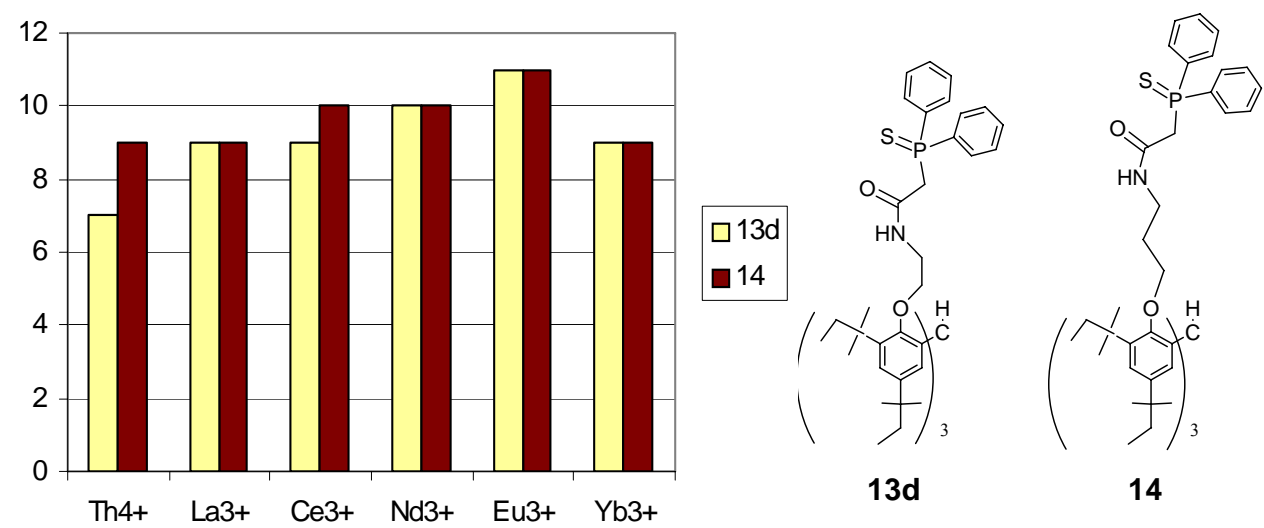

Chart 9. Metal extraction percentage $(\% \mathrm{E})$ for the ligands 13d, and $\mathbf{1 4 .}$

The significance of the interactions between metal ion and ligating moieties with respect to the cavity size and ligand flexibility is apparent in Chart 10. Due to the identical arm length and presence of the same substituents on the platform, except for the $\mathrm{P}=\mathrm{X}$ group, both the $\mathbf{1 0}$ and 14 should exhibit similar flexibility. The only difference concerns the nature of the donor atom of the phosphine oxide and phosphine sulfide. In the phosphine oxide (10), the flexibility increases the ability to bind metals while with phosphine sulfide (14) no enhancement is noted.
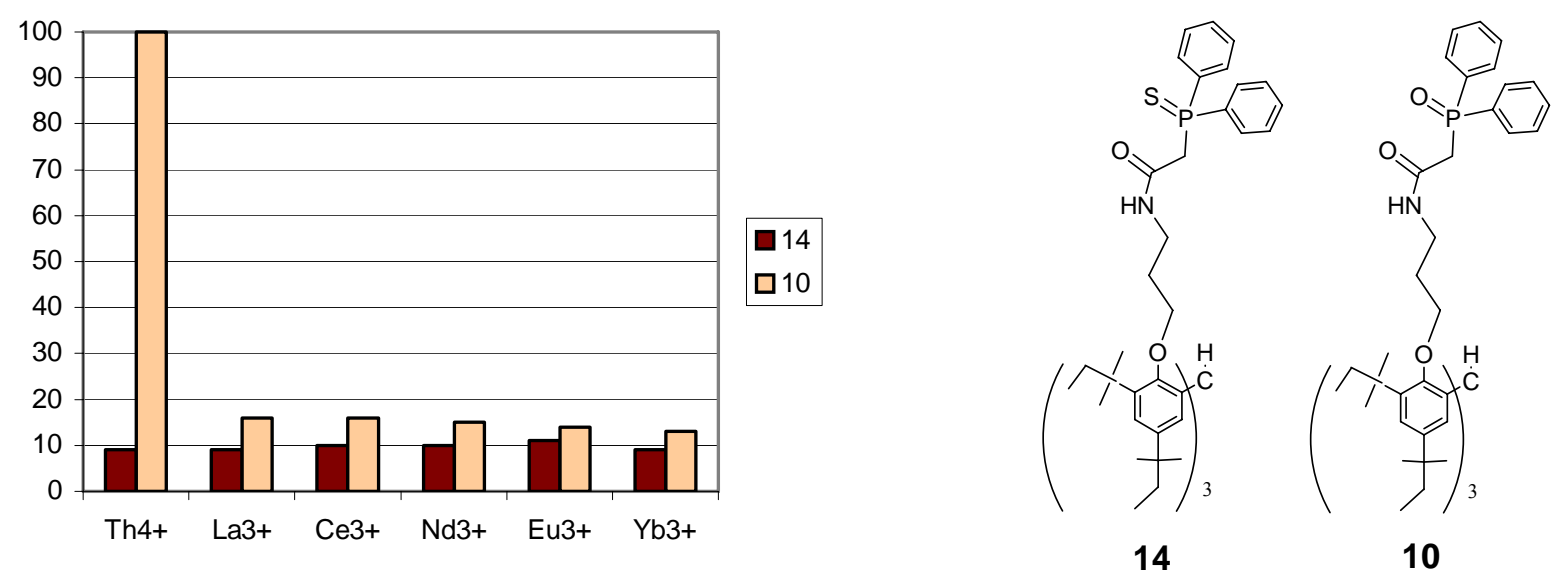

Chart 10. Metal extraction percentage (\%E) for the ligands 14 and 10. 
Table 6. Extraction percentage $(\% \mathrm{E})$ for ligands 8d, 13d, 10 and 14.

\begin{tabular}{c|c|c|c|c|c}
\hline $\begin{array}{c}\text { Cation }\left(10^{-4} \mathrm{M}\right) \\
\text { in } 1 \mathrm{M} \mathrm{HNO}_{3}\end{array}$ & $\begin{array}{c}\text { Equivs of ligand } \\
\text { in organic phase }\end{array}$ & $\begin{array}{c}\mathbf{8 d} \\
(\% \mathrm{E})\end{array}$ & $\begin{array}{c}\mathbf{1 4 d} \\
(\% \mathrm{E})\end{array}$ & $\begin{array}{c}\mathbf{1 0} \\
(\% \mathrm{E})\end{array}$ & $\begin{array}{c}\mathbf{1 4} \\
(\% \mathrm{E})\end{array}$ \\
\hline $\mathrm{Th}^{4+}$ & 10 & $100 \pm 1$ & $7 \pm 2$ & $100 \pm 1$ & $9 \pm 2$ \\
$\mathrm{La}^{3+}$ & 10 & $3 \pm 2$ & $9 \pm 2$ & $16 \pm 1$ & $9 \pm 2$ \\
$\mathrm{Ce}^{3+}$ & 10 & $1 \pm 1$ & $9 \pm 2$ & $16 \pm 2$ & $10 \pm 2$ \\
$\mathrm{Nd}^{3+}$ & 10 & $5 \pm 3$ & $10 \pm 2$ & $15 \pm 1$ & $10 \pm 1$ \\
$\mathrm{Eu}^{3+}$ & 10 & $2 \pm 1$ & $11 \pm 1$ & $14 \pm 2$ & $11 \pm 1$ \\
$\mathrm{Yb}^{3+}$ & 10 & $4 \pm 2$ & $9 \pm 1$ & $13 \pm 2$ & $9 \pm 1$ \\
\hline
\end{tabular}

A concerted effort was undertaken to characterize the structure of a lanthanide complex with the CMPS ligand, and single crystals of a Terbium species was isolated. An X-ray structural determination was performed, and as can bee seen in Figure 16, the three arms of 13d wrap around the metal center, but unlike the CMPO derivatives, the phosphine sulfide groups do not bind to the metal center. The coordination sphere of the terbium center contains three bidentate bound nitrate anions and three oxygen atoms from the three amide carbonyls on the platform. The phosphine sulfide groups in Figure 16 are much weaker donors in comparison to phosphine oxides, and in this instance, they are unable to compete with the nitrate groups for binding sites on the metal center. The ligand still binds the metal tightly and unlike the structure with $\mathbf{8}$, the metal maintains 3 nitrate counterions and the overall charge of the complex is neutral. Hence, the compound should be soluble in organic solvent and efforts to fully explore the extraction efficiency in a variety of solvents are still underway. 

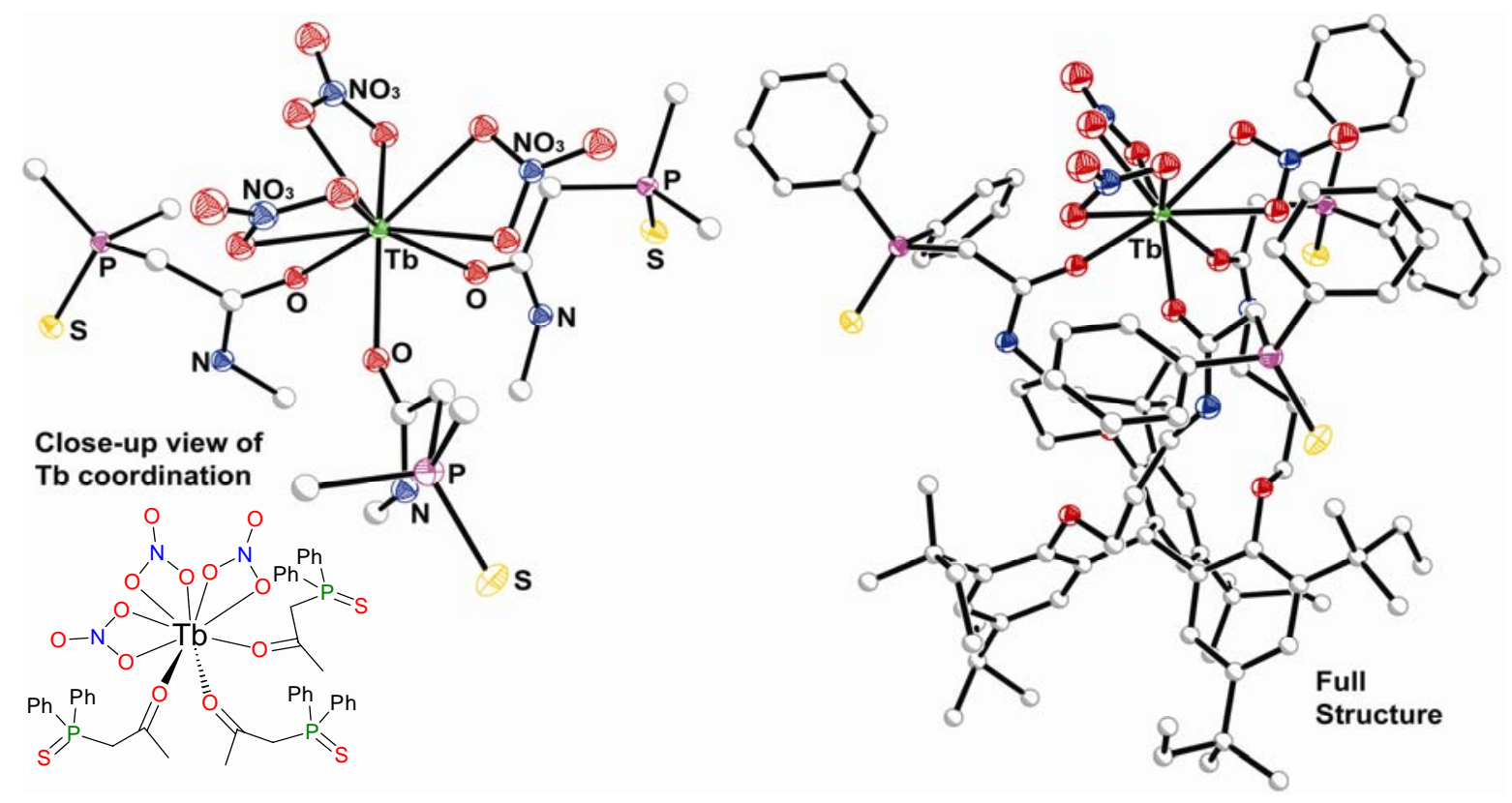

Figure 16. X-ray crystal structure of the Terbium complex of ligand 13d.

A large quantity of 13d was prepared by the Florida group, and a sample was sent to Argonne for testing a mixture of Am-241/Eu-152. For these experiments, approximately 1 or 2 $\mathrm{mL}$ of $10^{-3} \mathrm{M}$ solutions of $\mathbf{1 3 d}$ in dichloromethane were contacted with equal volumes of $1 \mathrm{M}$ $\mathrm{HNO}_{3}$ solutions containing $\mathrm{Am}^{3+}$ and $\mathrm{Eu}^{3+}$. After the phase separation, the aliquots were taken and analyzed by gamma counting. The tests were repeated 4 times with trace concentrations of the nuclides as well as in the presence of $10^{-4} \mathrm{M}$ stable $\mathrm{Eu}\left(\mathrm{NO}_{3}\right)_{3}$. The $\mathrm{D}$ values vary in the range from $4 \times 10^{-4}$ to $2 \times 10^{-3}$ for $\mathrm{Am}^{3+}$ and from $2 \times 10^{-4}$ to $1 \times 10^{-3}$ for $\mathrm{Eu}^{3+}$. In contrast, $\mathrm{D}$ values for the Ln(III) series, obtained at UF, are significantly higher- from 0.05 to 0.1 . Currently, the explanation for the observed differences in the $\mathrm{Eu}^{3+} \mathrm{D}$ values obtained at ANL and at UF is unclear, and given the low D values obtained in the extraction experiment and the inability of the phosphine sulfide groups to bind to the metal center as depicted in Figure 14, work on this ligand system was suspended during the first quarter. The work will be included in a future publication. 


\section{New Oxygen Ligands for Extraction}

The coordination number of trivalent lanthanide hydrated salts in solution vary from 9 to 8 across the series, ${ }^{47,48}$ and in the solid state, the lanthanide aqua complexes adopt nearly rigorous tricapped trigonal prismatic (TTP) geometry. ${ }^{49}$ Inspired by the widespread use of

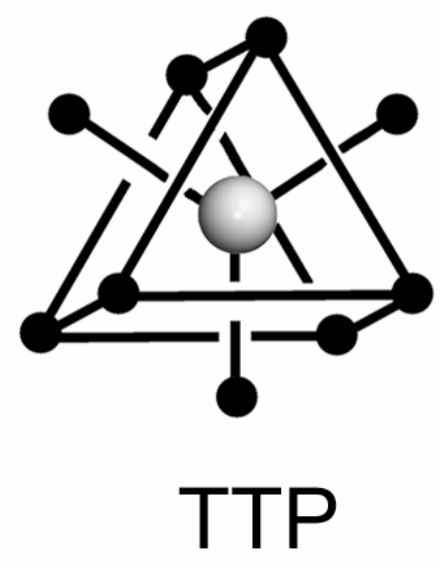
nuclear energy, decades of research effort have been dedicated to the development of ligands for liquid-liquid extractions of spent nuclear fuel with the intent to isolate the harmful actinides from the innocuous lanthanides, but there are few simple ligands compatible with highly acidic solutions that can fully satisfy the geometrical preferences of $\operatorname{Ln}(\mathrm{III})$ and An(III) centers. With this issue in mind, a highly soluble, tripodal chelate bearing three precisely arranged tridentate arms was synthesized. The choice of binding moiety was inspired by diglycolamide (DGA) molecules commonly known as effective, size selective binders of trivalent f-elements in the extraction systems. ${ }^{50-54}$ These tridentate, neutral chelates are very effective binders of trivalent lanthanides and minor actinides; in fact, DGAs are more efficient than the commercial DIAMEX (DIAMide EXtraction) extractants (Figure 17). Unlike other amide-based compounds, diglycolamides demonstrate significant selectivity within the lanthanide series, and the ligands favor the heavier lanthanides and can bind them very efficiently with $\mathrm{D}$ values $>100$ when concentrations of DGA are large as illustrated in Chart 11 In highly acidic nitric acid solutions common in nuclear waste reprocessing, two to four molecules of

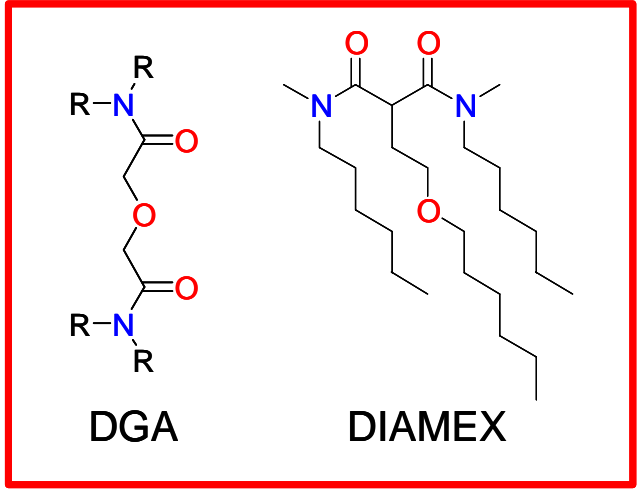

Figure 17. DGA and DIAMEX extractants 
diglycolamides appear to be involved in the coordination of trivalent f-element ions during extractions, ${ }^{55-58}$ and the preorganization of several ligating DGA units onto a molecular platform could potentially greatly improve the efficiency of the extraction. A single ligand with three DGA arms would present the metal with nine favorable donor groups, six of which are relatively hard amide oxygen donors. We have found the $C_{3}$-symmetric triphenoxymethane platform to have great utility for the preparation of ligands with three extended arms, much like calix[4]arene can serve as a base for four arm constructs. Once the three phenols have been derivatized, the triphenoxymethane molecule adopts exclusively an "all up" conformation wherein the oxygens orient in line with the central methine hydrogen.

More efficient extractant for $\mathrm{Ln}$ and Ac than malonamides Order of extractability: [An(III), An(IV) $>>A n(V I)>A n(V)]$ Selectivity within Ln group: heavier > lighter
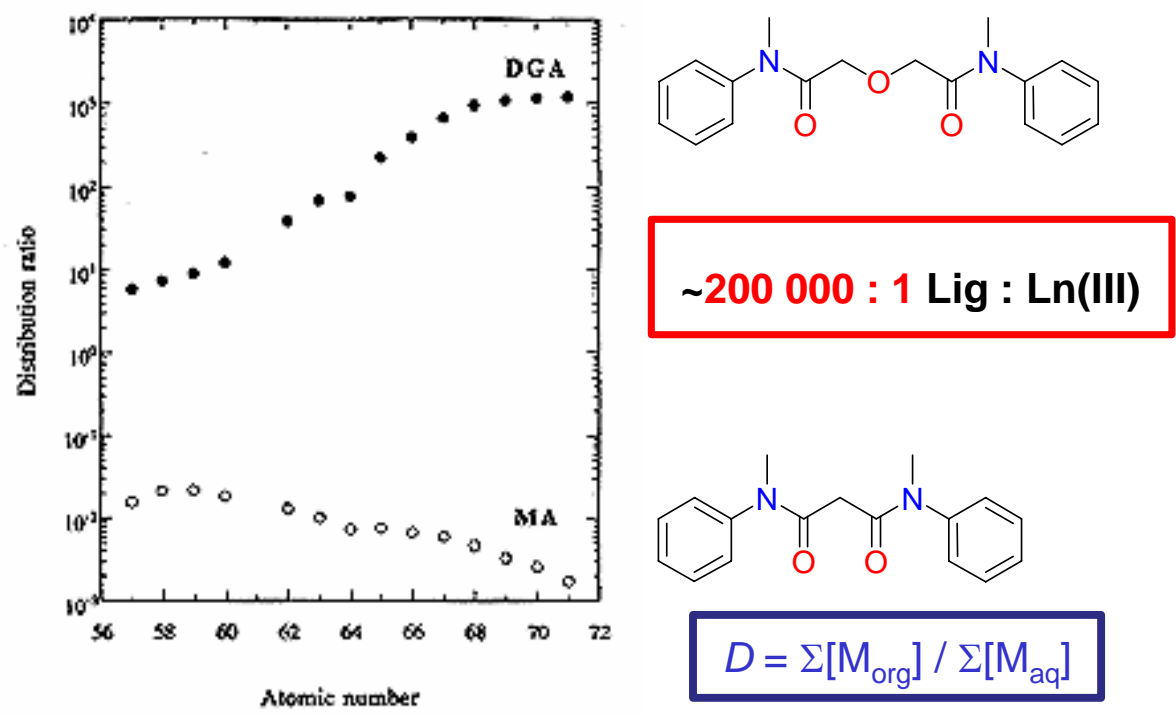

Distribution ratio of $\operatorname{Ln}(\mathrm{III})$ ions as a function of atomic number; 0.2M MA or DGA in $\mathrm{CHCl}_{3} ; 10^{-6} \mathrm{M} \mathrm{Ln}\left(\mathrm{NO}_{3}\right)_{2}$ in $4 \mathrm{M} \mathrm{HNO}_{3}$.

Chart 11: Comparison of the extraction efficiency of DGA and malonamides. ${ }^{56,59}$ 
The tris-diglycolamide ligands $\mathbf{1 5}$ and $\mathbf{1 7}$ were obtained in the reaction of primary amine with mono-substituted oxa-pentaneamide and with the coupling agent benzotriazole-1-yl-oxytrispyrrolidinophosphonium hexafluorophosphate (PyBOP), as presented in Scheme 4. The two compounds differ in the number of carbon atoms separating the oxygen donor groups and the triphenoxymethane platform. The simple diglycolamide $\mathbf{1 6}$ was synthesized according to a modified literature procedure and used as an extraction reference molecule. The solubility properties of the final ligand can be easily modulated through simple substitutions at the 2 and 4 positions of the phenols, as well as substitutions at the terminal amidic nitrogens.

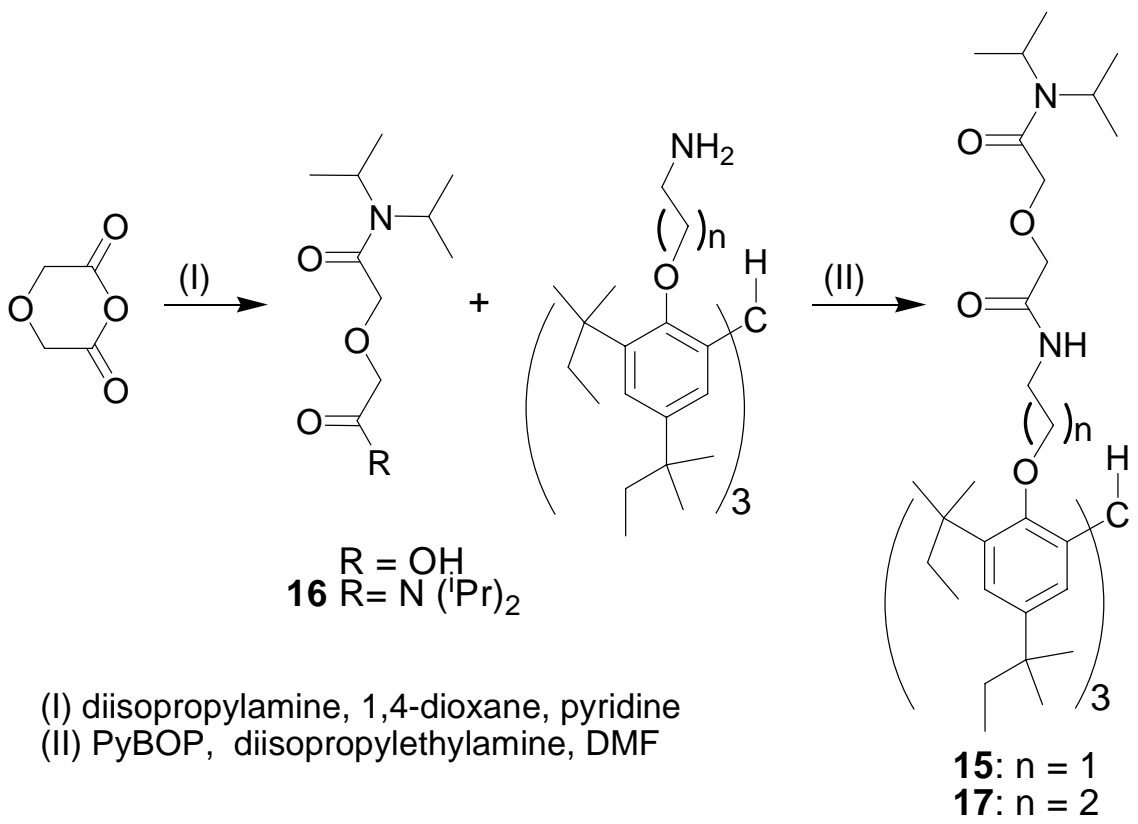

Scheme 4. Synthetic methodologies employed to place diglycolamide groups on platform.

The extraction experiments were performed on a series of eleven lanthanides, ${ }^{152} \mathrm{Eu}$, and ${ }^{241} \mathrm{Am}$ radioisotopes. Solutions of $10^{-4} \mathrm{M}$ metal nitrates in $1 \mathrm{M}$ nitric acid were mixed with equal volumes of $10^{-3}$ and $10^{-4} \mathrm{M}$ organic solutions for approximately $20 \mathrm{~h}$. The reference molecule 16 was consistently used at a three times higher concentration than the tris-DGA derivatives for a 
fair comparison. The concentration of lanthanide ions in the aqueous phase before and after the extraction were determined spectrophotometrically $(\lambda=655 \mathrm{~nm})$, or in the case of ${ }^{241} \mathrm{Am}$ and ${ }^{152} \mathrm{Eu}$, they were measured by a Canberra GammaTrac 1185 with Ge(Li) detector and AccuSpec$\mathrm{B}$ multi-channel analyzer. Extraction efficiencies were calculated using the formula: $\% \mathrm{E}=$ $100 \%\left(\mathrm{~A}_{1}-\mathrm{A}\right) /\left(\mathrm{A}_{1}-\mathrm{A}_{0}\right)$, where $\mathrm{A}$ is the absorbance of the extracted aqueous phase with the Arsenazo(III) indicator, $A_{1}$ is the absorbance of the aqueous phase before extraction with the indicator, and $\mathrm{A}_{0}$ is the absorbance of metal-free $1 \mathrm{M}$ nitric acid and the indicator. The errors, based on the precision of the spectrophotometer and the standard deviation from the mean of at least three measurements, were in most cases no higher than two percent. The extraction percentage was further converted into distribution ratios of the total metal ion concentration in the organic phase against the total metal ion concentration in the aqueous phase $(D=$ $\left.\Sigma\left[\mathrm{M}_{\mathrm{org}}\right] / \Sigma\left[\mathrm{M}_{\mathrm{aq}}\right]\right)$ and in view of the errors associated with the spectrophotometric technique, the maximum value that could be measured for the extraction percentage and distribution ratio was 99.

An excellent match between ionic radius, coordination requirements of the trivalent lanthanides and the binding pocket of the tris-DGA ligand, 15, has been demonstrated by the Xray crystal structures of the representatives of the heaviest and the lightest lanthanides, $\mathrm{Yb}\left(\mathrm{NO}_{3}\right)_{3}: \quad\left(15 \mathrm{Yb}\left(\mathrm{NO}_{3}\right)_{3} \cdot 2 \mathrm{MeOH}\right)$ and $\mathrm{Ce}\left(\mathrm{NO}_{3}\right)_{3}: \quad\left(15 \mathrm{Ce}\left[\mathrm{Ce}\left(\mathrm{NO}_{3}\right)_{6}\right] \cdot 4 \mathrm{MeOH} \cdot \mathrm{C}_{4} \mathrm{H}_{10} \mathrm{O}\right) . \quad \mathrm{A}$ depiction of the structure of the cationic complex $15 \mathrm{Yb}\left(\mathrm{NO}_{3}\right)_{3}$ is presented in Figure 17. 


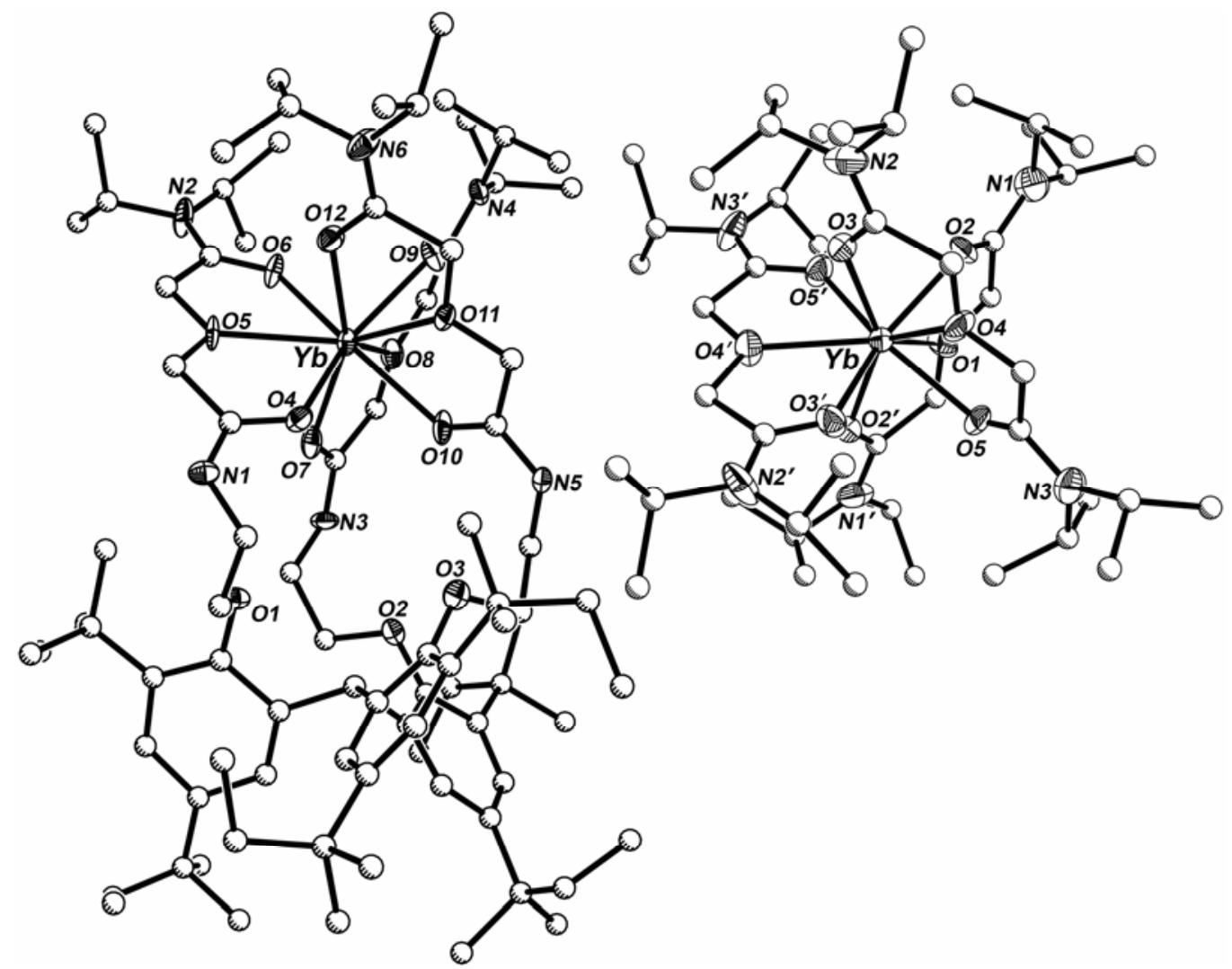

Figure 17. Diagram of the structures of $15 \mathrm{Yb}\left(\mathrm{NO}_{3}\right)_{3}$ (left) and $16 \mathrm{Yb}\left(\mathrm{NO}_{3}\right)_{3}$ (right) $(30 \%$ probability ellipsoids for $\mathrm{Yb}, \mathrm{N}$, and $\mathrm{O}$ atoms; carbon atoms drawn with arbitrary radii). For clarity, all hydrogen atoms and nitrates have been omitted. Primed and unprimed are related by a 2 -fold symmetry operation. Ce(III) ligated by 15 adopts structure nearly identical to $15 \mathrm{Yb}\left(\mathrm{NO}_{3}\right)_{3}$.

Each of the three arms of the ligand in both $15 \mathrm{Yb}\left(\mathrm{NO}_{3}\right)_{3}$ and $15 \mathrm{Ce}\left[\mathrm{Ce}\left(\mathrm{NO}_{3}\right)_{6}\right]$ are equally involved in the cooperative metal binding in a tridentate fashion. As a result, the ligand fully saturates the coordination sphere of the metal ion leaving no space for nitrates to bind. In the structure of $15 \mathrm{Yb}\left(\mathrm{NO}_{3}\right)_{3}$, two of the nitrate anions form hydrogen bonds with the ligand amide hydrogens, and the capacity of $15 \mathrm{Yb}\left(\mathrm{NO}_{3}\right)_{3}$ to form hydrogen bonds with the anions may facilitate the extraction event. Both compounds $\left(15 \mathrm{Yb}\left(\mathrm{NO}_{3}\right)_{3}\right.$ and $\left.15 \mathrm{Ce}\left[\mathrm{Ce}\left(\mathrm{NO}_{3}\right)_{6}\right]\right)$ are 9 coordinate and have the same slightly distorted tricapped trigonal prismatic geometry. The 
triangular faces of the carbonyl oxygens $\mathrm{O}(6), \mathrm{O}(9), \mathrm{O}(12)$ and $\mathrm{O}(4), \mathrm{O}(7), \mathrm{O}(10)$, are somewhat twisted about the three fold axis. The etheric oxygens (equatorial oxygens) $\mathrm{O}(5), \mathrm{O}(8)$, and $\mathrm{O}(11)$ cap the faces of the trigonal prism. Consistent with the size differences in the two metals (ionic radius for $\left.\mathrm{CN}=9, \mathrm{r}_{\mathrm{Ce}(\mathrm{III})}=1.336 \AA, \mathrm{r}_{\mathrm{Yb}(\mathrm{III})}=1.182 \AA\right)$, ${ }^{60}$ the smaller, more electropositive $\mathrm{Yb}(\mathrm{III})$ binds tighter to the ligand. The bond lengths to the amidic oxygens \{Ce: 2.396(9)2.479(8) $\AA$ [mean distance of 2.434(9)]; Yb: 2.301(2)-2.351(3) $\AA$ [mean distance of 2.313(3)]\} are shorter than to the etheric oxygens \{Ce: 2.544(7)-2.597(7) $\AA$, [mean 2.566(7)]; Yb: 2.413(2)$2.455(2) \AA$, [mean $2.429(2)]\}$ by approximately $0.11 \AA$. Interestingly, in the only structurally characterized example of a DGA-Ln(III) complex available in the literature, ${ }^{61}$ the bond distances to the etheric oxygens varied from $2.679 \AA$ to $2.849 \AA$ in a ten coordinate La(III) bis DGA complex. In order to ascertain the influence of the triphenoxymethane base on the metal center, the structure of the ytterbium complex with three $\mathrm{N}, \mathrm{N}, \mathrm{N}^{\prime}, \mathrm{N}^{\prime}$-tetra-isopropyl-3-oxapentanediamide reference molecule, 16, was determined (Fig. 17), and the $\mathrm{Yb}(\mathrm{III})$ center in this species maintains the same coordination environment. The distances between amidic oxygens 2.282(7)-2.344(9) $\AA$ [mean 2.317(9)] and the etheric oxygens and metal 2.421(8)-2.436(8) $\AA$ [2.426(8)] are virtually indistinguishable from the structure of $15 \mathrm{Yb}\left(\mathrm{NO}_{3}\right)_{3}$. The orientation of the oxygen atoms and the metal oxygen bond distances in the DGA complexes are somewhat different from the aqua groups. For example, in the nonaaqualanthanoid(III) complex $\left[\mathrm{M}\left(\mathrm{OH}_{2}\right)_{9}\right]^{3+}(\mathrm{M}=\mathrm{Ce}(\mathrm{III}), \mathrm{Yb}(\mathrm{III}))$ with trifluoromethanesulfonates anions, the distances to the prism oxygens are 2.489(2) and 2.302(2) $\AA$, and to the equatorial oxygens are 2.594(2) and 2.532(3) $\AA$ for the $\mathrm{Ce}$ and $\mathrm{Yb}$ respectively. The difference is most apparent in the case of $\mathrm{Yb}$, where the mean distance from the metal to equatorial oxygen is on average $0.103 \AA$ shorter in the tris-DGA complex than in the aqua complex, while the metal-prism oxygen distances are only 
marginally longer by $0.011 \AA$. The $\mathrm{Yb}(\mathrm{III})$ is held tightly by the ligand, and the twist angle of the trigonal prism is only $15.2^{\circ}$. In the case of $\mathrm{Ce}(\mathrm{III})$, both prismatic and equatorial bonds are shorter than in the aqua complex by $0.055 \AA$ and $0.028 \AA$, respectively, but the twist angle increases to $21.6^{\circ}$. Based on the size and similar coordination environment of the newly synthesized complex of $\mathbf{1 6}$ with $\mathrm{Eu}(\mathrm{III})$, the twist angle about the three fold axis should fall in between the values for $\mathrm{Ce}(\mathrm{III})$ and $\mathrm{Yb}(\mathrm{III})$ complexes of 15 . As anticipated, the value of the twist angle was found to be $20.0^{\circ}$. Interestingly, as the coordination geometry distorts away from an ideal TTP in the model complexes the extractant efficiency with $\mathbf{1}$ in the dichloromethane decreases with a separation factor of $\mathrm{SF}_{\mathrm{Yb} / \mathrm{Ce}}=450\left(\mathrm{SF}_{\mathrm{A} / \mathrm{B}}=\mathrm{D}_{\mathrm{A}} / \mathrm{D}_{\mathrm{B}}\right.$; the fraction of the distribution ratios of the two extractable solutes measured under the same conditions). At this stage of investigation, however, the conclusive determination of the origin of such selectivity in the solution is premature. A comparison of the structures with $\mathbf{1 5}$ and with the TPP structures of $\mathrm{Ln}\left(\mathrm{OH}_{2}\right)_{9}{ }^{3+}$ is contained in Figure 18.

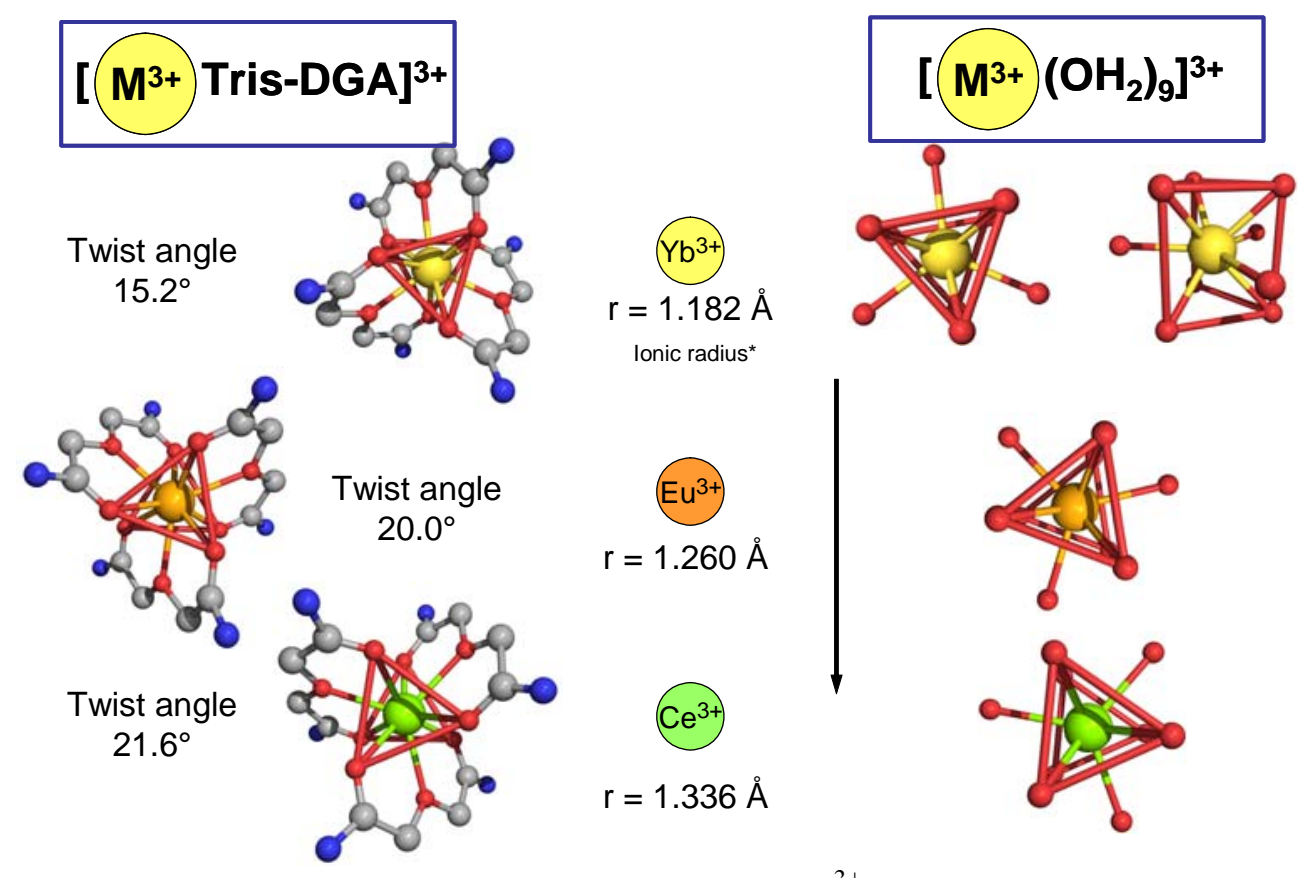

Figure 18. Comparison of the TPP structures of $\mathrm{Ln}\left(\mathrm{OH}_{2}\right)_{9}{ }^{3+}$ and $\mathrm{Ln}(\mathrm{III})$ complexes with 15. 
Typically, high distributions of trivalent f-elements in organic/acidic extraction systems are reported with approximately $\sim 100,000: 1$ DGA to metal ion concentration (e.g. $0.2 \mathrm{M} \mathrm{N}, \mathrm{N}^{\prime}-$ dimethyl-N,N'-diphenyl-3-oxapenanediamide DMDPhOPDA, $\left.10^{-6} \mathrm{M} \mathrm{Ln}(\mathrm{III})\right)^{55}$ With the triDGA ligand (15), comparable distribution ratios can be obtained with a 10:1 ligand to metal ratio. To provide some context for the extraction of efficiency of $\mathbf{1 5}$ under controlled experimental conditions, the properties of ligand have been evaluated with respect to the performance the related DGA, 16, and since $\mathbf{1 5}$ contains three arms, the concentration of $\mathbf{1 6}$ was increased by factor of three (Figure 19). This oversimplified comparison of preliminary data is used strictly to present the significant changes in the efficiency and selectivity of studied diglycolamide chelates. The delineation of the nature of extracted species requires further systematic investigation and will be published elsewhere.

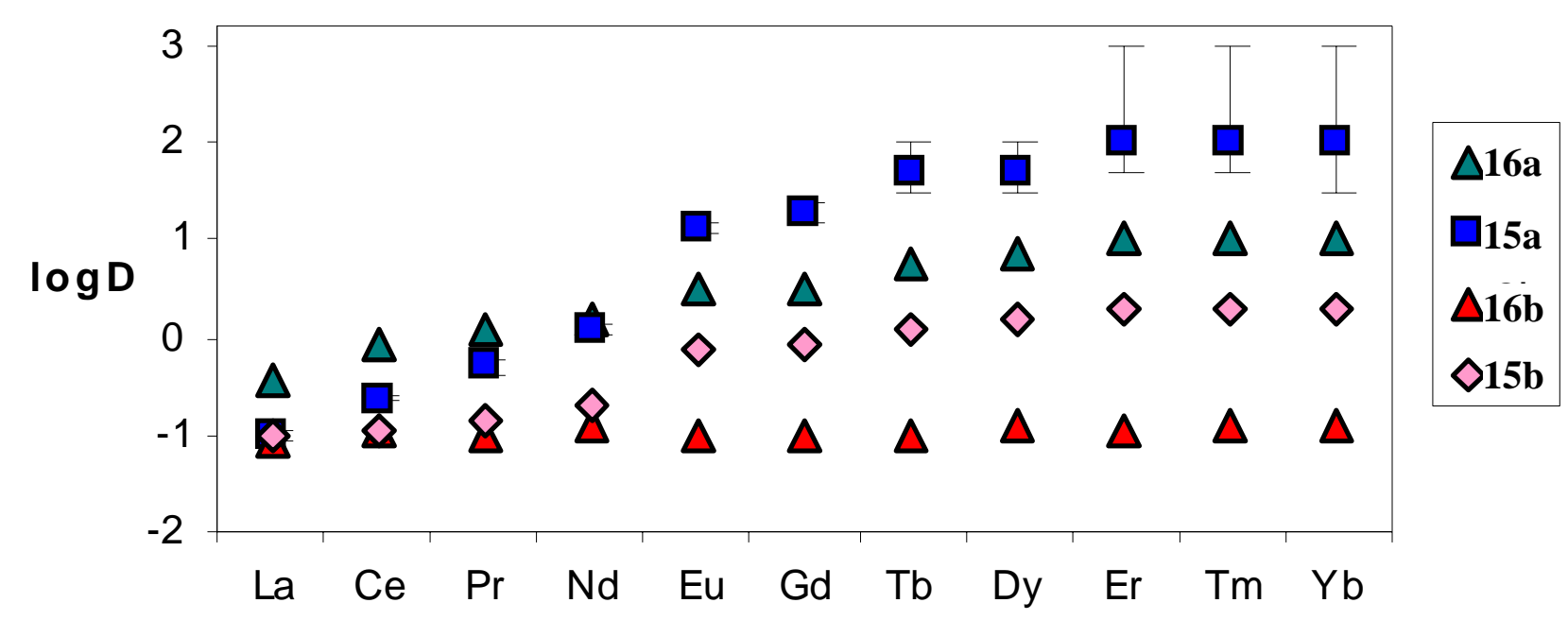

Figure 19 Extraction of $10^{-4} \mathrm{M}$ solutions of trivalent Lanthanides in $1 \mathrm{M} \mathrm{HNO}_{3}$ with dichloromethane solutions containing ligand 2 at $3 \times 10^{-3} \mathrm{M}(\mathbf{1 6 a})$ or $3 \times 10^{-4} \mathrm{M}(\mathbf{1 6 b})$ and solutions of 4 at concentrations of $10^{-3} \mathrm{M}(\mathbf{1 5 a})$ and $10^{-4} \mathrm{M}(\mathbf{1 5 b})$. Due to the limitations of the spectrochemical assay, the error bars for D are quite large at high extraction efficiency $(>98 \%)$ 
An experiment with the reference molecule at $3 \times 10^{-3} \mathrm{M}$ (15a) showed the typical extraction pattern for diglycolamides, which gradually ascends across the lanthanide series. Once three DGA moieties were attached to the triphenoxymethane platform (15), the efficiency of the ligand for the heaviest lanthanides was remarkably improved. Only ten-fold excess of ligand 15 allowed for quantitative removal of trivalent erbium, thulium and ytterbium from $1 \mathrm{M}$ $\mathrm{HNO}_{3}$ solution. Even though the direct comparison of these two compounds (16 and 15) is impossible due to the fundamental differences in the character of the extracted species, considering only the concentrations required for high extractability, the efficiency and therefore economy gain in the case of $\mathbf{1 5}$ is clearly evident. Moreover, this unique design of rather flexible, nine oxygen donor cavitand allowed for much more sensitive ion size recognition than in the case of any other DGA chelates. Enhanced affinity of tris-DGA for the heaviest Ln and decreased attraction for the lightest ( $\mathrm{La}, \mathrm{Ce}, \mathrm{Pr})$, resulted in improved separation factor between the elements in the group. For instance, the value of the $\mathrm{SF}$ of $\mathrm{Yb}(\mathrm{III})$ and $\mathrm{La}(\mathrm{III})$ increased from $\mathrm{SF}_{\mathrm{Yb} / \mathrm{La}}=26$ for $16 \mathbf{a}$ to $\mathrm{SF}_{\mathrm{Yb} / \mathrm{La}}=1138$ for 15a. Surprisingly, further dilution of the organic phase to a 1:1 metal to ligand ratio maintained a high extraction efficiency for the heaviest lanthanides; over two thirds of $\mathrm{Tm}(\mathrm{III})$ and $\mathrm{Yb}(\mathrm{III})$ was transferred into the organic phase. At the same time, with a three times higher concentration of $16 \mathrm{~b}\left(3 \times 10^{-4} \mathrm{M}\right)$, the extraction was negligible and no separation was observed suggesting necessity of the significant excess of ligand $\mathbf{1 6}$ to achieve appreciable extraction, and once again confirming the efficiency gain through the DGA preorganization in the compound 15. 


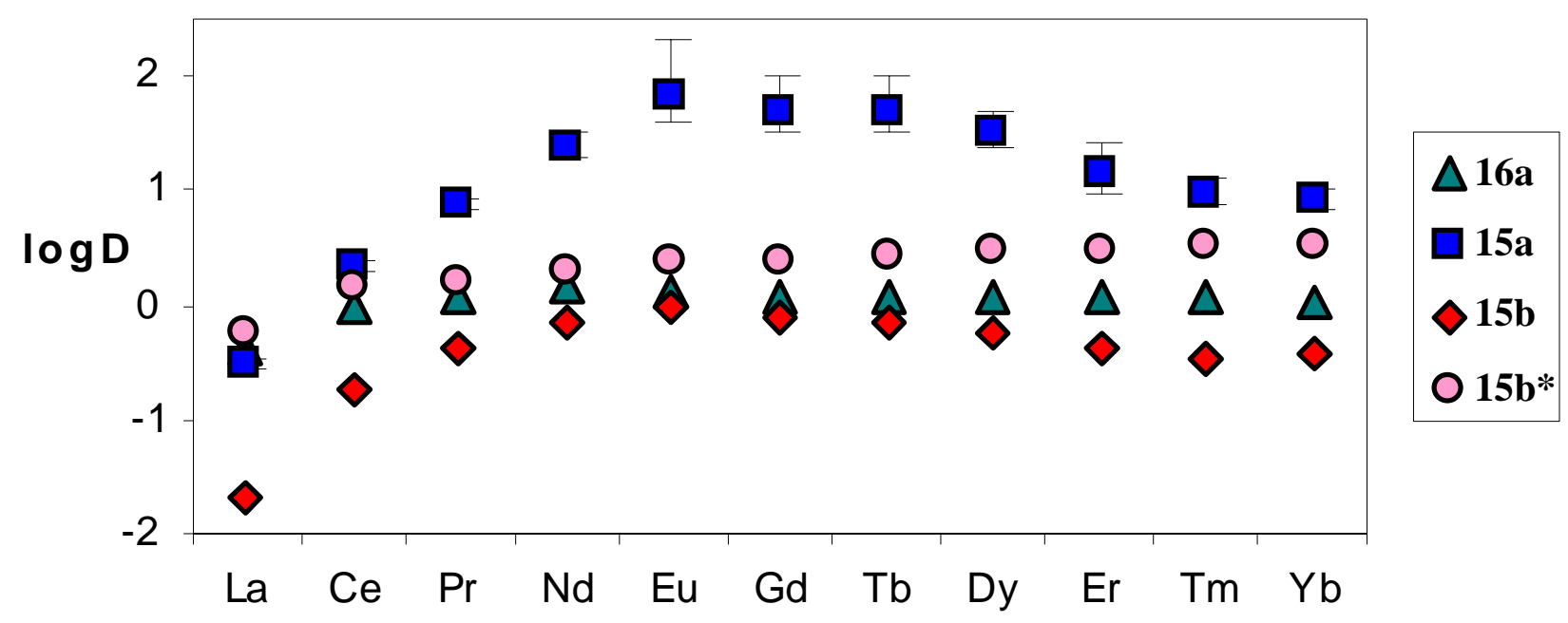

Figure 20 Extraction of $10^{-4} \mathrm{M}$ solutions of trivalent Lanthanides in $1 \mathrm{M} \mathrm{HNO}_{3}$ with solutions containing ligand 2 in octanol at $3 \times 10^{-3} \mathrm{M}(\mathbf{1 6 a})$ or ligand 15 in octanol at $10^{-3} \mathrm{M}$ (16a) or $10^{-4} \mathrm{M}(\mathbf{1 6 b})$ or in $\mathrm{n}$-dodecane at $10^{-4} \mathrm{M}\left(\mathbf{1 6} \mathbf{b}^{*}\right)$. Due to the limitations of the spectrochemical assay, the error bars for D are quite large at high extraction efficiency $(>98 \%)$

The separation of An(III) from the chemically similar Ln(III) has been the most challenging task in nuclear waste partitioning. As is the case of most hard donor extractants compound 15 is not particularly effective in discrimination of these two groups of elements. The separation factor of 6.16 obtained for trivalent europium and americium in dichloromethane was only slightly higher in comparison to the literature data for simple DGAs in chlorinated solvents (e.g. $0.1 \mathrm{M}$ N,N,N',N'-tetraoctyl-3-oxapenanediamide: 3.43 in dichloroethane, 0.81 in chloroform). ${ }^{56}$

There are many complex processes that influence the transfer of the metal ion from an acid layer into an organic phase, and in a very simplistic view, the three major factors dominate 
the extraction event: solubility, steric hindrance presented by a ligand, and the electronic effect. ${ }^{62}$ The first tris-diglycolamide ligand with two isopropyl groups on the terminal amides (15) was found to be a highly effective agent for the extraction of the heaviest lanthanides into dichloromethane. With the desire to use more environmentally "friendly" solvents, the extraction profile was examined in 1-octanol and n-dodecane, but during the acidic extraction in n-dodecane, formed complexes quickly precipitated out of the organic solution. In order to increase the lipophilicity of the tris-DGA chelate, and therefore, potentially enhance the solubility of the extracted metal complex in the nonpolar diluents, a new derivative with two nbutyl substituents attached to each of the terminal amidic nitrogens was synthesized (18). As expected, the new ligand is highly compatible with nonpolar solvents, but at the same time, the binding ability of $\mathbf{1 8}$ relative to $\mathbf{1 5}$ is considerably suppressed (Figure 21). A similar trend has been noted in simple diglycolamides. ${ }^{56}$ In four different diluents: chloroform, toluene, n-hexane and n-dodecane, the distribution coefficients of the ligands decreased when the length of the alkyl chains was extended.

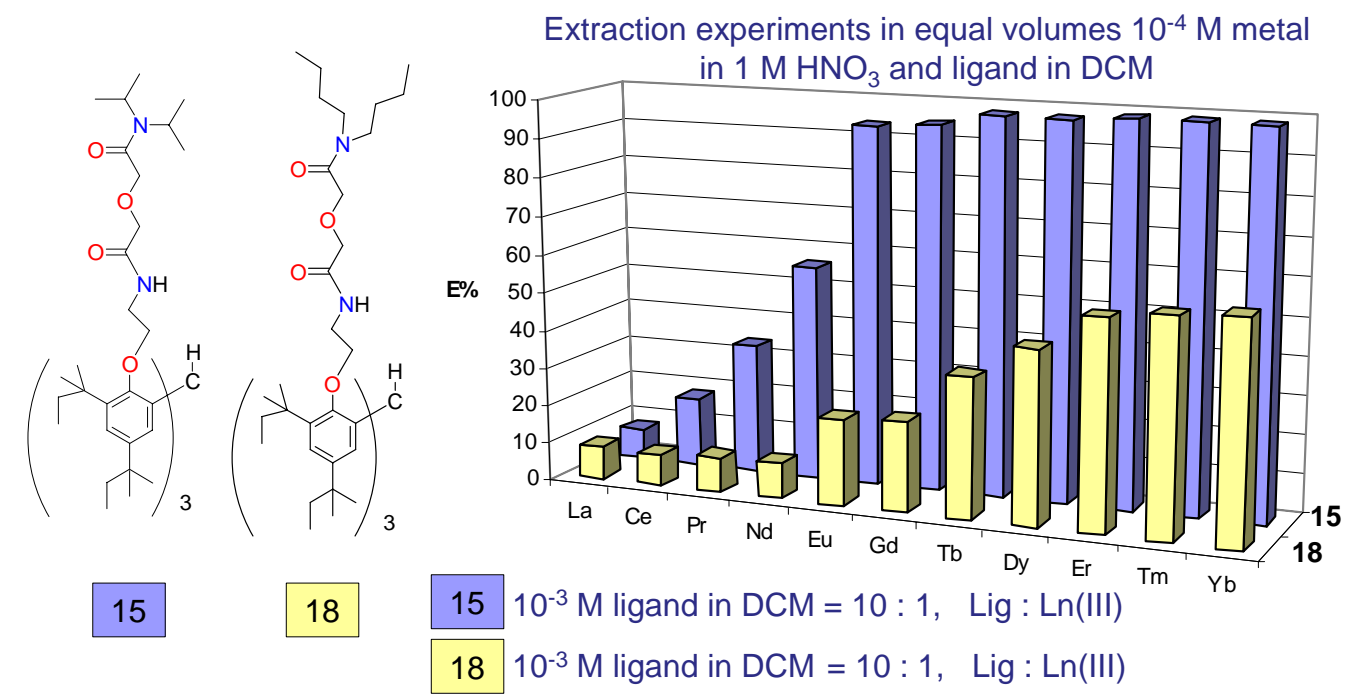

Figure 21. Extraction of $10^{-4} \mathrm{M}$ solutions of trivalent lanthanides in $1 \mathrm{M} \mathrm{HNO}_{3}$ with dichloromethane solutions containing ligands 15 and 18 at $10^{-3} \mathrm{M}$. 
At a ratio of 10:1 ligand to metal in the dichloromethane/1 $\mathrm{M} \mathrm{HNO}$ system, the extraction efficiency of $\mathbf{1 8}$ relative to $\mathbf{1 5}$ is reduced by nearly $50 \%$, and in the case of the heaviest lanthanides, distribution ratio for the extraction with $18(D \sim 1)$ is significantly lower than the corresponding value for $15(D>99)$. Even though both ligands exhibit the same general trend for preferential extraction of the heavier lanthanides, the selectivity of the two is notably different. For example, the separation between $\mathrm{Yb}(\mathrm{III})$ and $\mathrm{La}(\mathrm{III})$ drops from $\mathrm{SF}_{\mathrm{Yb} / \mathrm{La}}=1138$ for 15, to $\mathrm{SF}_{\mathrm{Yb} / \mathrm{La}}=14$ for $18\left(\mathrm{SF}_{\mathrm{A} / \mathrm{B}}=\mathrm{D}_{\mathrm{A}} / \mathrm{D}_{\mathrm{B}}\right.$; the fraction of the individual distribution ratios of two extractable solutes measured under the same conditions). In addition, the extraction efficiency for the four lightest lanthanides is significantly muted, and the limitations of the spectrophotometric analysis complicate the analysis of this trend. Experiments with 15 in 1octanol and n-dodecane are underway as are efforts to delineate fully the extraction behavior of the ligands.

In previous work with Calix[4]arenes and triphenoxymethane molecule appended with CMPO arms, the extraction efficiency of the constructs was amplified by the increased flexibility of the linker between the CMPO and the base skeleton. ${ }^{34,63}$ This trend can be attributed to the enhanced ability of ligand to satisfy the geometrical requirements of the metal center, but often, the improvement in binding affinity comes at the expense of selectivity. In 15, the DGA groups are tethered to the triphenoxymethane platform by only two carbons, and to test the effect of the length of this arm linker on the extraction ability, a new tri-substituted diglycolamide was synthesized with three carbons linking the DGA arms to the triphenoxymethane base (17). Considering the high efficiency of the "more rigid" chelate 15 at the 10:1 ligand to metal proportion, and expected performance enhancement of 17 over 15, the experiment has been conducted with only $10^{-4} \mathrm{M}$ concentration of $\mathbf{1 7}$ in the dichloromethane (1:1 ligand to metal 
ratio). Interestingly, the new extractant did not appear to be more effective or less selective than its "more rigid" equivalent. In fact, the $\mathbf{1 7}$ exhibits the same extraction behavior as compound 15, suggesting that the binding environment in the two ligands is nearly identical (Figure 22). Interestingly, the coordination environment of the metal center in the Eu(III) complex of $\mathbf{1 7}{ }^{64}$ is nearly indistinguishable from $\mathrm{Yb}(\mathrm{III})$ and $\mathrm{Ce}(\mathrm{III})$ complexes of $15 .{ }^{65}$ Both ligands are perfectly suited to fulfill the coordination requirements of trivalent lanthanides in the organic solution.

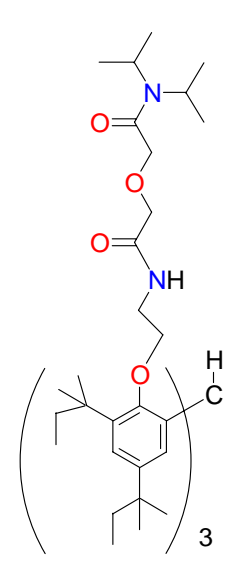

15

$15^{*}$

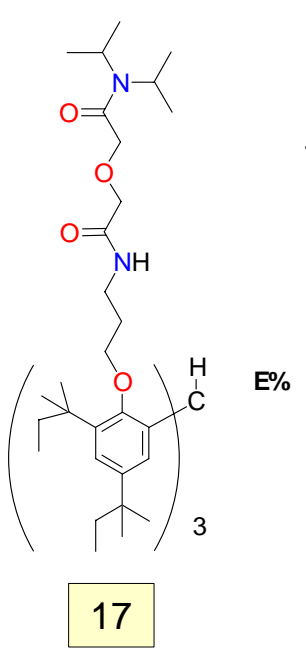

15
Extraction experiments in equal volumes $10^{-4} \mathrm{M}$ metal in $1 \mathrm{M} \mathrm{HNO}_{3}$ and ligand in $\mathrm{DCM}$

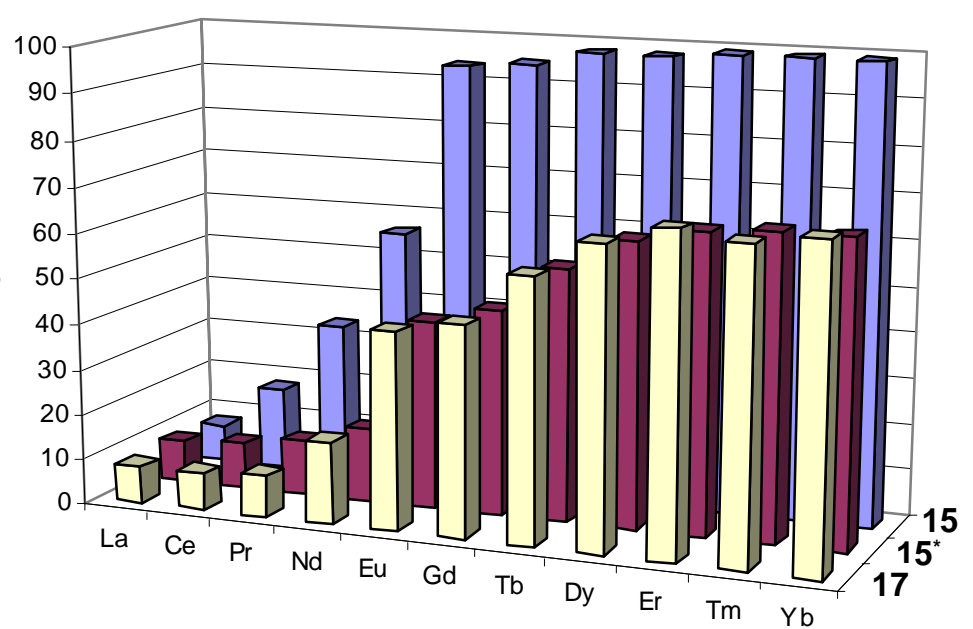

$17^{15}$

$15 \quad 10^{-3} \mathrm{M}$ ligand in DCM = $10: 1, \quad$ Lig : Ln(III)

15* $\quad 10^{-4} \mathrm{M}$ ligand in DCM = $1: 1, \quad$ Lig : $\operatorname{Ln}(\mathrm{III})$

$17 \quad 10^{-4} \mathrm{M}$ ligand in $\mathrm{DCM}=1: 1$, Lig : $\operatorname{Ln}(\mathrm{III})$

Figure 22. Extraction of $10^{-3} \mathrm{M}$ and $10^{-4} \mathrm{M}$ solutions of trivalent lanthanides in $1 \mathrm{M} \mathrm{HNO}_{3}$ with dichloromethane solutions containing ligands $\mathbf{1 5}$ and $\mathbf{1 7 .}$

Given the ability of 1 equivalent of $\mathbf{1 5}$ to extract $\sim 70 \%$ of the heaviest lanthanides from the acidic layer, the reaction can be easily monitored when deuterated dichloromethane is used for the extraction experiment. Figure 23 presents three superimposed ${ }^{1} \mathrm{H}$ NMR spectra of the 
ligand 15 equilibrated with $1 \mathrm{M}$ nitric acid (a), the extracted species generated in upon complexation of $\mathrm{Lu}(\mathrm{III})$ by ligand 15 in the $1 \mathrm{M}$ nitric acid/D2-dichloromethane extraction system (b), and the $\mathrm{Lu}\left(\mathrm{NO}_{3}\right)_{3}$ complex with 15 formed directly in D2-dichloromethane (c). The chemical shifts of protons in the close proximity to the coordination site significantly change upon formation of complex. Protons that belong to the $\mathrm{CH}_{2} \mathrm{CH}_{2}$ tripod-DGA linker become more distinct. Complexation of metal through amidic and etheric oxygens deshields the surrounding protons and results in noticeable downfield change in their chemical shifts. Without a metal, the ${ }^{1} \mathrm{H}$ NMR spectrum of $\mathbf{1 5}$ exhibits two sharp singlets for the DGA $\mathrm{CH}_{2} \mathrm{OCH}_{2}$ protons and these signals broaden, merge, and shift downfield when a metal is added. The resonances for the protons of secondary amides are the most affected by metal complexation and they shift from a value of $8.08 \mathrm{ppm}$ for $\mathbf{1 5}$ to $9.78 \mathrm{ppm}$ for the $\mathrm{Lu}(\mathrm{III})$ complex of $\mathbf{1 5}$. In the case Lu-trisDGA species extracted from the acid layer, the presence of a significant amount of water and acid may influence the chemical shift of the amidic protons causing a less significant change in their position relative to the metal complex formed in dry dichloromethane. Nevertheless, the spectrum demonstrates that a $C_{3}$-symmetric complex is formed, and all three arms of the ligand simultaneously bind the metal center during the extraction event. In addition, the central methine hydrogen $(\mathrm{CH})$, aromatic $(7.1 \mathrm{ppm})$ and $\mathrm{CH}_{2} \mathrm{OCH}_{2}$ regions in the $\mathbf{b}$ spectrum show some residual amount of a free ligand which agrees with the extraction data at a 1:1 metal to ligand ratio highlighted in Figure 22. Given the similarities between the two $\mathrm{Lu}(\mathrm{III})$ spectrum, it appears that the solid state structure depicted in Figure 17 is maintained during the extraction experiment, and the extracted species adapts a TPP geometry with $\mathbf{1 5}$ and 3 nitrate ions balance the charge in the organic layer. Ligand $\mathbf{1 5}$ exploits the preference for TPP geometry and affords the most efficient binder known for Ln(III) ions from acidic waste! 


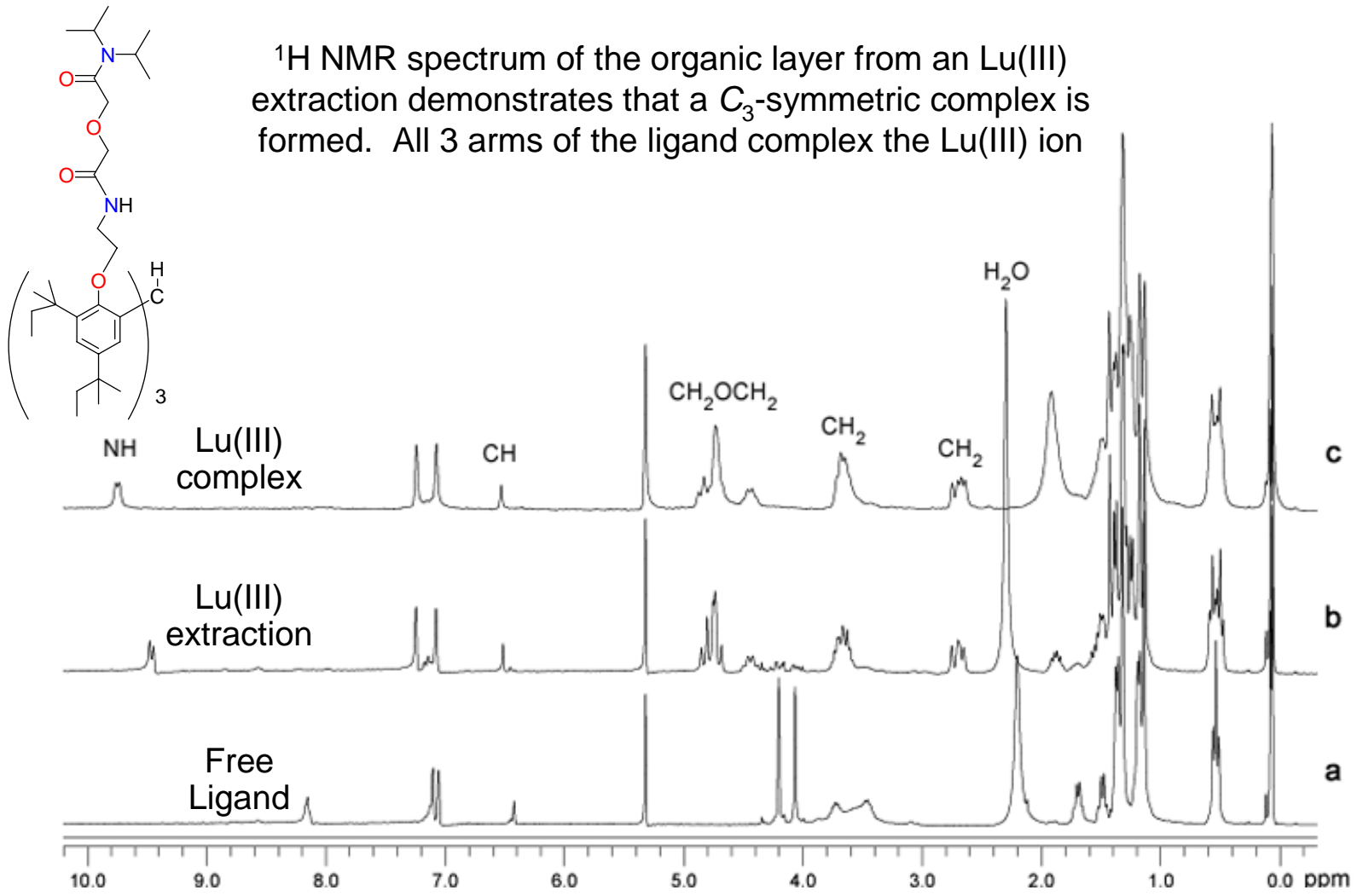

Figure 23. Superimposed ${ }^{1} \mathrm{H}$ NMR spectra of ligand 15 equilibrated with $1 \mathrm{M}$ nitric acid (a), $\mathrm{Lu}(\mathrm{III})$ extracted by ligand 15 from $1 \mathrm{M}$ nitric acid into the D2-dichloromethane (b) and $\mathrm{Lu}(\mathrm{III})$ complex with 15 formed in D2-dichloromethane (c).

The properties of an organic solvent strongly influence almost every aspect of the liquidliquid extraction process, and in our previous studies with 15, a significant modulation in the extraction pattern was noted when 1-octanol was substituted for dichloromethane as the organic solvent (Figure 24). From a gradually rising affinity toward heavier lanthanides in dichloromethane, the extractant tends to favor the middle lanthanides in 1-octanol, in particular europium. The heaviest lanthanides are still more readily extracted than the lightest ones, although the separation between $\mathrm{Yb}(\mathrm{III})$ and $\mathrm{La}(\mathrm{III})$ significantly decreases from $\mathrm{SF}_{\mathrm{Yb} / \mathrm{La}}=1138$ to 
$\mathrm{SF}_{\mathrm{Yb} / \mathrm{La}}=27$. The preference of $\mathrm{Eu}(\mathrm{III})$ binding arises apparently from combined effects of the best fit between metal and ligand, and the complex stabilization provided by 1-octanol. Therefore, the origin of selectivity in dichloromethane may not be simply related to the careful recognition of size of the metal ion or an increased charge density on the metal center. The selectivity must be strongly associated with the properties of an organic phase and results from the combined effect of many possible interactions between the ligand, metal and both aqueous and organic solutes.

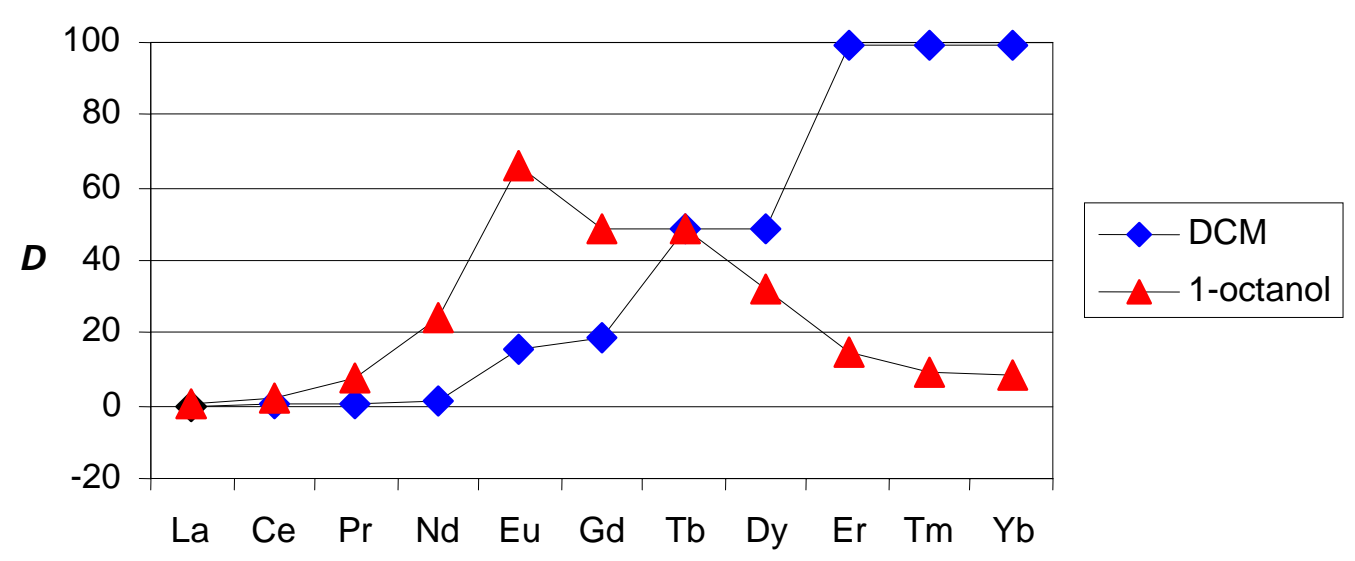

Figure 24. Extraction of $10^{-4} \mathrm{M}$ solutions of trivalent lanthanides in $1 \mathrm{M} \mathrm{HNO}_{3}$ with dichloromethane (DCM) and 1-octanol solutions containing ligand 15 at $10^{-3} \mathrm{M}$

Most successful extractants for lanthanide(III)/actinide(III) separations contain soft donor atoms for metal binding, ${ }^{43-46,52,54,66-68}$ and the central oxygen atom in the DGA ligand can be replaced with a softer sulfur atom producing a thiodiglycolamide (TDGA). Based on a comparison of the extraction ability of TDGA and the related glutalamide (GLA) ligand with a $\mathrm{CH}_{2}$ group in place of the central oxygen, it appears that the central sulfur atom in TDGA may 

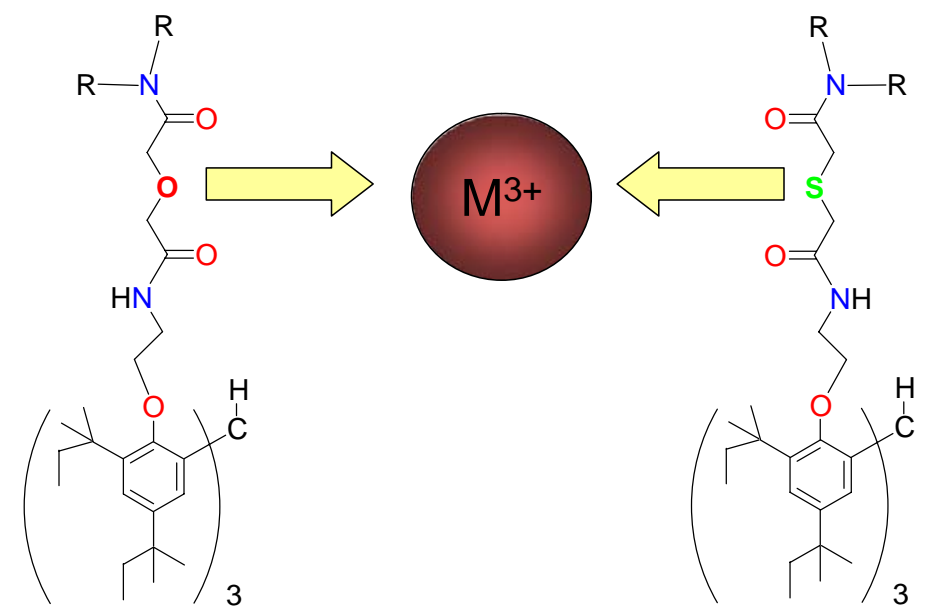

interact with the $\mathrm{Am}(\mathrm{III})$ center in a $1 \mathrm{M}$

$\mathrm{NaClO}_{4} /$ nitrobenzene extraction system $(\mathrm{pH}=3) \cdot{ }^{54}$ Since the size and flexibility of the group linking the amide donors is very similar, the groups would form a nearly identical 8membered chelate with americium if

the sulfur atom does not interact with the metal. The much higher extraction efficiency of the TDGA with respect to the GLA suggests otherwise. At $\mathrm{pH}>3$ and/or in the absence of a synergistic agent (e.g., thenoyltrifluoroacetone) however, the thiodiglycolamides (TDGA) lose their ability to bind efficiently Am(III). Given that the mutual arrangement of ligating TDGA units could enhance binding much like the DGA derivative 15, a thiodiglycolamide derivative (19) was synthesized, and its extraction potential was tested on a series of trivalent lanthanides including ${ }^{152} \mathrm{Eu}$ and actinide ${ }^{241} \mathrm{Am}$. It was anticipated that the softness of the sulfur as well as the significant difference in the size of sulfur and oxygen (atomic radius: $\mathrm{S}=1.27 \AA, \mathrm{O}=0.65$ $\AA$ ) would strongly affect the interactions between the ligand and the metal, and possibly help differentiate trivalent lanthanides and actinides. In spite of the advantageous entropic effect, experiments with the preorganized thiodiglycolamides showed negligibly low distribution coefficients for both lanthanides and americium in $1 \mathrm{M} \mathrm{HNO}_{3}\left(10^{-3} \mathrm{M}\right.$ of 19 in dichloromethane $\left.D_{\text {Am(III) }}<0.001\right)$ suggesting a fundamental requirement of the etheric oxygen for metal binding under these particular conditions (Figure 25). 


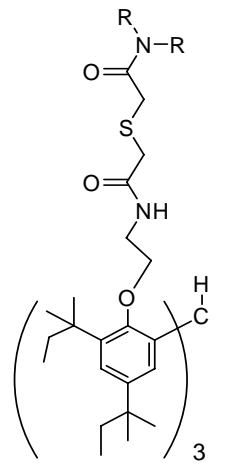

19

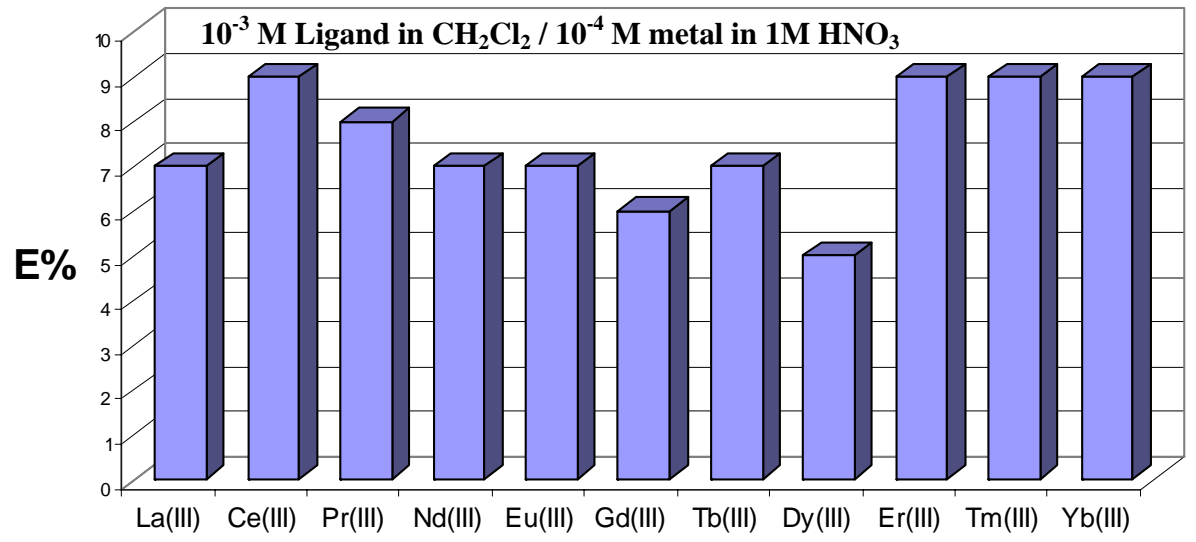

Figure 25. Extraction Data (\% removed from acid layer) for the Sulfur-Diamide Ligands

The structural studies of N,N'-dimethyl-N,N'-diphenyl-diglycolamide complexes with Ln(III) in solution system via EXAFS (extended X-ray fine structure) spectroscopy revealed participation of the etheric oxygens in the metal binding. ${ }^{59}$ Consequently, the structure of trisDGA complexes with lanthanides both in the solid state and in the solution could be very similar. If the etheric oxygen is involved in metal binding in the extracted species, replacing it with much bigger sulfur atom would cause a severe distortion from TTP geometry, and ultimately result in poor metal binding. In view of the crowded environment of the nonadentate ligand $\mathbf{1 5}$ and the inability of the ligand arms to rotate once placed on the triphenoxymethane platform, the extracted species would likely interact with several of the donor groups presented by the ligand, and the ethereal oxygens appear to be very important in this event. 


\section{New Oxygen Ligands for Extraction}

In view of the inability of the sulfur groups in the CMPS derivatives to bind to the metals in the presence of nitrate as outlined in the last quarterly report, a new ligand system has been designed which incorporates $\mathrm{N}$-oxide groups (Scheme 4). The donor properties of the $\mathrm{N}$-oxide groups should be intermediate between the phosphine oxide donors in $\mathbf{8 d}$ and the sulfur groups in the CMPS compounds 13d and 14. Moreover, the steric constraints imposed by the ligand arms should be significantly decreased in these pyrindine $\mathrm{N}$-oxide derivatives, allowing for the binding of additional nitrate groups. The synthesis of one derivative, 20, has been completed and the binding properties were subsequently examined at the University of Florida.

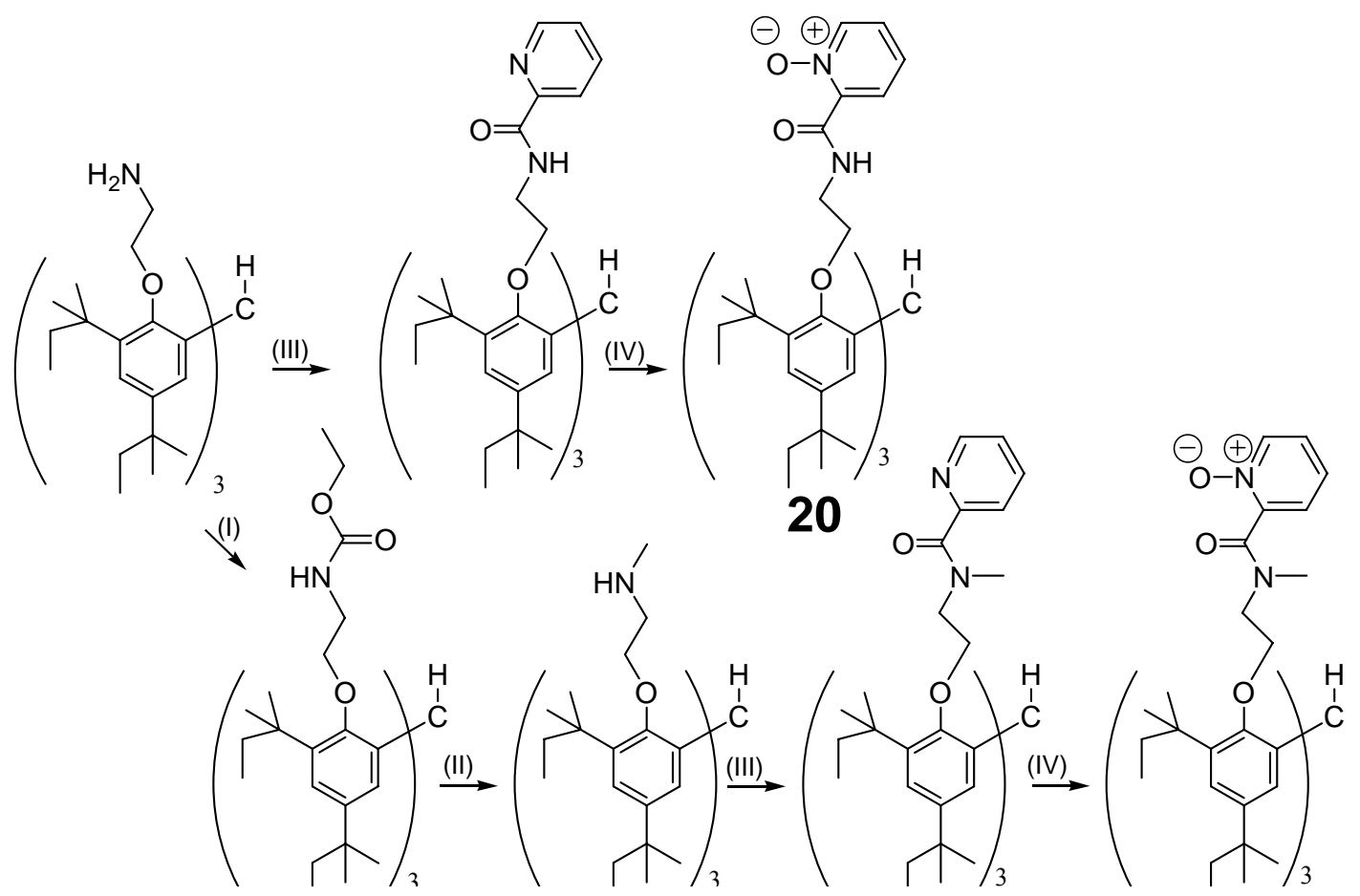

Scheme 5. Synthetic methodology used to prepare N-oxide donor lignads. 
Table 7. Extraction percentage $(\% \mathrm{E})$ for the three ligands prepared for this study incorporating CMPO, CMPS, and Pyrdine N-Oxide donors; 8d, 13d, and 20. \%E = $100 \%\left(\left[\mathrm{M}^{\mathrm{n}+}\right]_{\text {org }} /\left[\mathrm{M}^{\mathrm{n}+}\right]_{\text {total }}\right)$ after extraction as determined by Arsenazo(III) assay.

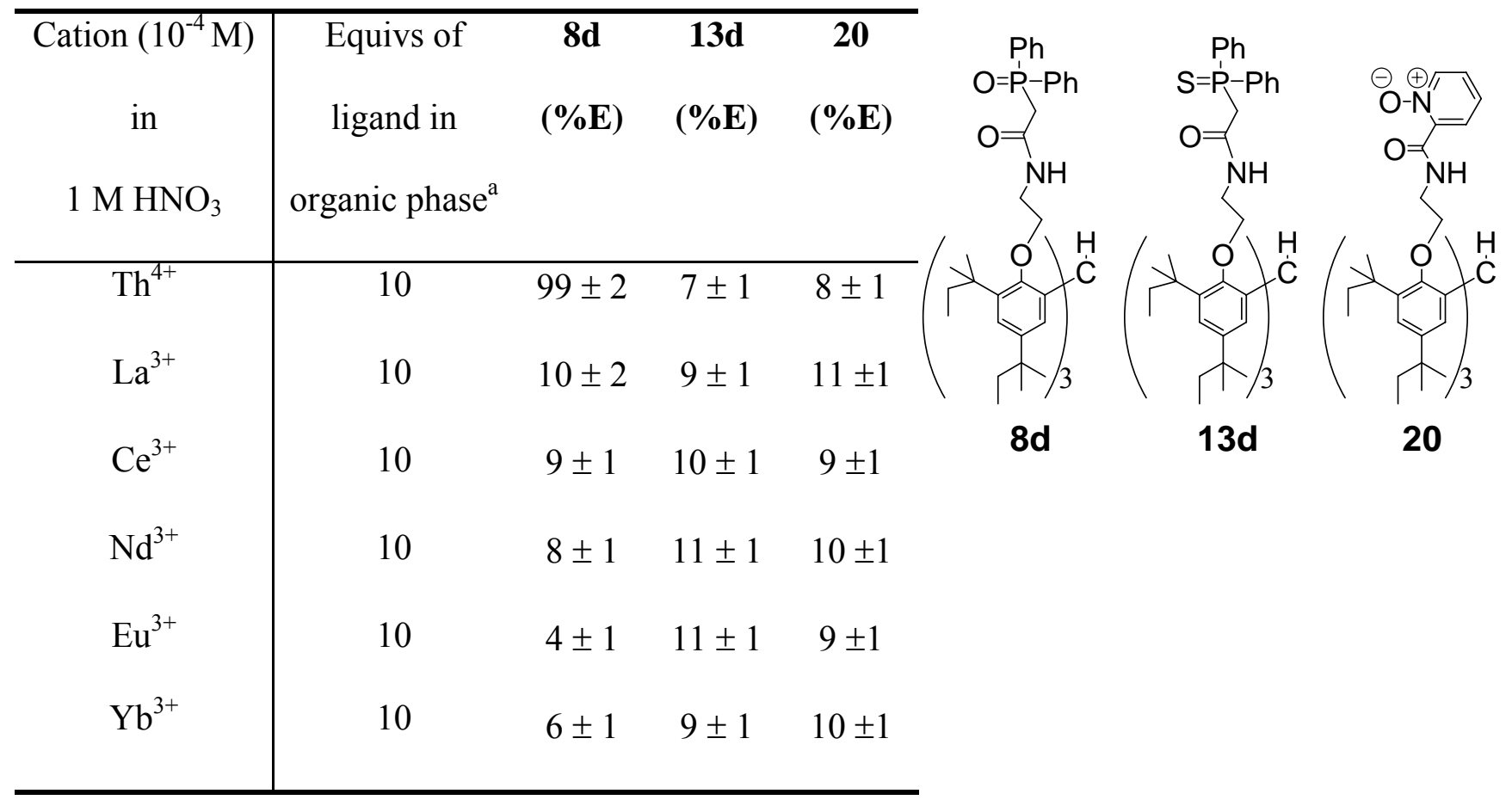

As can be seen in Table 7, the pyridine N-oxide donor ligand, 15, has a low and constant affinity for both the actinides and lanthanides, as is the case with the exception of $\mathbf{8 d}$ and An(IV). Nevertheless, the compound is more effective than CMPO at binding both actinides and lanthanides illustrated in Figure 15. 

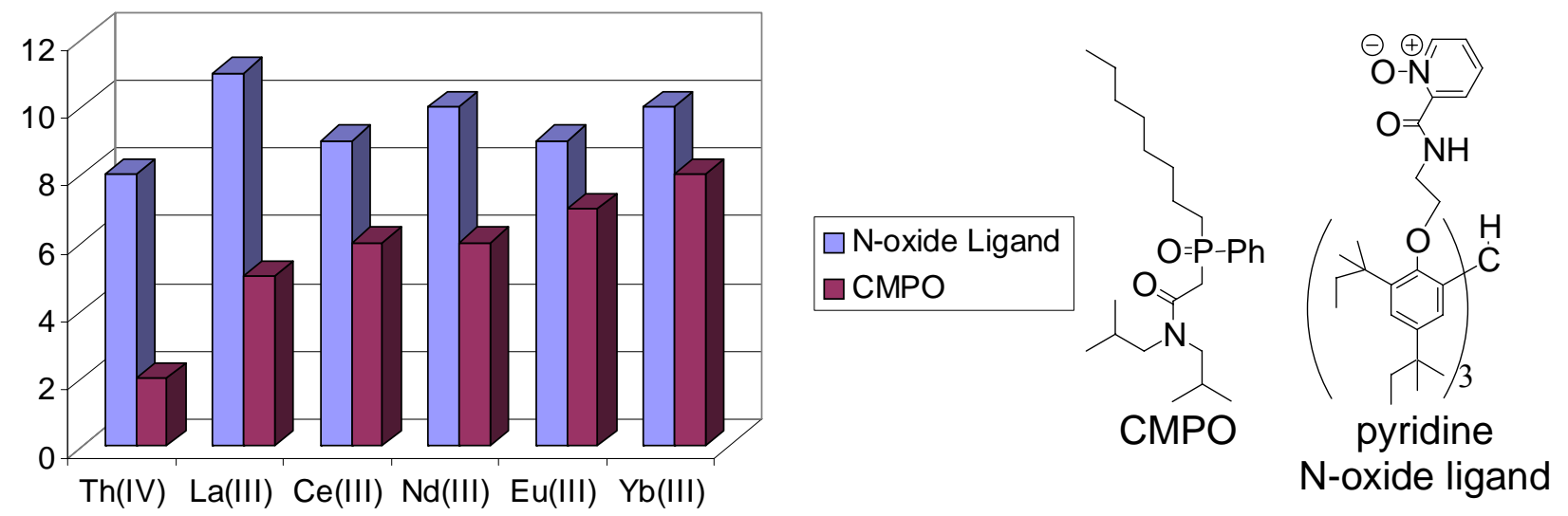

Figure 26. Graph comparing the metal binding ability of CMPO and Pyridine-N-oxide ligand.

As can be seen in Table 7, the pyridine N-oxide donor ligand has a low and constant affinity for both the actinides and lanthanides, and in comparison to CMPO, it is a much better binder. In view of this trend, an effort to structurally characterize a lanthanide complex with this ligand was undertaken during the fourth quarter, and crystals suitable for x-ray structural analysis were grown with $\mathrm{Yb}(\mathrm{III})$. In the solid-state structure of the $\mathrm{Yb}(\mathrm{III})$ complex presented in Figure 27 , the three arms of the N-oxide ligand wrap around the metal center, providing a total of five donor groups. Surprisingly, a single amide oxygen donor remains unattached to the metal center, but there are two nitrate ions coordinated to the metal so that it can adopt a nine-coordinate structure. The compound has been sent to Argonne for testing in the next quarter to see if there is any affinity for the dangling amide to bind $\mathrm{An}(\mathrm{III})$ ions.

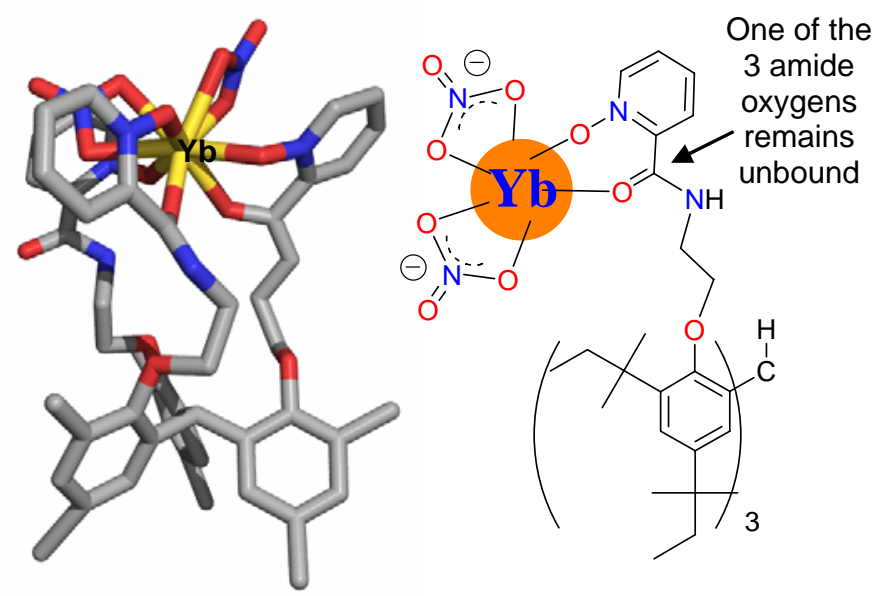

Figure 27. Solid-state structure of $\mathrm{Yb}(\mathrm{III})$ complex with $\mathrm{N}$-oxide ligand 


\section{Synthesis of Pyridinedicarboxylamide Ligands}

Given the success of the ether linked diamides such as $\mathbf{1 5}$ as described above and our desire to replace the ether linkers with a softer donor atom, work on a new ligand 21, outlined in Scheme 6, was undertaken. In this ligand, the two diamide groups are linked by a pyridine spacer instead of the ether linker presented in 15. These nitrogen donor groups should provide three soft donor groups to the extracted metal much as was hoped for with the sulfur donor, but the nitrogen atom is significantly smaller than sulfur. Hence, the ligand should have modulated affinity for the soft actinide
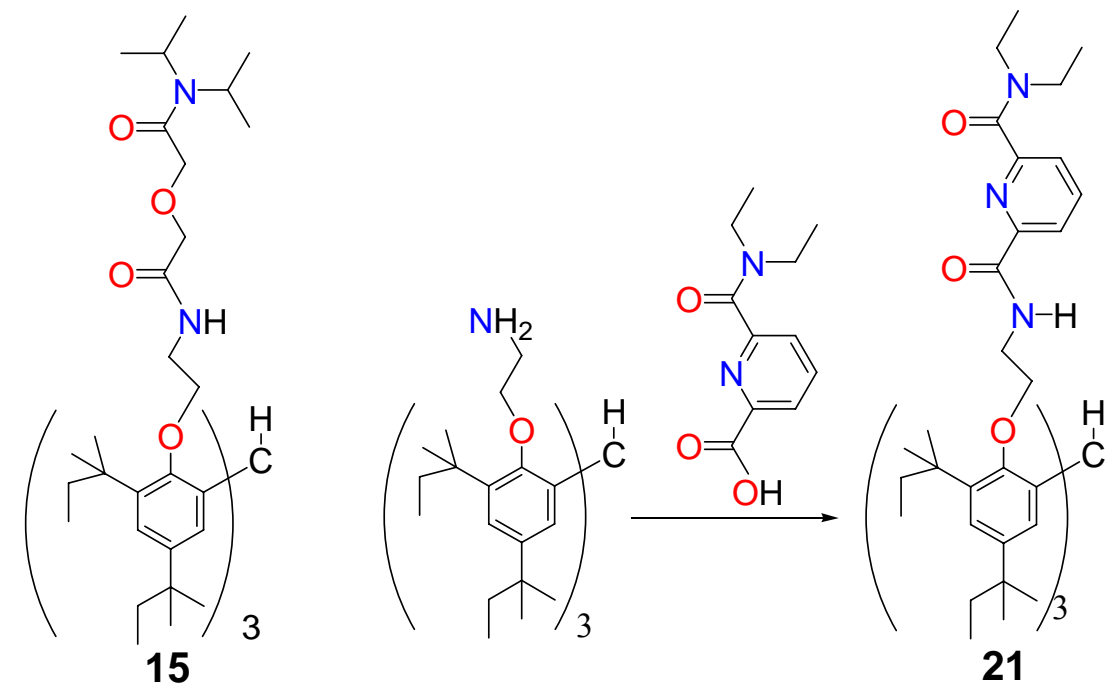

centers in comparison to the

Scheme 6. Synthesis of ligand 21 with pyridine spacer and harder ether linkers in $\mathbf{1 5}$ comparison to $\mathbf{1 5}$

Moreover, the nitrogen donor should be a better ligand for the metal as opposed to sulfur, particularly since the metal-ligand bond will be smaller and the distortion away from the idealized tricapped trigonal prismatic geometry should not be as pronounced.

A concerted effort was made to understanding the binding attributes of this ligand, 21, particularly in comparison to $\mathbf{1 4}$. Several attempts were made to grow crystals of the ligand with various lanthanide ions and single crystals of $\mathrm{Eu}(\mathrm{III}), \mathrm{Tm}(\mathrm{III})$, and $\mathrm{Yb}(\mathrm{III})$ were obtained. The compounds were all characterized by X-ray crystallography and they all adopt a TPP structure in the solid-state as depicted in Figure 28. The structures are very similar to the solid-state 


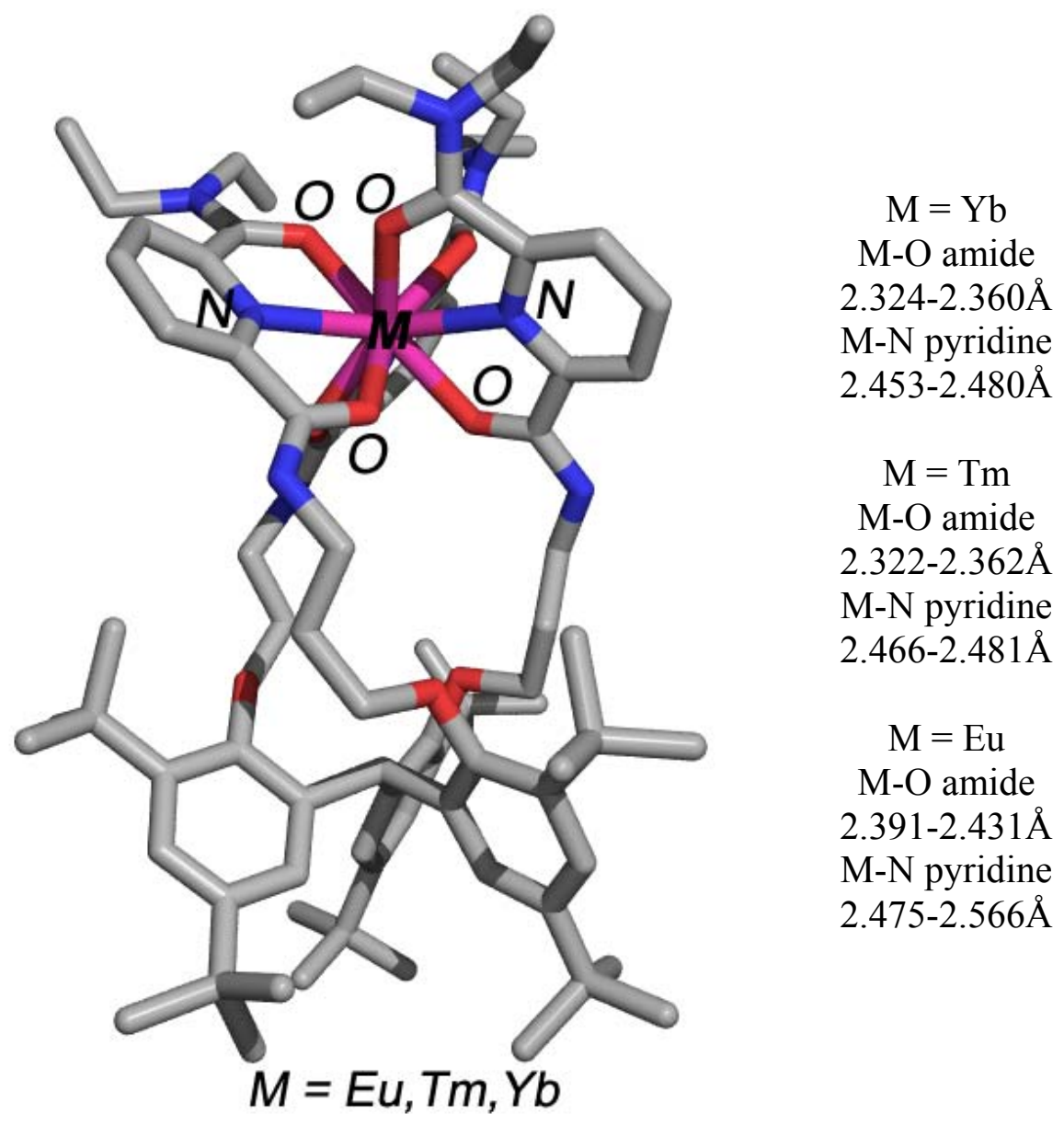

Figure 28. Depiction of the solid state structure of 21 with $\mathrm{Tm}(\mathrm{III})$ with selected bond distances. The structures of $\mathbf{2 1}$ with $\mathrm{Yb}(\mathrm{III})$ and $\mathrm{Eu}(\mathrm{III})$ are virtually indistinguishable from the Tm(III) structure.

structures of 15 (Figure 17) and in the case of $\mathrm{Tm}(\mathrm{III})$, the distortion of idealized tricapped trigonal primatic geometry is very small (Figure 29). The compound, however, is very ineffective for binding $\mathrm{Ln}(\mathrm{III})$ ions from nitric acid solution despite the fact that it matched the TPP geometrical requirements of the metal. Previous work with simple 2,6pyridinedicarboxylamide have seen similar results wherein the ligand is a very poor extractor of metal ions from acidic solutions. In these systems, however, the inclusion of $0.1 \mathrm{M}$ solutions of chlorinated cobalt dicarbolides (CCD) significantly increased the binding efficiency of the ligand and the authors were able to bind Am(III) with D values $>500 .^{69}$ There are many examples of 
systems wherein the addition of the synergistist $\mathrm{CCD}$ greatly facilitates the extraction event, ${ }^{70-77}$ presumably due to the fact that the resulting metal complex is more soluble in the organic media with large cations. The extraction experiment with $\mathrm{CCD}$ and $\mathbf{2 1}$ will be run in the future and should produce an active extractant

\section{Bismuth Extraction with the Tris-CMPO Ligand System}

The Bismuth Phosphate process was the first method used in early 40's for large-scale separation of plutonium from uranium and their fission products. The process involved the quantitative and selective coprecipitation of $\mathrm{Pu}^{4+}$ from an acid solution by a bismuth phosphate carrier. The process generated tremendous amount of leftover bismuth nitrate intermixed with the fission products like Am(III) as a waste by-product. Ultimately, the design of an extraction system that would be able to selectively extract the radioactive actinides and leave behind nonradioactive bismuth waste is highly desirable. In order to test affinity of the tris-CMPO extractant for $\mathrm{Bi}(\mathrm{III}), 10^{-4} \mathrm{M}$ solutions of the bismuth nitrate salt in $1 \mathrm{M}$ nitric acid was extracted with an equal volume of a $10^{-3} \mathrm{M}$ methylene chloride ligand solution. The extractability of the bismuth ion was determined by measuring the metal concentration in the nitric acid phase before and after the extraction with solutions of ligands.

Results of the extraction experiment revealed (Chart 12 and Table 8), that the tris-CMPO ligand system is a relatively poor binder for $\mathrm{Bi}(\mathrm{III})$. The extractability of $\mathrm{Bi}(\mathrm{III})$ is very similar to values obtained for trivalent lanthanides and Am(III). Therefore, to find application of our ligand system in extraction of actinides from high bismuth content waste and for general cleanup operations, selectivity for trivalent actinides over Bi(III) needs to be accomplished. 

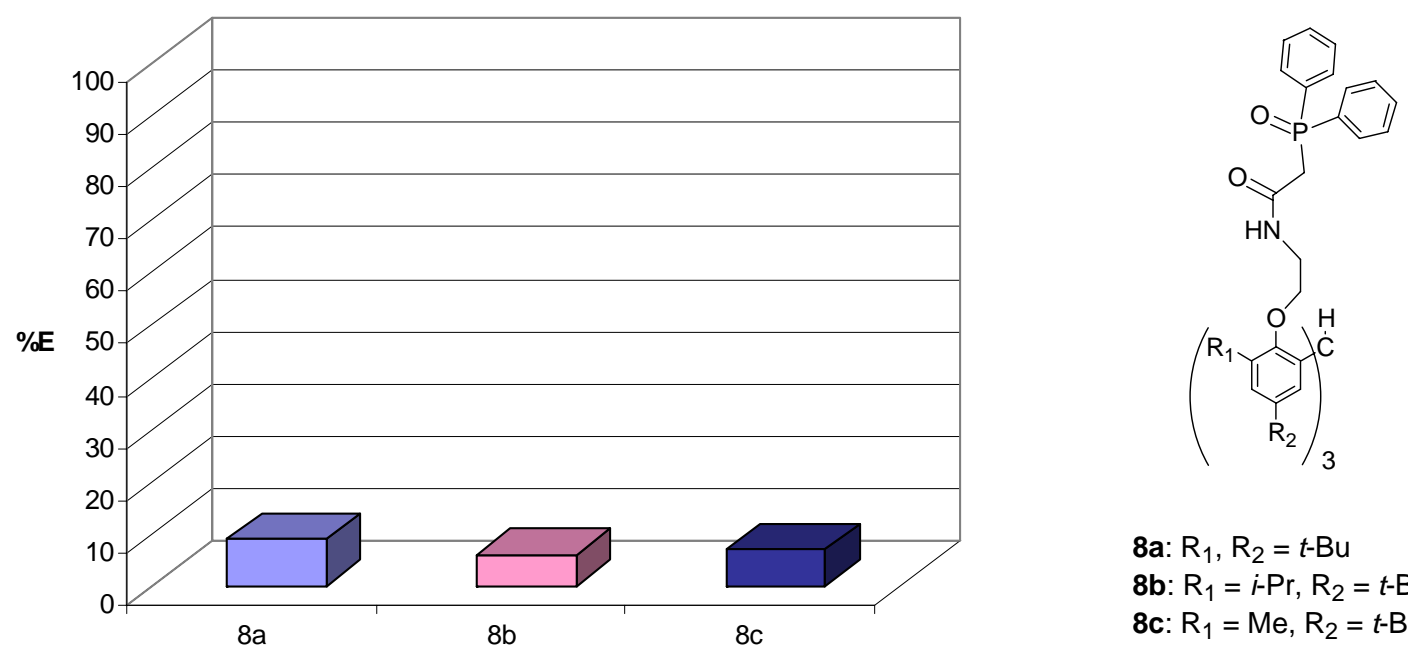

8a: $\mathrm{R}_{1}, \mathrm{R}_{2}=t-\mathrm{Bu}$
8b: $\mathrm{R}_{1}=i-\mathrm{Pr}, \mathrm{R}_{2}=t-\mathrm{Bu}$
8c: $\mathrm{R}_{1}=\mathrm{Me}, \mathrm{R}_{2}=t-\mathrm{Bu}$

Chart 12. Bismuth(III) Extraction Percentage $(\% \mathrm{E})$ for the Ligands 8a-c.

Table 8. Bismuth(III) Extraction Percentage (\%E) for the Ligands 8a-c.

\begin{tabular}{c|c|c|c|c}
\hline Cation $\left(10^{-4} \mathrm{M}\right)$ in \\
$1 \mathrm{M} \mathrm{HNO}_{3}$ & organic phase & $(\% \mathrm{E})$ & $(\% \mathrm{E})$ & $\mathbf{8}$ \\
\hline $\mathrm{Bi}^{3+}$ & 10 & $9 \pm 1$ & $6 \pm 1$ & $7 \pm 1$ \\
\hline
\end{tabular}

In order to determine the composition of extracted species, the bismuth nitrate complex of $\mathbf{8 c}\left(\mathrm{R}^{1}=\mathrm{Me}, \mathrm{R}^{2}=t-\mathrm{Bu}\right)$ has been synthesized and characterized. The solid- and solution-state structures of the Bi(III) complex 15c was determined using X-ray crystallography, NMR, and mass spectrometry. Interestingly, x-ray crystal structure of the bismuth(III) (Figure 29) resembles the structure of the anhydrous complex of neodymium(III) with the 8a ligand scaffold. $^{37}$ The complex contains a bismuth ion fully coordinated by the three CMPO moieties from $8 \mathrm{c}$ and a single bidentate nitrate counterion. The $2+$ charge of the complex is balanced by two $\mathrm{NO}_{3}{ }^{2-}$ counterions. All three CMPO arms of 8c have wrapped around metal ion in a 
bidentate fashion. The FT-ICR-MS analysis confirmed existence of these $2+$ cationic $\left[\mathbf{8 c} \bullet \mathrm{Bi}\left(\mathrm{NO}_{3}\right)\right]^{2+}$ species in solution accompanied by $\left[\mathbf{8} \mathrm{c} \bullet \mathrm{Bi}\left(\mathrm{NO}_{3}\right)_{2}\right]^{1+}$ molecules. As in case of Th(IV) and $\operatorname{Ln}(\mathrm{III})$, the single phosphorus resonance in the ${ }^{31} \mathrm{P}$ NMR shifts almost $8 \mathrm{ppm}$ downfield with respect to the unbound ligand, confirming the simultaneous metal binding by all three CMPO moieties.
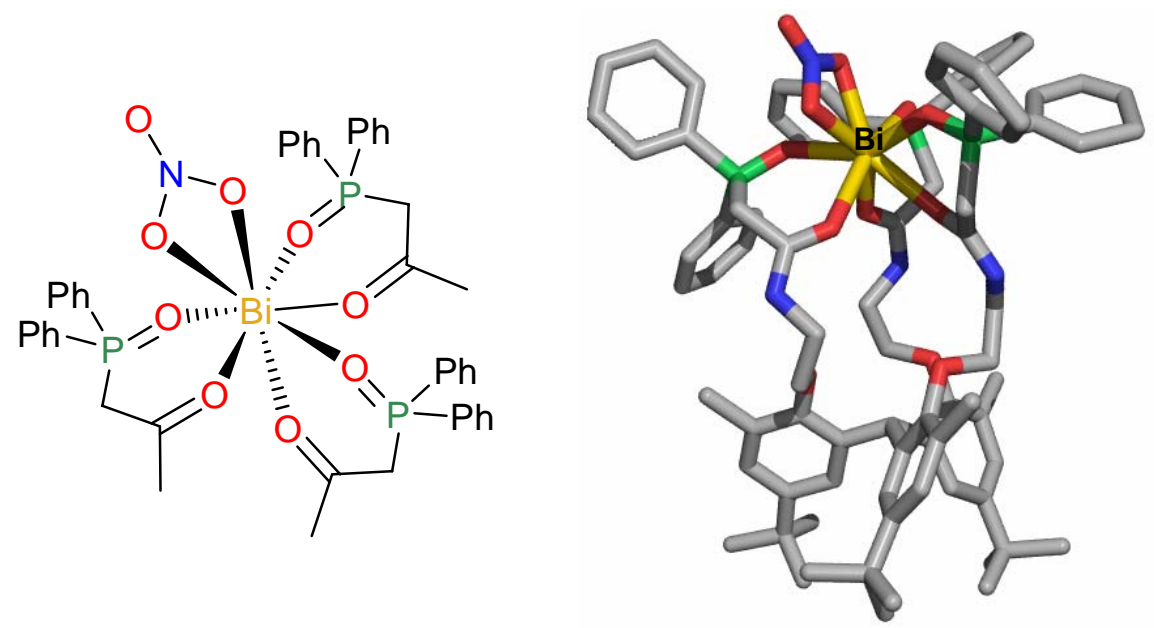

Figure 29. Crystal structure of the coordinate +2 cationic bismuth(III) nitrate complex ligand $8 \mathrm{c}$ with one $\mathrm{NO}_{3}{ }^{2-}$ coordinated counterion.

\section{Preparation of Mixed Nitrogen-Sulfur Ligands}

In the second year of the project, work began on a variety of different ligands that contain both sulfur and amide oxygens donors on the three arms since previous literature work has shown that similar ligand systems have a proclivity to bind actinides. A simple reaction between isocyanates and a primary amine will afford a new ligand type in high yield as outlined in Figure 30. Preliminary work at the University of Florida has demonstrated that this ligand is not particularly adept at binding metals in $1 \mathrm{M} \mathrm{HNO}_{3}$, but at elevated $\mathrm{pH}$, these ligands should be able to discriminate between Am(III) and Ln(III) based on work by Reinhoudt and coworkers. ${ }^{78}$ 

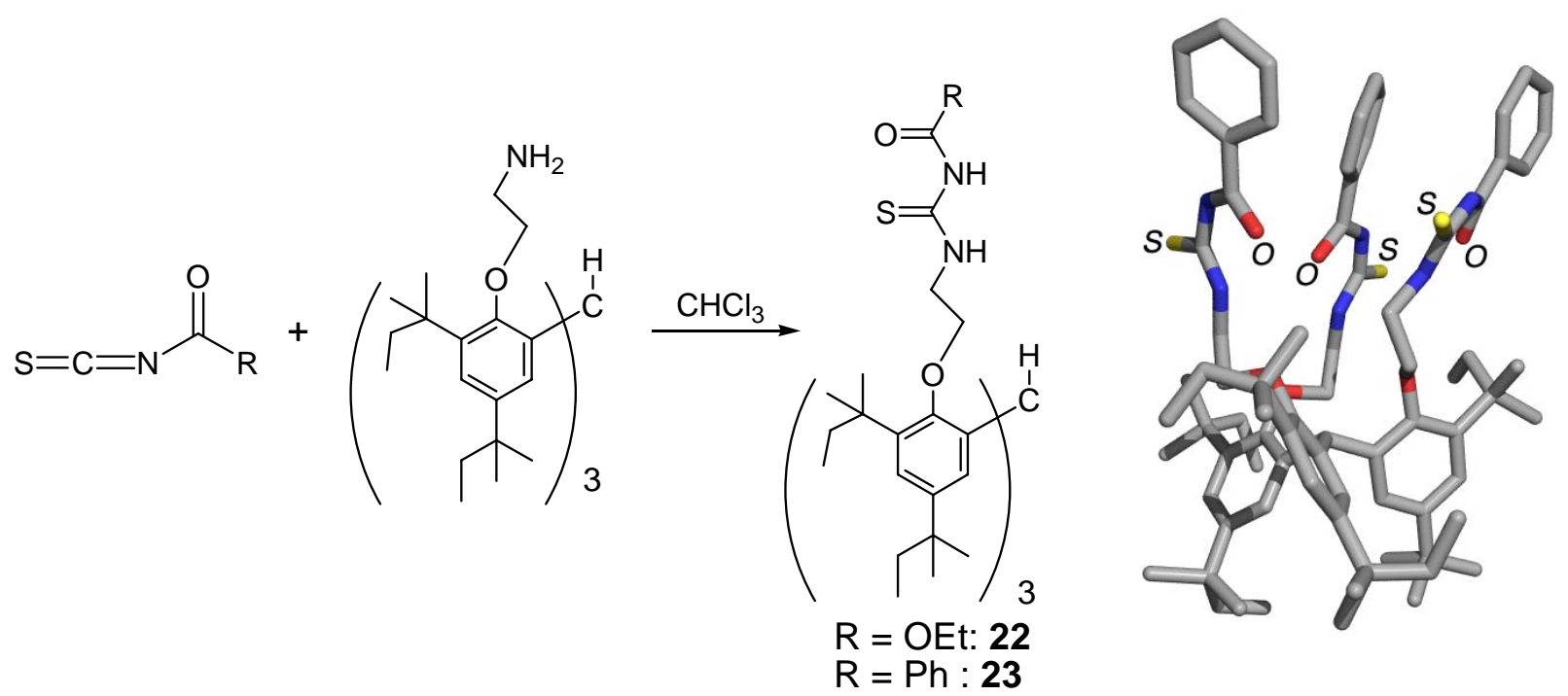

Figure 30. Synthetic Procedure for Mixed Sulfur-amide Ligands and Solid-State Structure of 23.

In addition to the ligands above, a series of mixed-sulfur amide ligands were isolated during the first quarter in multi-gram quantities as outlined in Scheme 7. The extraction and binding properties of these will be determined during the third quarter and if the data looks promising, the material will be sent to Argonne for further testing.

Scheme 7: New Sulfur-Amide ligands

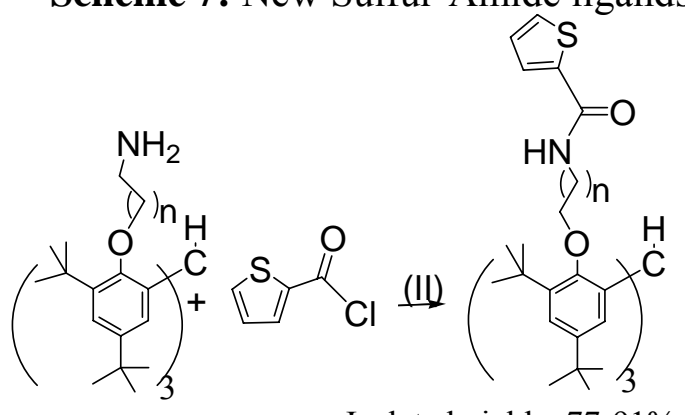

\section{Conclusions}

Increasing the selectivity of ligand systems for An(III) over the Ln(III) ions in acidic nitrate solutions is essential if current nuclear waste treatment processes are to be improved. For example, the transmutation of actinides into short-lived fission products by neutron bombardment is impractical at this time since there is no efficient $\mathrm{An}(\mathrm{III}) / \mathrm{Ln}(\mathrm{III})$ separation protocol. If an efficient protocol can be developed for their partitioning, neutron bombardment 
can be employed, and along with aiding the processing of acid nuclear waste streams, this methodology should ease some of the concerns expressed by the American public involving the hazards associated with the long-term storage of nuclear waste.

The triphenoxymethane ligand system shows promise as an improved extractant for both tetravalent and trivalent actinide recoveries form high level liquid wastes and a general actinide clean-up procedure. The selectivity of the standard extractant for tetravalent actinides, $(N, N-$ diisobutylcarbamoylmethyl) octylphenylphosphineoxide (CMPO), was markedly improved by the attachment of three CMPO-like functions onto a triphenoxymethane platform, and a ligand that is both highly selective and effective for An(IV) ions was isolated. A 10 fold excess of ligand will remove virtually all of the $4+$ actinides from the acidic layer without extracting appreciable quantities of An(III) and Ln(III) unlike simple CMPO ligands.

Three new tripodal chelates bearing three diglycolamide and thiodiglycolamide units precisely arranged on a triphenoxymethane platform have been synthesized for an highly efficient extraction of trivalent f-element cations from nitric acid media. A single equivalent of ligand will remove $80 \%$ of the $\operatorname{Ln}(\mathrm{III})$ ion from the acidic layer since the ligand is perfectly suited to accommodate the tricapped trigonal prismatic geometry preferred by the metal center. The ligand is perhaps the most efficient binder available for the heavier lanthanides and due to this unique attribute, the extraction event can be easily followed by ${ }^{1} \mathrm{H}$ NMR spectroscopy confirming the formation of a TPP complex. The most lipophilic di-n-butyl tris-diglycolamide was found to be a significantly weaker extractant in comparison to the di-isopropyl analogs. The distance separating the metal binding groups from the triphenoxymethane platform had little influence on the selectivity or binding efficiency of the ligands. The tris-thiodiglycolamide 
derivative proved to be an ineffective chelate for f-elements in the $1 \mathrm{M}$ nitric acid extraction system and demonstrated the importance of the etheric oxygens in the metal binding.

The results presented herein clearly demonstrate a cooperative action of these three ligating groups within a single molecule, confirmed by composition and structure of the extracted complexes, and since actinides prefer to have high coordination numbers, the ligands should be particularly adept at binding with three arms. The use of such an extractant permits the extraction of metal ions form highly acidic environment through the ability of the compound to buffer the effect of high acid concentration. Stability toward hydrolysis and ease of synthesis and purification are additional favorable properties. The ligands describe above based on the triphenoxymethane platform are not only easily available in large quantities but also amenable to nearly unlimited chemical modifications. Finally, with this platform, two highly effective ligands incorporating CMPO and glycoldiamide moieties have been prepared and fully characterized, and both examples are perhaps the most efficient and selective examples of these important classes of ligands. Continued refinements of these systems have the potentially further improve the selectivity and affinity for An(III) ions 


\section{Presentations and Publications}

\section{Conference Presentations Outlining the Progress on the Project}

"Tripodal Thio/Diglycolamide-Based Ligands for Actinide/Lanthanide Separations" K. Matloka, A. Gelis, M. Regalbuto, G. Vandegrift, M. J. Scott. Presented at the The 14th Symposium on Separation Science and Technology for Energy Application, Gatlinburg, TN, 2005

"Synthesis and evaluation of new tripodal diamide-based ligands for actinide/lanthanide separations" K. Matloka, A. Gelis, M. Regalbuto, G. Vandegrift, M. J. Scott. Presented at the 229th ACS National Meeting, San Diego, CA, March 13, 2005

"Tripodal thio/diglycolamide-based ligands for actinide/lanthanide separations" K. Matloka, A. Gelis, M. Regalbuto, G. Vandegrift, M. J Scott. Presented at the 29th Annual Actinide Separations Conference, Nashevillle, TN, 2005

" $C_{3}$-symmetric Ligands for the Selective Separation of Actinides and Lanthanides" seminar presented by M. J. Scott, at the Expert Seminar present to the Chemistry Department, Westfälische Wilhelms-Universität Münster, Germany, November 16, 2004

"Extraction of Actinides from Acidic Solutions Using a Tripodal Tris-CMPO Ligand System" M. J. Scott, K. Matloka, A. Guelis, A. Sah, M. Peters Presented at the 228th ACS National Meeting, Philadelphia, PA, August 2004

"Evaluation of tris-CMPO and tris-CMPS ligands as extractants for actinide/lanthanide separations" K. Matloka, M. W. Peters, E. J. Werner, A. K. Sah, A. Guelis, G. F. Vandegrift, M. J. Scott. Presented at the 28th Annual Actinide Separations Conference, Ashevillle, NC, July 2004

"Extraction of actinides from acidic solutions using a tripodal tris-CMPO ligand system" M. J. Scott, K. Matloka, A. Guelis, M. Regalbuto, G. F. Vandegrift, A. Sah, M. Peters. Presented at the XXXVIth International Conference on Coordination Chemistry (36 ICCC), Merida, Mexico, July, 2004

" $C_{3}$-symmetric Ligands for the Selective Separation of Actinides and Lanthanides" seminar presented by M. J. Scott, Harvard/MIT Joint Inorganic Seminar at the Massachusetts Institute of Technology, April 6, 2004

"Actinide/lanthanide extraction properties of a tris-CMPO ligand system" K. Matloka, M. W. Peters, E. J. Werner, G. F. Vandegrift, M. J. Scott. Presented at the 225th ACS National Meeting, New Orleans, LA, 2003

"Actinide/lanthanide extraction properties of a tris-CMPO ligand system" K. Matloka, M. W. Peters, E. J. Werner, A. K. Sah, A. Guelis, G. F. Vandegrift, M. J. Scott. Presented at the 27th Annual Actinide Separations Conference, Argonne, IL, 2003 


\section{Publications Outlining the Progress on the Project}

"Highly efficient binding and separation of trivalent f-elements with a $C_{3}$-symmetric tripodal ligand containing diglycolamide arms" K. Matloka, A. Gelis, M. Regalbuto, G. Vandegrift, M. J. Scott. J. Chem. Soc. Dalton Transactions 2005, 3719

"CMPO functionalized $C_{3}$-symmetric tripodal ligands for nitric acid liquid/liquid extraction system: highly selective recognition of $\mathrm{Pu}(\mathrm{IV})$ and low affinity for 3+ actinides and lanthanides" K. Matloka, A. K. Sah, M. W. Peters, P. Srinivasan, A. Gelis, M. Regalbuto, G. Vandegrift, M. J. Scott. Submitted to Inorganic Chemistry

"Tripodal thio/diglycolamide-based ligands for actinide/lanthanide separations" K. Matloka, A. Gelis, M. Regalbuto, G. Vandegrift, M. J. Scott Submitted to Solvent Extraction and Ion Exchange

"Evaluation tris-CMPS ligands as extractants for actinide/lanthanide separation" K. Matloka, A. K. Sah, A. Gelis, M. Regalbuto, G. Vandegrift, M. J. Scott manuscript in preparation

"Separation of trivalent lanthanides and actinides with picolinamide and pyridine $\mathrm{N}$-oxide based extractants from nuclear waste solutions" K. Matloka, P. Srinivasan, A. Gelis, M. Regalbuto, G. Vandegrift, M. J. Scott manuscript in preparation

Binding of trivalent lanthanides and actinides with $C_{3}$-symmetric pyridinedicarboxylamide ligands" O. Ozbek, K. Matloka, A. Gelis, M. Regalbuto, G. Vandegrift, M. J. Scott manuscript in preparation 


\section{Methodology Utilized to Prepare and Characterize Compounds}

\section{Experimental Section}

General considerations. The lanthanide and actinide salts, $\mathrm{La}\left(\mathrm{NO}_{3}\right)_{3} \cdot \mathrm{H}_{2} \mathrm{O}$ (Alpha Aesar), $\mathrm{Ce}\left(\mathrm{NO}_{3}\right)_{3} \cdot 6 \mathrm{H}_{2} \mathrm{O}$ (Aldrich), $\mathrm{Nd}\left(\mathrm{NO}_{3}\right)_{3} \cdot 6 \mathrm{H}_{2} \mathrm{O}$ (Aldrich), $\mathrm{Eu}\left(\mathrm{NO}_{3}\right)_{3} \cdot 5 \mathrm{H}_{2} \mathrm{O}$ (Aldrich), $\mathrm{Yb}\left(\mathrm{NO}_{3}\right)_{3} \cdot 5 \mathrm{H}_{2} \mathrm{O}$ (Aldrich), $\mathrm{Bi}\left(\mathrm{NO}_{3}\right)_{3} \cdot 5 \mathrm{H}_{2} \mathrm{O}$ (Acros), $\mathrm{Tb}\left(\mathrm{NO}_{3}\right)_{3} \cdot 6 \mathrm{H}_{2} \mathrm{O}$ (Aldrich), $\mathrm{Bi}\left(\mathrm{NO}_{3}\right)_{3} \cdot 5 \mathrm{H}_{2} \mathrm{O}$ (Acros), and $\mathrm{Th}\left(\mathrm{NO}_{3}\right)_{4} \cdot 4 \mathrm{H}_{2} \mathrm{O}$ (Strem), were used as received. The solutions were prepared from $18 \mathrm{M} \Omega$ Millipore deionized water, TraceMetal grade $\mathrm{HNO}_{3}$ (Fisher Scientific), and HPLC grade organic solvents. The Arsenazo(III) assay was performed on a a Varian Cary $50 \mathrm{UV} / \mathrm{vis}$ spectrophotometer while a 2500TR Packard liquid scintillation analyzer was used for counting alpha-emitting $\mathrm{Pu}$ and $\mathrm{U}$ radionuclides. A Canberra GammaTrac 1185 with Ge detector and AccuSpec-B multi-channel analyzer was used for ${ }^{241} \mathrm{Am}$ and ${ }^{152} \mathrm{Eu}$ counting. $\mathrm{All}{ }^{1} \mathrm{H},{ }^{13} \mathrm{C}$ and ${ }^{31}$ P NMR spectra were recorded on a Varian VXR-300 or Mercury-300 spectrometer at 299.95 and $121.42 \mathrm{MHz}$ for the proton and phosphorus channels, respectively. Elemental analyses were performed by Complete Analysis Laboratories, Inc. in Passipany, New Jersey. Mass spectrometry samples were analyzed by Dr. Lidia Matveeva and Dr. Dave Powell at the University of Florida on a Bruker Apex II 4.7T Fourier transform ion cyclotron resonance mass spectrometer. Fast atom bombardment (FAB), ionization energy (IE) and liquid secondary ion mass spectrometry (LSIMS) mass spectra were recorded on Finnigan MAT95Q Hybrid Sector.

Metal ions extractions. The lanthanides, bismuth and thorium extraction experiments followed previously reported procedure..$^{34,37,79}$ The extractability of each cation was calculated as $\% E=100 /\left(A_{1}-A\right) /\left(A_{1}-A_{0}\right)$, where $A$ is the absorbance of the extracted aqueous phase with the Arsenazo(III) indicator, $\mathrm{A}_{1}$ is the absorbance of the aqueous phase before extraction with the indicator, and $\mathrm{A}_{0}$ is the absorbance of metal-free $1 \mathrm{M}$ nitric acid and the indicator. The distribution coefficients $(D)$ of cations defined by equation: $D=\Sigma\left[\mathrm{M}_{\mathrm{org}}\right] / \Sigma\left[\mathrm{M}_{\mathrm{aq}}\right]$ (where $\Sigma$ $\left[\mathrm{M}_{\mathrm{org}}\right], \Sigma\left[\mathrm{M}_{\mathrm{aq}}\right]$ are the total concentration of the metal species in the organic and aqueous phase, respectively) were calculated using formula: $D=\% \mathrm{E} /(100-\% \mathrm{E})$.

In case of ${ }^{239} \mathrm{Pu},{ }^{238} \mathrm{U},{ }^{241} \mathrm{Am}$ and ${ }^{152} \mathrm{Eu}$ isotopes, a solution of ligand, $10^{-3}-10^{-2} \mathrm{M}$ in $\mathrm{CH}_{2} \mathrm{Cl}_{2}$, or 1-octanol has been contacted with $1 \mathrm{M} \mathrm{HNO}_{3}$ containing radioactive nuclides. Test tubes containing 1-2 $\mathrm{mL}$ of the aqueous phase and an equal volume of the organic phase were 
placed into an orbital shaker at $20{ }^{\circ} \mathrm{C}$. After a certain period of time, a test tube was removed from the rotator, the layers were allowed to separate, and then were transferred into the shell vials. Equal aliquots of the organic and the aqueous phases were taken for counting and distribution coefficient determination.

\section{Isotopes stock solutions.}

\section{Plutonium stock solution}

The stock solution of tetravalent ${ }^{239} \mathrm{Pu}$ was purified using anion exchange method. ${ }^{80}$ The method is based on the retention of $\mathrm{Pu}\left(\mathrm{NO}_{3}\right)_{6}{ }^{2-}$ in $7.5 \mathrm{M} \mathrm{HNO}_{3}$ by the anion exchanger (Bio-Rad AG-1 x 8). All the cations were eluted from the column with $7.5 \mathrm{M} \mathrm{HNO}_{3}$. Subsequently, $\mathrm{Pu}$ was stripped from the column with a solution of $0.3 \mathrm{M} \mathrm{HNO}_{3}$ at $60{ }^{\circ} \mathrm{C}$. The strip was taken to a wet salt with a few drops of concentrated $\mathrm{HClO}_{4}$ to destroy any organic impurities. The resulting $\mathrm{Pu}(\mathrm{VI})$ salt was dissolved in $1 \mathrm{M} \mathrm{HNO}_{3}$ and was treated with $0.1 \mathrm{~mL}$ of concentrated $\mathrm{H}_{2} \mathrm{O}_{2}$ to convert $\mathrm{Pu}$ to tri- and tetravalent oxidation states. ${ }^{80}$ To oxidize $\mathrm{Pu}(\mathrm{III})$ to $\mathrm{Pu}(\mathrm{IV}), 20 \mathrm{mg}$ of solid $\mathrm{NaNO}_{2}$ was added to the solution. An electron absorption spectrum, collected in 400-900 nm range, revealed no evidence of either $\mathrm{Pu}(\mathrm{III})$ or $\mathrm{Pu}(\mathrm{VI})$. The solution was diluted with $1 \mathrm{M}$ $\mathrm{HNO}_{3}$ to get $10^{-5} \mathrm{M} \mathrm{Pu}(\mathrm{IV})$ and was used for the experiments.

Uranium stock solution.

A weighted amount of ${ }^{238} \mathrm{U}_{3} \mathrm{O}_{8}$ of analytical purity was dissolved in $14.7 \mathrm{M} \mathrm{HNO}_{3}$ and then diluted with water to $1.6 \mathrm{M} \mathrm{UO}_{2}\left(\mathrm{NO}_{3}\right)_{2}$ in $1 \mathrm{M} \mathrm{HNO}_{3}$. The solution was then diluted with 1 $\mathrm{M} \mathrm{HNO}_{3}$ to $0.01 \mathrm{M} \mathrm{UO}_{2}\left(\mathrm{NO}_{3}\right)_{2}$ and was spiked with ${ }^{233} \mathrm{U}(\mathrm{VI})\left(\mathrm{T}_{1 / 2}=1.59 \times 10^{5}\right.$ y) to increase the effectiveness of the liquid scintillation counting.

Americium stock solution.

The purity of the ${ }^{241} \mathrm{Am}$ stock solution was determined by the ICPMS analysis. The solution was evaporated to dryness and re-dissolved in $1 \mathrm{M} \mathrm{HNO}_{3}$.

Europium stock solution

The ${ }^{152} \mathrm{Eu}$ stock was purchased from Isotope Products Laboratories. The original $0.5 \mathrm{M}$ $\mathrm{HCl}$ solution was taken to a wet salt with nitric acid twice and was then redissolved in $1 \mathrm{M}$ $\mathrm{HNO}_{3}$. 
Synthesis. The synthetic methodology for the preparation of $\mathbf{8}$ and $\mathbf{1 2}$ has been adapted from procedures developed in work with phenols and calix $[n]$ arene platforms. ${ }^{32,33}$ Detailed synthetic procedures were previously reported for preparation of molecule $\mathbf{8 b} .^{37,38,81}$

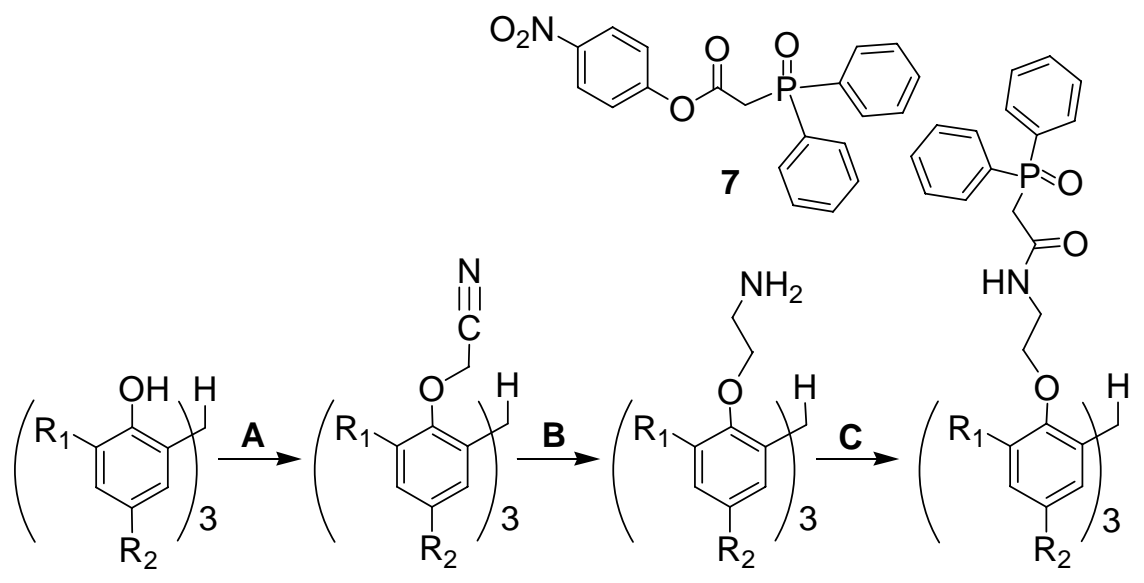

$$
4 \mathrm{a}, \mathrm{b}, \mathrm{c} \quad 5 \mathrm{a}, \mathrm{b}, \mathrm{c} \quad 6 \mathrm{a}, \mathrm{b}, \mathrm{c} \quad 8 \mathrm{a}, \mathrm{b}, \mathrm{c}
$$
a: $R_{1}, R_{2}=t-P e n t y l$
b: $R_{1}, R_{2}=t-B u$
c: $R_{1}=M e, R_{2}=t-B u$

${ }^{a}$ Key: (A) NaI, $\mathrm{K}_{2} \mathrm{CO}_{3}$, chloroacetonitrile, refluxing acetone, 3 days; (B) LAH, diethyl ether; (C) p-nitrophenyl(diphenylphosphoryl)acetate (7), 45-50 ${ }^{\circ} \mathrm{C}$ chloroform.

Scheme $2^{\mathrm{a}}$

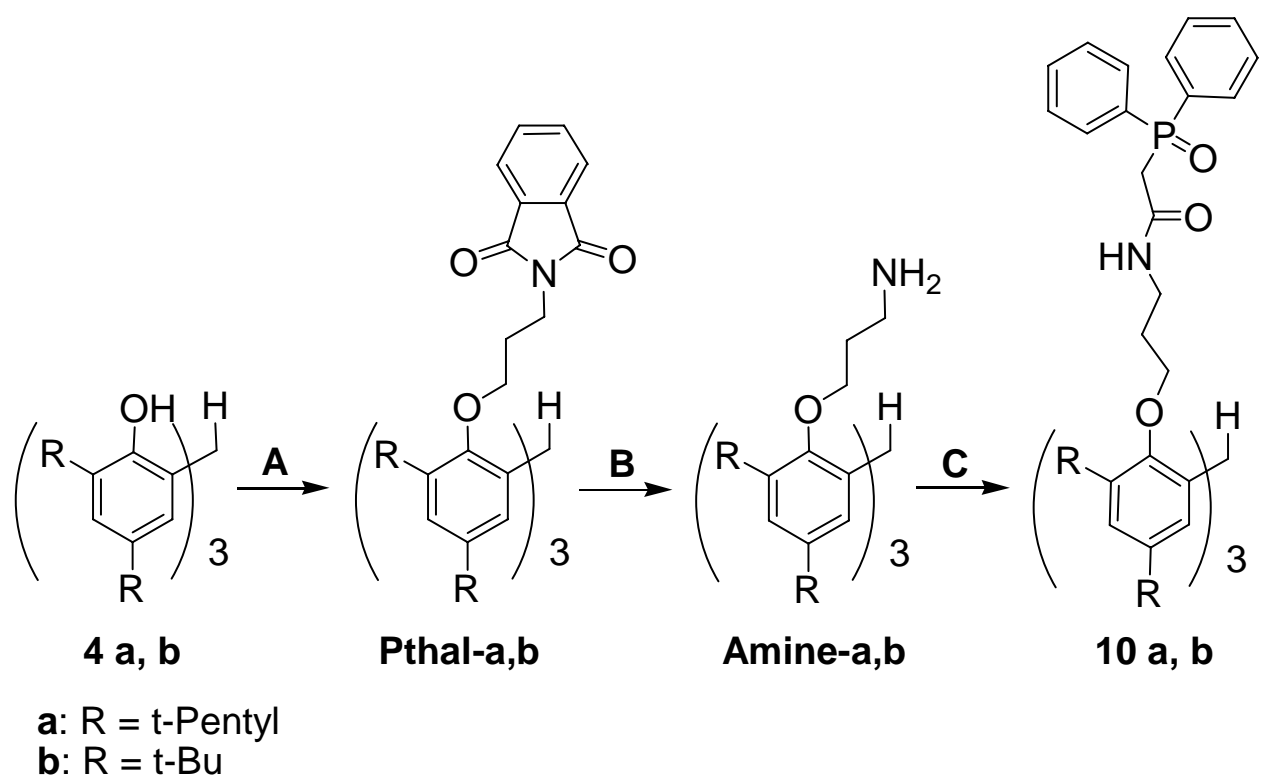

${ }^{\mathrm{a}}$ Key: (A) N-(3-bromopropyl)phthalimide, $\mathrm{Cs}_{2} \mathrm{CO}_{3}, 80-85^{\circ} \mathrm{C}$ DMF, 6 days; (B) hydrazine mono hydrate, refluxing ethanol, 24h; (C) p-nitrophenyl(diphenylphosphoryl)acetate (7), 45-50 ${ }^{\circ} \mathrm{C}$ chloroform, 3 days. 
Scheme $3^{\mathrm{a}}$

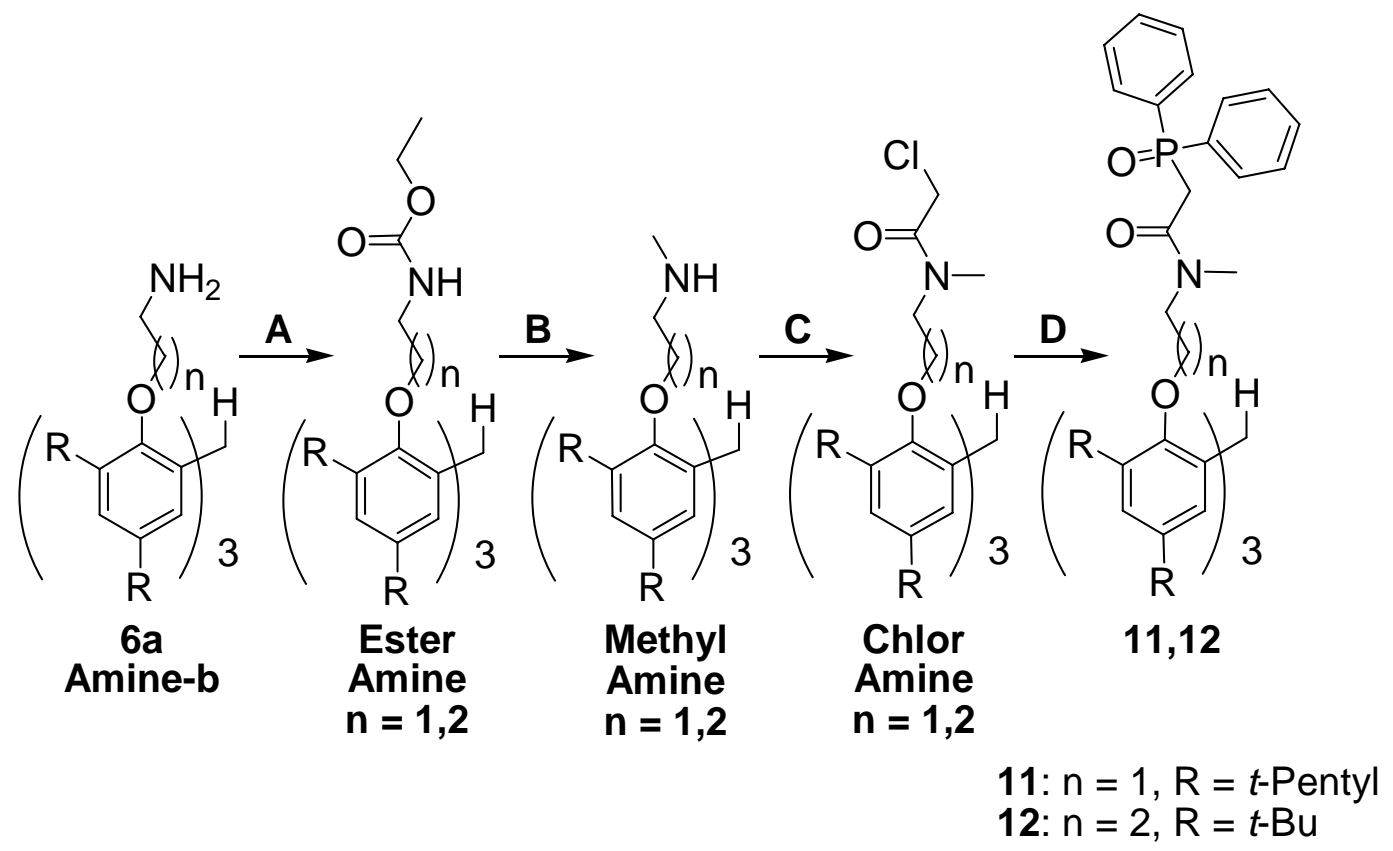

${ }^{a}$ Key: (A) ethylchloroformate, $\mathrm{K}_{2} \mathrm{CO}_{3}$, dichloromethane, 3 days, rt; (B) LAH, THF, 5 days, rt; (C) chloroacetyl chloride, $\mathrm{K}_{2} \mathrm{CO}_{3}, 24 \mathrm{~h}$, refluxing dichloromethane; (D) ethyl diphenylphosphinite, $150^{\circ} \mathrm{C}, 40 \mathrm{~h}$.

Preparation of Tris(3,5-tert-pentyl-2-(cyanomethoxy)phenyl)methane, 5a. Following the procedure described in reference 19 for $5 \mathbf{b}$, a $10.70 \mathrm{~g}$ portion $(15.00 \mathrm{mmol})$ of $\mathbf{4 a}$ was dissolved in dry acetone $(200 \mathrm{~mL})$ with $20.73 \mathrm{~g}(150.00 \mathrm{mmol})$ of potassium carbonate, $22.48 \mathrm{~g}$ (150.00 $\mathrm{mmol})$ of sodium iodide, and $7.59 \mathrm{~g}(120.0 \mathrm{mmol})$ of chloroacetonitrile, and the solution was refluxed 48 hours under nitrogen. After the solvent was removed in vacuo, the product was taken up in ether, dried with $\mathrm{MgSO}_{4}$, filtered, and the solvent was removed. Recrystallization of the crude material from ethanol afforded $8.91 \mathrm{~g}(72 \%)$ of product. ${ }^{1} \mathrm{H}$ NMR $\left(\mathrm{CDCl}_{3}\right): \delta=0.55$ $\left(\mathrm{m}, 18 \mathrm{H} ; \mathrm{CH}_{2} \mathrm{CH}_{3}\right), 1.13$ (s, $\left.18 \mathrm{H} ; \mathrm{C}_{-} \mathrm{CH}_{3}\right), 1.36$ (s, $\left.18 \mathrm{H} ; \mathrm{C}_{-} \mathrm{CH}_{3}\right), 1.48$ (q, J = 7.4, $6 \mathrm{H}$; $\left.\mathrm{CH}_{2} \mathrm{CH}_{3}\right), 1.74$ (q, $\left.J=7.5,6 \mathrm{H} ; \mathrm{CH}_{2} \mathrm{CH}_{3}\right), 4.14$ (s, $\left.6 \mathrm{H} ; \mathrm{CH}_{2} \mathrm{CN}\right), 6.17(\mathrm{~s}, 1 \mathrm{H} ; \mathrm{CH}), 7.04$ (d, J= 2.6, $3 \mathrm{H}$; Ar- $H$ ), 7.15 (d, $J=2.3,3 \mathrm{H}$; Ar- $H$ ). ${ }^{13} \mathrm{C}$ NMR $\left(\mathrm{CDCl}_{3}\right): \delta=9.4,9.7,28.6,29.4,35.5$, 37.0, 38.1, 38.5, 39.5, (aliphatic); $57.8\left(\right.$ Ar- $\left.-\mathrm{CH}_{2}\right) ; 115.0(\mathrm{CN}) ; 126.3,127.5,136.0,141.5$, 
145.7, 151.8 (aromatic). Anal. Calcd for $\mathrm{C}_{55} \mathrm{H}_{79} \mathrm{~N}_{3} \mathrm{O}_{3}: \mathrm{C}, 79.57 ; \mathrm{H}, 9.59 ; \mathrm{N}, 5.06$. Found: $\mathrm{C}$, 79.75; H, 10.07; N, 4.96.

Preparation of Tris(3-methyl-5-tert-butyl-2-(cyanomethoxy)phenyl)methane, 5c. Following the procedure described above, a $0.55 \mathrm{~g}(1.1 \mathrm{mmol})$ portion of $4 \mathrm{c}$ yielded $0.59 \mathrm{~g}(89 \%)$ of pure product. ${ }^{1} \mathrm{H}$ NMR $\left(\mathrm{CDCl}_{3}\right): \delta=1.18\left(\mathrm{~s}, 27 \mathrm{H}\right.$; $\left.\mathrm{Ar}-\mathrm{C}\left(\mathrm{CH}_{3}\right)_{3}\right), 2.37\left(\mathrm{~s}, 9 \mathrm{H} ; \mathrm{Ar}^{-} \mathrm{CH}_{3}\right), 4.14(\mathrm{~s}, 6 \mathrm{H}$; Ar-O-CH $\mathrm{CH}_{2} \mathrm{CN}$ ), 6.22(s, $1 \mathrm{H}$; C-H), 6.85 (b, $3 \mathrm{H}$; Ar- $\left.\mathrm{H}\right), 7.12$ (d, $3 \mathrm{H}$; Ar- $\left.\mathrm{H}\right) .{ }^{13} \mathrm{C}$ NMR $\left(\mathrm{CDCl}_{3}\right)$ : $\delta=17.1,31.2,34.3,37.7,57.2$ (aliphatic); $115.5(\mathrm{CN})$; 125.5, 127.4, 130.9, 135.0, 147.9, 151.4 (aromatic). Anal. Calcd for $\mathrm{C}_{40} \mathrm{H}_{49} \mathrm{~N}_{3} \mathrm{O}_{3}: \mathrm{C}, 77.51 ; \mathrm{H}, 7.97 ; \mathrm{N}, 6.78$. Found: $\mathrm{C}, 77.68 ; \mathrm{H}, 8.36$; N, 6.71 .

1,1'-bis(3,5-di-tert-butyl-2-(cynomethoxy)phenyl)ethane. As described for 5a, a $6.57 \mathrm{~g}$ (14.98 mmol) portion of 2,2'-ethylidenebis(4,6-di-tert-butylphenol) to afford $4.20 \mathrm{~g}(54 \%)$ of product. ${ }^{1} \mathrm{H}$ NMR $\left(\mathrm{CDCl}_{3}\right): \delta=1.18\left(\mathrm{~s}, 18 \mathrm{H} ; \mathrm{CCH}_{3}\right), 1.34\left(\mathrm{~s}, 18 \mathrm{H} ; \mathrm{CCH}_{3}\right), 1.60(\mathrm{~d}, J=6.9,3 \mathrm{H}$; $\left.\mathrm{CHCH}_{3}\right), 4.52\left(\mathrm{~m}, 4 \mathrm{H} ; \mathrm{CH}_{2} \mathrm{CN}\right), 4.65$ (q, $\left.J=7.1,1 \mathrm{H} ; \mathrm{CHCH}_{3}\right), 7.11$ (d, $\left.J=2.6,2 \mathrm{H} ; \mathrm{Ar}-\mathrm{H}\right)$, $7.18\left(\mathrm{~d}, J=2.6,2 \mathrm{H}\right.$; Ar- $H$ ). ${ }^{13} \mathrm{C}$ NMR $\left(\mathrm{CDCl}_{3}\right): \delta=23.3,31.6,31.7,32.3,34.9,35.7$, (aliphatic); 58.9 (Ar-O-CH 2$), 115.7(\mathrm{CN}) ; 123.4,124.2,138.4,142.5,147.7,152.2$, (aromatic). Anal. Calcd for $\mathrm{C}_{34} \mathrm{H}_{48} \mathrm{~N}_{2} \mathrm{O}_{2}$ : C, 79.02; H, 9.36; N, 5.42. Found: C, 80.39; H, 9.82; N, 5.44.

Preparation of Tris(3,5-di-tert-pentyl-2-(aminomethoxy)phenyl)methane As outlined in a previous publication, ${ }^{37}$ a diethyl ether solution of $5 \mathbf{a}(7.12 \mathrm{~g}, 8.58 \mathrm{mmol})$ was added dropwise over $30 \mathrm{~min}$ to a slurry of lithium aluminum hydride $(4.36 \mathrm{~g}, 129.00 \mathrm{mmol})$ in diethyl ether at $0^{\circ}$ C. The mixture was allowed to warm to room temperature and stirred for an additional 12-15 h. A $10 \mathrm{~mL}$ portion of $5 \% \mathrm{NaOH}$ was slowly added to the slurry, and the solution was allowed to stir for 30 minutes. The solution was dried with $\mathrm{MgSO}_{4}$, filtered, and the solvent was removed in vacuo. The crude white solid was recrystallized from acetonitrile to give to give $6.00 \mathrm{~g} \mathrm{(83 \% )}$ of product. ${ }^{1} \mathrm{H}$ NMR $\left(\mathrm{CDCl}_{3}\right): \delta=0.48\left(\mathrm{~m}, 18 \mathrm{H} ; \mathrm{CH}_{2} \mathrm{CH}_{3}\right), 1.11\left(\mathrm{~s}, 18 \mathrm{H} ; \mathrm{CCH}_{3}\right), 1.30(\mathrm{~s}, 18 \mathrm{H}$; $\mathrm{CCH}_{3}$ ), 1.43 (q, $J=7.4,6 \mathrm{H} ; \mathrm{CH}_{2} \mathrm{CH}_{3}$ ), 1.67 (q, $J=7.4,6 \mathrm{H} ; \mathrm{CH}_{2} \mathrm{CH}_{3}$ ), 2.89 (t, $J=5.0,6 \mathrm{H}$; $\mathrm{CH}_{2} \mathrm{CH}_{2}-\mathrm{NH}_{2}$ ), 3.32 (t, $J=5.0,6 \mathrm{H} ; \mathrm{O}-\mathrm{CH}_{2} \mathrm{CH}_{2}$ ), 6.38 (s, $1 \mathrm{H} ; \mathrm{CH}$ ), 7.00 (d, J = 2.6, $3 \mathrm{H} ; \mathrm{Ar}-\mathrm{H}$ ), $7.12(\mathrm{~d}, J=2.3,3 \mathrm{H}$; $\mathrm{Ar}-H) .{ }^{13} \mathrm{C} \mathrm{NMR}\left(\mathrm{CDCl}_{3}\right): \delta=9.3,9.8,28.8,29.7,35.3,37.1,37.9,38.8$, 39.4 (aliphatic); $42.8\left(\mathrm{CH}_{2}-\mathrm{NH}_{2}\right) ; 74.4\left(\mathrm{O}_{-} \mathrm{CH}_{2}\right) ; 125.0,128.2,138.0,140.1,142.8,152.9$ 
(aromatic). Anal. Calcd for $\mathrm{C}_{55} \mathrm{H}_{91} \mathrm{~N}_{3} \mathrm{O}_{3}: \mathrm{C}, 78.42 ; \mathrm{H}, 10.89 ; \mathrm{N}, 4.99$. Found: C, 78.13; H, 11.35; N, 4.66.

Preparation of Tris(3-methyl-5-tert-butyl-2-(aminomethoxy)phenyl)methane Following the procedure outlined for $6 \mathrm{a}$, a $6.46 \mathrm{~g}(10.0 \mathrm{mmol})$ portion of $5 \mathrm{c}$ gave $5.7 \mathrm{~g}(86 \%)$ of product. ${ }^{1} \mathrm{H}$ $\operatorname{NMR}\left(\mathrm{CDCl}_{3}\right): \delta=1.18\left(\mathrm{~s}, 27 \mathrm{H} ; \mathrm{Ar}-\mathrm{C}\left(\mathrm{CH}_{3}\right)_{3}\right), 2.26\left(\mathrm{~s}, 9 \mathrm{H} ; \mathrm{Ar}-\mathrm{CH}_{3}\right) 2.87(\mathrm{t}, J=5.1 \mathrm{~Hz}, 6 \mathrm{H}$; Ar-O-CH $\mathrm{CH}_{2}, 3.31$ (t, $J=5.2 \mathrm{~Hz}, 6 \mathrm{H}$; Ar-O-CH $\left.\mathrm{CH}_{2} \mathrm{NH}_{2}\right), 6.76(\mathrm{~s}, 1 \mathrm{H} ; \mathrm{CH}), 6.92$ (d, J = 2.6 Hz, $3 \mathrm{H}$; $\mathrm{Ar}-H), 7.00(\mathrm{~d}, J=2.6 \mathrm{~Hz}, 3 \mathrm{H}$; $\mathrm{Ar} H) .{ }^{13} \mathrm{C} \mathrm{NMR}\left(\mathrm{CDCl}_{3}\right): \delta=16.8,31.3,34.1,36.9,42.4$,

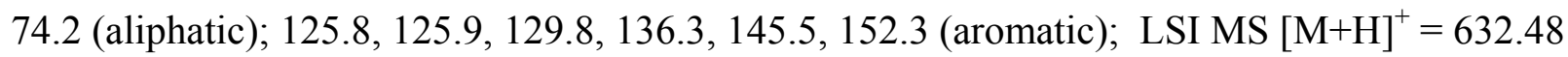

1,1'-bis(3,5-di-tert-butyl-2-(2-aminoethoxy)phenyl)ethane. Lithium aluminum hydride (1.49 $\mathrm{g}, 39.26 \mathrm{mmol})$ was suspended in dry ether $(80 \mathrm{~mL})$ and the reaction flask was cooled to $0{ }^{\circ} \mathrm{C}$. 1,1'-bis(3,5-di-tert-butyl-2-(cynomethoxy)phenyl)ethane $(2.70 \mathrm{~g}, 5.23 \mathrm{mmol})$ was added in three portions with stirring. The reaction mixture was warmed to room temperature and stirred overnight. The reaction was monitored by TLC, (pentane:ether 80:20) and once completed, 5\% sodium hydroxide solution $(4.5 \mathrm{~mL})$ was added dropwise (ice bath) and the mixture was stirred until the suspension became milky white. The resulting white solid was discarded through filtration and the organic layer was dried over $\mathrm{MgSO}_{4}$. Removal of solvent under vacuum yielded analytically pure product. Yield $2.30 \mathrm{~g}(84 \%) .{ }^{1} \mathrm{H} \mathrm{NMR}\left(\mathrm{CDCl}_{3}\right): \delta=1.27(\mathrm{~s}, 18 \mathrm{H}$, $\mathrm{CH}_{3}$ ), 1.42 (s, $18 \mathrm{H}, \mathrm{CH}_{3}$ ), 1.67 (d, $3 \mathrm{H}, J=7.2 \mathrm{~Hz}, \mathrm{CHCH}_{3}$ ), 3.15 (b t, $4 \mathrm{H}, \mathrm{N}-\mathrm{CH}_{2} \mathrm{CH}_{2}-\mathrm{O}$ ), 3.89 (m, 4 H, N-CH $2 \mathrm{CH}_{2}-\mathrm{O}$ ), 4.70 (q, $\left.1 \mathrm{H}, J=7.2 \mathrm{~Hz}, \mathrm{CH}\right), 7.21$ (s, $\left.2 \mathrm{H}, \mathrm{Ar}-H\right), 7.24$ (s, $2 \mathrm{H}, \mathrm{Ar}-H$ ). ${ }^{13} \mathrm{C} \mathrm{NMR}\left(\mathrm{CDCl}_{3}\right): \delta=23.95,30.18,31.57,31.69,32.33,34.70,35.64,42.52$ (aliphatic); 75.62 $\left(\mathrm{O}-\mathrm{CH}_{2}\right) ; 122.54,124.69,139.02,141.80,145.18,153.66$ (aromatic). Anal. Calcd for $\mathrm{C}_{34} \mathrm{H}_{56} \mathrm{~N}_{2} \mathrm{O}_{2}$ : C, 77.81; H, 10.76; N, 5.34. Found: C, 78.32; H, 11.14; N, 5.08

Preparation of compound 8a. The synthesis of $\mathbf{8 a}$ followed the preparation method for $\mathbf{8} \mathbf{b}^{37}$ A chloroform solution of $6 \mathbf{a}(2.92 \mathrm{~g}, 3.47 \mathrm{mmol})$ and p-nitrophenyl(diphenylphosphoryl)acetate, 7 , (4.16 g, $10.91 \mathrm{mmol})$ were stirred at $45^{\circ} \mathrm{C}$ for three days. After cooling to room temperature, a 1 $\mathrm{M}$ solution of $\mathrm{NaOH}(100 \mathrm{~mL})$ was added and the mixture was stirred for 2 hours. The pnitrophenol sodium salt was extracted from the chloroform solution using 5\% sodium carbonate $(6 \times 300 \mathrm{~mL})$ and the organic layer was further extracted with brine. The organic phase was 
dried with $\mathrm{MgSO}_{4}$, filtered, and the solvent removed in vacuo to give $4.21 \mathrm{~g} \mathrm{(77 \% )} \mathrm{of} \mathrm{product} \mathrm{as}$ an off-white solid material. ${ }^{1} \mathrm{H}$ NMR $\left(\mathrm{CDCl}_{3}\right): \delta=0.46\left(\mathrm{~m}, 18 \mathrm{H} ; \mathrm{CH}_{2} \mathrm{CH}_{3}\right), 1.06(\mathrm{~s}, 18 \mathrm{H}$; $\left.\mathrm{CCH}_{3}\right), 1.23$ (s, $\left.18 \mathrm{H} ; \mathrm{CCH}_{3}\right), 1.40$ (q, J = 7.3, 6H; $\left.\mathrm{CH}_{2} \mathrm{CH}_{3}\right), 1.57$ (b, $\left.6 \mathrm{H} ; \mathrm{CH}_{2} \mathrm{CH}_{3}\right), 3.41$ (b, m, $18 \mathrm{H}$; O-CH $\left.\mathrm{CH}_{2}-\mathrm{NHC}(\mathrm{O})-\mathrm{CH}_{2}-\mathrm{P}\right), 6.28(\mathrm{~s}, 1 \mathrm{H} ; \mathrm{CH}), 6.92$ (d, $\left.J=2.3,3 \mathrm{H} ; \mathrm{Ar}-\mathrm{H}\right), 6.95$ (d, J = 2.1, 3 H; Ar-H), 7.38 (m, 18 H; P-Ar H), 7.72 (m, 12 H; P-Ar H), 7.89 (b, $3 \mathrm{H} ; \mathrm{NH}$ ). ${ }^{13} \mathrm{C}$ NMR $\left(\mathrm{CDCl}_{3}\right): \delta=9.3,9.8,28.7,29.7,35.5,37.1,37.8,38.7,39.3,39.5$ (aliphatic); $40.4\left(\mathrm{CH}_{2}-\mathrm{NH}_{2}\right)$; $70.4\left(\mathrm{O}-\mathrm{CH}_{2}\right) ; 125.0,127.7,128.7,128.9,131.2,131.3,132.1,132.2,137.8,139.9,142.8,153.2$ (aromatic); 165.4; $165.5(\mathrm{C}=\mathrm{O})$. ${ }^{31} \mathrm{P} \mathrm{NMR}\left(\mathrm{CDCl}_{3}\right): \delta=29.8$. Anal. Calcd for $\mathrm{C}_{97} \mathrm{H}_{124} \mathrm{~N}_{3} \mathrm{O}_{9} \mathrm{P}_{3}$ : C, 74.26; H, 7.97; N, 2.68. Found: C, 74.59; H, 8.14; N, 2.70.

Preparation of compound 8c. Following the procedure described above for 8a, a $2.60 \mathrm{~g}(4.11$ $\mathrm{mmol})$ portion of $\mathbf{6 c}$ was reacted with $4.90 \mathrm{~g}(12.85 \mathrm{mmol})$ of 7 to afford $1.97 \mathrm{~g}(35 \%)$ of product. ${ }^{1} \mathrm{H} \mathrm{NMR}\left(\mathrm{CDCl}_{3}\right): \delta=1.14$ (s, $27 \mathrm{H}$; Ar-C( $\left.\left(\mathrm{CH}_{3}\right)_{3}\right), 2.12$ (s, $9 \mathrm{H}$; Ar- $\left.\mathrm{CH}_{3}\right), 3.29$ (b, $12 \mathrm{H}$; Ar-O$\mathrm{CH}_{2} \mathrm{CH}_{2}$ ), 3.49 (d, $\left.J(\mathrm{H}, \mathrm{P})=13.9 \mathrm{~Hz}, 6 \mathrm{H} ; \mathrm{CH}_{2}-\mathrm{POAr}_{2}\right), 6.65$ (s, $\left.1 \mathrm{H} ; \mathrm{CH}\right), 6.84$ (d, J = 2.4 Hz, 3 H; Ar-H), 6.94 (d, J=2.5 Hz, 3 H; Ar-H), 7.38 (m, 12 H; P-Ar H), 7.47 (m, 6 H; P-Ar H), 7.76 (m, $12 \mathrm{H}$; P-Ar H), 8.00 (b, $3 \mathrm{H}$; N-H). ${ }^{13} \mathrm{C}$ NMR [CDCl 3 ]: $\delta=16.79,31.2,34.0,38.7,39.5$, 40.0 (aliphatic); $70.6\left(\mathrm{O}_{-} \mathrm{CH}_{2}\right) ; 152.1,145.6,135.9,132.7,131.9,131.4,131.0,130.9,129.7$, 128.6, 128.4,126.0, 125.5(aromatic); 165.1, $165.09(\mathrm{C}=\mathrm{O}) .{ }^{31} \mathrm{P}$ NMR $\left(\mathrm{CD}_{3} \mathrm{OD}\right): 8=30.77 . \mathrm{HR}$ ESI-ICR MS (sample injected as solution in $1 \% \mathrm{HNO}_{3} / \mathrm{MeOH}$ ): $[\mathrm{M}+\mathrm{H}]^{+}=1358.62$. Anal. Calcd for $\mathrm{C}_{82} \mathrm{H}_{94} \mathrm{~N}_{3} \mathrm{O}_{9} \mathrm{P}_{3}$ : C, 72.49; H, 6.97; N, 3.09. Found: C, 72.37; H, 6.97; N, 3.38 .

Preparation of compound 9. The synthesis of $\mathbf{9}$ was adapted from that described above for $8 \mathrm{a}$,

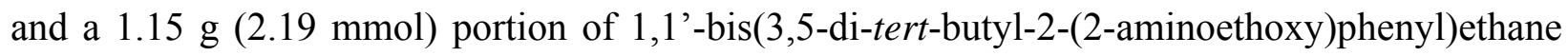
was treated with $1.76 \mathrm{~g}(4.62 \mathrm{mmol})$ of 7 to afford $2.00 \mathrm{~g}(90 \%)$ of product. ${ }^{1} \mathrm{H}$ NMR $\left(\mathrm{CDCl}_{3}\right)$ : $\delta$ $=1.25\left(\mathrm{~s}, 18 \mathrm{H}, \mathrm{CH}_{3}\right), 1.33\left(\mathrm{~s}, 18 \mathrm{H}, \mathrm{CH}_{3}\right), 1.43\left(\mathrm{~d}, 3 \mathrm{H}, J=8.6 \mathrm{~Hz}, \mathrm{CHCH}_{3}\right), 3.42-3.71$ (several multiplets, $8 \mathrm{H}, \mathrm{P}-\mathrm{CH}_{2}-\mathrm{C}(\mathrm{O})+\mathrm{N}-\mathrm{CH}_{2} \mathrm{CH}_{2}-\mathrm{O}$ ), 3.99 (m, $4 \mathrm{H}, \mathrm{N}-\mathrm{CH}_{2} \mathrm{CH}_{2}-\mathrm{O}$ ), 4.70 (q, 1 H, J = 6.6 Hz, CH), 7.15 (b s, 2 H, Ar-H), 7.18 (b s, 2 H, Ar-H), $7.27-7.47$ (m, 12 H, P-Ar), 7.78 (b m, $8 \mathrm{H}, \mathrm{P}-\mathrm{Ar}$ ), 8.27 (b, $3 \mathrm{H}, \mathrm{NH}) .{ }^{13} \mathrm{C} \mathrm{NMR}\left(\mathrm{CDCl}_{3}\right): \delta=24.07,31.59,34.62,35.51$, 38.89, 39.69, 40.26 (aliphatic); $71.94\left(\mathrm{O}^{\left.-\mathrm{CH}_{2}\right)}\right.$; 122.46, 124.10, 128.69, 128.85, 130.99, 131.12, $132.23,132.61,139.40,141.65,141.65,145.36,153.22$ (aromatic); $165.36(\mathrm{C}=\mathrm{O}) .{ }^{31} \mathrm{P}$ NMR 
$\left(\mathrm{CDCl}_{3}\right): \delta=30.41$. Anal. Calcd for $\mathrm{C}_{62} \mathrm{H}_{78} \mathrm{~N}_{2} \mathrm{O}_{6} \mathrm{P}_{2}: \mathrm{C}, 73.78 ; \mathrm{H}, 7.79 ; \mathrm{N}, 2.78$. Found: C, 73.85; H, 7.98; N, 2.73.

General procedure for synthesis of compounds Pthal. A stirring suspension of triphenoxymethane molecule $(4)^{38}$, N-(3-bromopropyl)phthalimide and cesium carbonate in DMF was heated to $80-85{ }^{\circ} \mathrm{C}$ for six days. The reaction mixture was cooled to room temperature and poured into cold water resulting in formation of a white solid product. The mixture was transferred to a separation funnel and extracted with diethyl ether. The solid product suspended in the ether layer and was collected by filtration and dried.

Compound (Pthal-a). Using a 10.01 g (14.04 mmol) portion of tris(3,5-di-tert-pentyl-2hydroxyl)methane (4a) afforded $11.53 \mathrm{~g}(64 \%)$ of product. ${ }^{1} \mathrm{H} \mathrm{NMR}\left(\mathrm{CDCl}_{3}\right): \delta=0.50(\mathrm{~m}, 18$ $\left.\mathrm{H} ; \mathrm{CH}_{2} \mathrm{CH}_{3}\right), 1.13$ (s, $\left.18 \mathrm{H} ; \mathrm{CCH}_{3}\right), 1.32$ (s, $\left.18 \mathrm{H} ; \mathrm{CCH}_{3}\right), 1.45$ (q, J=7.4, $\left.6 \mathrm{H} ; \mathrm{CH}_{2} \mathrm{CH}_{3}\right), 1.70$ (q, J = 7.5, $\left.6 \mathrm{H} ; \mathrm{CH}_{2} \mathrm{CH}_{3}\right), 2.12$ (b, $\left.6 \mathrm{H} ; \mathrm{CH}_{2} \mathrm{CH}_{2} \mathrm{CH}_{2}\right), 3.50\left(\mathrm{~b}, 6 \mathrm{H} ; \mathrm{CH}_{2} \mathrm{CH}_{2} \mathrm{CH}_{2}-\mathrm{N}\right), 4.01$ (m, 6 $\mathrm{H}$; O- $\mathrm{CH}_{2} \mathrm{CH}_{2} \mathrm{CH}_{2}$ ), 6.42 (s, $\left.1 \mathrm{H} ; \mathrm{CH}\right), 7.01$ (d, $\left.J=2.3,3 \mathrm{H} ; \mathrm{Ar}-H\right), 7.10$ (d, J=2.1, $\left.3 \mathrm{H} ; \mathrm{Ar}-H\right)$, $7.45\left(\mathrm{~m}, 6 \mathrm{H}\right.$; Ar-H), 7.54 (m, $6 \mathrm{H}$; Ar-H). ${ }^{13} \mathrm{C} \mathrm{NMR}\left(\mathrm{CDCl}_{3}\right): \delta=9.3,9.8,28.8,29.6,29.7$, 35.1, 36.3, 37.1, 37.9, 39.4 (aliphatic); $69.8\left(\mathrm{O}-\mathrm{CH}_{2}\right)$; 122.9, 124.9, 128.1, 132.8, 132.9, 133.3, 138.3, 140.1, 142.5, 153.4 (aromatic); 168.3(C=O). FAB MS m/z $=1274.77[\mathrm{M}+\mathrm{H}]^{+}$.

Compound (Pthal-b). The material was obtained in $89 \%$ yield. ${ }^{1} \mathrm{H}$ NMR $\left(\mathrm{CDCl}_{3}\right): \delta=1.19(\mathrm{~s}$, $\left.27 \mathrm{H} ; \mathrm{CCH}_{3}\right), 1.34$ (s, $\left.27 \mathrm{H} ; \mathrm{CCH}_{3}\right), 2.19\left(\mathrm{~m}, 6 \mathrm{H} ; \mathrm{CH}_{2} \mathrm{CH}_{2} \mathrm{CH}_{2}\right), 3.58$ (t, J=5.5, $6 \mathrm{H} ; \mathrm{CH}_{2} \mathrm{CH}_{2-}$ N), 4.03 (m, $6 \mathrm{H}$; O-CH2 $\left.\mathrm{CH}_{2}\right), 6.48(\mathrm{~s}, 1 \mathrm{H} ; \mathrm{CH}), 7.15$ (d, J=2.3, $2 \mathrm{H}$; Ar-H), 7.23 (m, 2 H; Ar$H), 7.47$ (m, $6 \mathrm{H}$; Ar-H), $7.54(\mathrm{~m}, 6 \mathrm{H} ; \mathrm{Ar}-H) .{ }^{13} \mathrm{C} \mathrm{NMR}\left(\mathrm{CDCl}_{3}\right): \delta=29.6,31.5,31.7,34.7$, 35.7, 36.3 (aliphatic); $70.3\left(\mathrm{O}-\mathrm{CH}_{2}\right) ; 122.4$ 122.9, 127.3, 132.8, 133.3, 138.0, 142.2, 144.6, 153.7 (aromatic); $168.3(\mathrm{C}=\mathrm{O}) . \mathrm{FAB} \mathrm{MS} \mathrm{m} / \mathrm{z}=1212.66[\mathrm{M}+\mathrm{Na}]^{+}$

General procedure for synthesis of compounds Amine-a and Amine-b. To a suspension of compound Pthal in absolute ethanol, hydrazine mono hydrate (4 eq) was slowly added and the mixture was refluxed for $24 \mathrm{~h}$. The reaction was cooled to room temperature and the solvent was partially evaporated under reduced pressure. The resulting residue was poured into ice-cold water and a white precipitate quickly formed. The product was collected by filtration. Compound Amine-a. Yield 97\%. ${ }^{1} \mathrm{H} \mathrm{NMR}\left(\mathrm{CDCl}_{3}\right): \delta=0.40-0.49\left(\mathrm{~m}, 18 \mathrm{H}, \mathrm{CH}_{2} \mathrm{CH}_{3}\right), 1.04(\mathrm{~s}$, $\left.18 \mathrm{H}, \mathrm{CH}_{3}\right), 1.25$ (s, $\left.18 \mathrm{H}, \mathrm{CH}_{3}\right), 1.37$ (q, J=7.5 Hz, $\left.6 \mathrm{H}, \mathrm{CH}_{2} \mathrm{CH}_{3}\right), 1.62$ (q, J = 7.5 Hz, $6 \mathrm{H}$, 
$\mathrm{CH}_{2} \mathrm{CH}_{3}$ ), 1.77 (quintet, , $J=6.6 \mathrm{~Hz}, 6.9 \mathrm{~Hz}, 6 \mathrm{H}, \mathrm{N}-\mathrm{CH}_{2} \mathrm{CH}_{2} \mathrm{CH}_{2}-\mathrm{O}$ ), 2.58 (b s, $6 \mathrm{H}, \mathrm{NH}_{2}$ ), 2.80 (t, J=6.9 Hz, $6 \mathrm{H}, \mathrm{N}-\mathrm{CH}_{2} \mathrm{CH}_{2} \mathrm{CH}_{2}-\mathrm{O}$ ), 3.38 (b t, $6 \mathrm{H}, \mathrm{N}-\mathrm{CH}_{2} \mathrm{CH}_{2} \mathrm{CH}_{2}-\mathrm{O}$ ), 6.23 (s, $1 \mathrm{H}, \mathrm{CH}$ ), 6.95 (s, $6 \mathrm{H}, \mathrm{Ar}-\mathrm{H}) .{ }^{13} \mathrm{C} \mathrm{NMR}\left(\mathrm{CDCl}_{3}\right): \delta=39.5,39.4,39.2,37.7,36.9,35.0,34.2,29.5,28.7,9.7$, 9.2 (aliphatic); $70.4\left(\mathrm{O}-\mathrm{CH}_{2}\right) ; 153.5,147.4,142.3,139.7,138.2$, 128.0, 124.7 (aromatic). FAB MS m/z $=884.76[\mathrm{M}+\mathrm{H}]^{+}$. Compound Amine-b. Yield 92\%. ${ }^{1} \mathrm{H}$ NMR $\left(\mathrm{CDCl}_{3}\right): \delta 1.12(\mathrm{~s}, 27$ $\mathrm{H}, \mathrm{CH}_{3}$ ), 1.25 (s, $27 \mathrm{H}, \mathrm{CH}_{3}$ ), 1.83 (quintet, $J=7.5 \mathrm{~Hz}, 6.6 \mathrm{~Hz}, 6 \mathrm{H}, \mathrm{N}-\mathrm{CH}_{2} \mathrm{CH}_{2} \mathrm{CH}_{2}-\mathrm{O}$ ), 2.87 (t, $\left.J=7.5 \mathrm{~Hz}, 6 \mathrm{H}, \mathrm{N}-\mathrm{CH}_{2} \mathrm{CH}_{2} \mathrm{CH}_{2}-\mathrm{O}\right), 3.38\left(\mathrm{t}, J=6.6 \mathrm{~Hz}, 6 \mathrm{H}, \mathrm{N}_{-} \mathrm{CH}_{2} \mathrm{CH}_{2} \mathrm{CH}_{2}-\mathrm{O}\right), 6.25(\mathrm{~s}, 1 \mathrm{H}$, $\mathrm{CH}), 7.10-7.16(\mathrm{~m}, 6 \mathrm{H}, \mathrm{Ar}-\mathrm{H}) .{ }^{13} \mathrm{C} \mathrm{NMR}\left(\mathrm{CDCl}_{3}\right): \delta=31.32,31.45,33.17,34.51,35.46,38.50$, 38.98 (aliphatic); $70.50\left(\mathrm{O}_{-} \mathrm{CH}_{2}\right) ; 122.47,126.0,127.38,129.83,131.79,137.61,141.79,144.68$, 153.35 (aromatic). FAB MS m/z $=800.67[\mathrm{M}+\mathrm{H}]^{+}$.

General procedure for synthesis of compounds 10a and 10b. A chloroform solution of $0.75 \mathrm{~g}$ of amine (Amine) and 3.1 eq. of $p$-nitrophenyl(diphenylphosphoryl)acetate (7) was stirred at 45$50{ }^{\circ} \mathrm{C}$ for 3 days. The reaction mixture was cooled to room temperature; $1 \mathrm{M}$ sodium hydroxide solution was added and stirred for $2 \mathrm{~h}$. The organic phase was extracted with $5 \%$ sodium carbonate followed by brine, and the solution was dried over $\mathrm{MgSO}_{4}$. The solvent was removed in vacuo and acetonitrile $(15 \mathrm{~mL})$ was added resulting in product precipitation. The solid was filtered, washed with acetonitrile, and dried to afford pure product. 10a Yield 70\%. ${ }^{1} \mathrm{H}$ NMR $\left(\mathrm{CDCl}_{3}\right): \delta$ 0.36-0.42 (m, $\left.18 \mathrm{H}, \mathrm{CH}_{2} \mathrm{CH}_{3}\right), 1.04\left(\mathrm{~s}, 18 \mathrm{H}, \mathrm{CH}_{3}\right), 1.15$ (s, $\left.18 \mathrm{H}, \mathrm{CH}_{3}\right), 1.36$ (q, $J=$ $7.5 \mathrm{~Hz}, 12 \mathrm{H}, \mathrm{CH}_{2} \mathrm{CH}_{3}$ ), 1.50 (q, J $=7.5 \mathrm{~Hz}, 6 \mathrm{H}, \mathrm{CH}_{2} \mathrm{CH}_{3}$ ), 1.80 (b s, $6 \mathrm{H}, \mathrm{N}-\mathrm{CH}_{2} \mathrm{CH}_{2} \mathrm{CH}_{2}-\mathrm{O}$ ), 3.23 - 3.40 (several multiplets, $18 \mathrm{H}, \mathrm{P}(\mathrm{O})-\mathrm{CH}_{2}-\mathrm{C}(\mathrm{O}) \mathrm{N}-\mathrm{CH}_{2} \mathrm{CH}_{2} \mathrm{CH}_{2}-\mathrm{O}$ ), 6.15 (s, $1 \mathrm{H}, \mathrm{CH}$ ), 6.88 (d, $J=1.8 \mathrm{~Hz}, 3 \mathrm{H}, \mathrm{Ar}-H$ ), 7.00 (d, $J=1.8 \mathrm{~Hz}, 3 \mathrm{H}, \mathrm{Ar}-H$ ), 7.28-7.48 (m, $18 \mathrm{H}, \mathrm{P}-\mathrm{Ar} H$ ), 7.647.84 (m, $12 \mathrm{H}, \mathrm{P}-\mathrm{Ar} H) .{ }^{13} \mathrm{C}$ NMR $\left(\mathrm{CDCl}_{3}\right): \delta=9.2,9.7,28.7,29.6,30.5,35.1,37.0,37.7,38.1$, 39.2, (aliphatic); $69.7\left(\mathrm{O}_{-} \mathrm{CH}_{2}\right) ; 124.7,127.9,128.7,128.9,131.1,131.6,132.2,133.0,137.8$, 139.7, 142.3, 147.4, 153.3 (aromatic); 165.22, $165.16(\mathrm{C}=\mathrm{O}) .{ }^{31} \mathrm{P}$ NMR: $\delta=30.3$. ESI FT -ICR MS m/z $=1633.88[\mathrm{M}+\mathrm{Na}]^{+}$. Compound 10b. Yield 49\% . ${ }^{1} \mathrm{H}$ NMR $\left(\mathrm{CDCl}_{3}\right): \delta=1.16(\mathrm{~s}, 27$ $\mathrm{H} ; \mathrm{CCH}_{3}$ ), 1.21 (s, $27 \mathrm{H} ; \mathrm{CCH}_{3}$ ), 1.91 (b, $6 \mathrm{H} ; \mathrm{CH}_{2} \mathrm{CH}_{2} \mathrm{CH}_{2}$ ), 3.39 (several multiplets, $18 \mathrm{H}$; O$\left.\mathrm{CH}_{2} \mathrm{CH}_{2} \mathrm{CH}_{2}-\mathrm{NH}-\mathrm{C}(\mathrm{O}) \mathrm{CH}_{2} \mathrm{P}(\mathrm{O})\right), 6.28(\mathrm{~s}, 1 \mathrm{H} ; \mathrm{CH}), 7.08(\mathrm{~d}, J=2.3,3 \mathrm{H} ; \mathrm{Ar}-\mathrm{H}), 7.23$ (d, $J=$ 2.6, 3 H; Ar-H), 7.40 (m, 18 H; P-Ar H), 7.77 (m, 12 H; P-Ar H), 7.87 (t, $J=5.4,3 \mathrm{H} ; \mathrm{NH}$ ). ${ }^{13} \mathrm{C}$ $\operatorname{NMR}\left(\mathrm{CDCl}_{3}\right): \delta=30.6$ 31.6, 31.7, 34.6, 35.6, 38.1, 38.9, 39.7 (aliphatic); $70.3\left(\mathrm{O}-\mathrm{CH}_{2}\right) ; 122.3$, 127.1, 128.7, 128.9, 131.1, 131.2, 131.7, 132.17, 132.21, 133.1, 137.6, 141.9, 144.4, 153.6 
(aromatic); 165.2, 165.1(C=O). ${ }^{31} \mathrm{P}$ NMR $\left(\mathrm{CDCl}_{3}\right): \delta=29.8 . \quad$ ESI FT $-\mathrm{ICR} \mathrm{MS} \mathrm{m} / \mathrm{z}=1549.79$ $[\mathrm{M}+\mathrm{Na}]^{+}$.

Ester amine-1. To a mixture of $6 a(2.16 \mathrm{~g}, 2.56 \mathrm{mmol})$ and $\mathrm{KOH}(4.32 \mathrm{~g})$ in $40 \mathrm{~mL}$ of dichloromethane, ethylchloroformate $(1.6 \mathrm{~mL}, 1.82 \mathrm{~g}, 17 \mathrm{mmol})$ was added. The mixture was stirred for 3 days at room temperature. The solution was then washed with $200 \mathrm{~mL}$ of water and brine $(50 \mathrm{~mL})$, and dried over $\mathrm{MgSO}_{4}$. The solvent was evaporated to afford $2.5 \mathrm{~g}$ of product in 92\% yield. ${ }^{1} \mathrm{H}$ NMR $\left(\mathrm{CD}_{3} \mathrm{OD}\right): \delta=0.56\left(\mathrm{t}, 9 \mathrm{H}, \mathrm{CH}_{2} \mathrm{CH}_{3}\right), 0.59\left(\mathrm{t}, J=7.5,9 \mathrm{H}, \mathrm{CH}_{2} \mathrm{CH}_{3}\right), 1.18$ $\left(\mathrm{s}, 18 \mathrm{H}, \mathrm{CCH}_{3}\right), 1.26\left(\mathrm{t}, J=7.5,9 \mathrm{H}, \mathrm{OCH}_{2} \mathrm{CH}_{3}\right), 1.37\left(\mathrm{~s}, 18 \mathrm{H}, \mathrm{CCH}_{3}\right), 1.54$ (q, J = 7.5, $6 \mathrm{H}$, $\mathrm{CH}_{2} \mathrm{CH}_{3}$ ), 1.76 (q, $J=7.5,6 \mathrm{H}, \mathrm{CH}_{2} \mathrm{CH}_{3}$ ), $3.39-3.65$ (b m, $6 \mathrm{H}, \mathrm{O}-\mathrm{CH}_{2} \mathrm{CH}_{2}-\mathrm{N}+6 \mathrm{H}, \mathrm{O}-$ $\left.\mathrm{CH}_{2} \mathrm{CH}_{2}-\mathrm{N}\right), 4.12$ (q, J=7.2, $\left.6 \mathrm{H}, \mathrm{O}-\mathrm{CH}_{2} \mathrm{CH}_{3}\right)$, ), $6.42(\mathrm{~s}, 1 \mathrm{H}, \mathrm{CH}), 7.15(\mathrm{~b}, 6 \mathrm{H}, \mathrm{Ar}-\mathrm{H}) .{ }^{13} \mathrm{C}$ NMR $\left(\mathrm{CD}_{3} \mathrm{OD}\right): \delta=9.8,10.2,15.2,29.3,30.3,36.3,38.0,38.9,40.4,42.4$ (aliphatic); 62.0 $\left(\mathrm{CH}_{2}-\mathrm{O}\right) ; 72.0\left(\mathrm{CH}_{2}-\mathrm{OAr}\right) ; 126.4,129.1,139.3,141.4,144.2,154.4$ (aromatic); $159.1(\mathrm{C}=\mathrm{O})$. LSI MS: $\mathrm{m} / \mathrm{z}=1058.77[\mathrm{M}+\mathrm{H}]$. Anal. Calcd. for $\mathrm{C}_{64} \mathrm{H}_{103} \mathrm{~N}_{3} \mathrm{O}_{9}: \mathrm{C}, 72.62 ; \mathrm{H}, 9.81 ; \mathrm{N}, 3.97$; Found: C, 72.86; H, 10.30; N, 3.90 .

Ester amine-2. To a mixture of Amine-b (5 g, $6.3 \mathrm{mmol})$ and $\mathrm{KOH}(11.4 \mathrm{~g})$ in $20 \mathrm{~mL}$ of dichloromethane, ethylchloroformate $(2.8 \mathrm{~mL}, 3.2 \mathrm{~g}, 29 \mathrm{mmol})$ was added. The mixture was stirred for 3 days at room temperature. Subsequently solution was washed with $250 \mathrm{~mL}$ of water and brine $(50 \mathrm{~mL})$, dried over $\mathrm{MgSO}_{4}$ and evaporated. Yield: 75\% (4.75 g). ${ }^{1} \mathrm{H} \mathrm{NMR}\left(\mathrm{CDCl}_{3}\right)$ : $\delta=1.18\left(\mathrm{~s}, 27 \mathrm{H}, \mathrm{CH}_{3}\right), 1.23\left(\mathrm{t}, J=6.90 \mathrm{~Hz}, 9 \mathrm{H}, \mathrm{CH}_{3}\right), 1.33\left(\mathrm{~s}, 27 \mathrm{H}, \mathrm{CH}_{3}\right.$ ) $), 1.98(\mathrm{~m}, 6 \mathrm{H}, \mathrm{N}-$ $\mathrm{CH}_{2} \mathrm{CH}_{2} \mathrm{CH}_{2}-\mathrm{O}$ ), 3.39 (m, $\left.6 \mathrm{H}, \mathrm{N}-\mathrm{CH}_{2} \mathrm{CH}_{2} \mathrm{CH}_{2}-\mathrm{O}\right), 3.52$ (m, $\left.6 \mathrm{H}, \mathrm{N}-\mathrm{CH}_{2} \mathrm{CH}_{2} \mathrm{CH}_{2}-\mathrm{O}\right), 4.11(\mathrm{q}, \mathrm{J}=$ $\left.6.20 \mathrm{~Hz}, 6 \mathrm{H}, \mathrm{O}-\mathrm{CH}_{2} \mathrm{CH}_{3}\right), 5.39$ (b s, $\left.3 \mathrm{H}, \mathrm{NH}\right), 6.35(\mathrm{~s}, 1 \mathrm{H}, \mathrm{CH}), 7.13-7.26(\mathrm{~m}, 6 \mathrm{H}, \mathrm{Ar}-\mathrm{H}) .{ }^{13} \mathrm{C}$ NMR $\left(\mathrm{CDCl}_{3}\right): \delta=14.9,30.9,31.6,34.6,35.7,39.1,60.7,71.0$ (aliphatic); 122.6, 127.3, 144.7, 137.8, 141.9, 153.6 (aromatic); 157.1(C=O). FAB MS: m/z $=1016.73[\mathrm{M}+\mathrm{H}]^{+}$. Anal. Calcd. for $\mathrm{C}_{61} \mathrm{H}_{97} \mathrm{~N}_{3} \mathrm{O}_{9}$ : C, 72.08; H, 9.62; N, 4.13; Found: C, 72.07; H, 9.88; N, 4.06.

Methyl amine-1. To a stirred solution of lithium aluminium hydride $(2.53 \mathrm{~g}, 0.067 \mathrm{~mol})$ in tetrahydrofuran $(500 \mathrm{~mL})$ at $0^{\circ} \mathrm{C}, 2.4 \mathrm{~g}(2.27 \mathrm{mmol})$ of ester Ester amine-1 was added dropwise, and the reaction mixture was stirred at room temperature for 5 days. In order to quench LAH, the solution was cooled to $0^{\circ} \mathrm{C}$, treated with $3 \mathrm{ml}$ of water and stirred for 5 minutes. A total of 
$3 \mathrm{ml}$ of $15 \% \mathrm{NaOH}$ was then added dropwise, and after additional 30 minutes, more water $(9 \mathrm{ml})$ was added (Steinhard's method). ${ }^{82}$ The solid was separated, and the organic phase was dried over $\mathrm{MgSO}_{4}$. The solution was evaporated to give crude product that was further purified by precipitation in acidified pentane, dissolution in diethyl ether and extraction with $1 \mathrm{M} \mathrm{NaOH}$. The organic phase was dried with $\mathrm{MgSO}_{4}$ and evaporated to yield $2 \mathrm{~g}$ of product (95\%) of pure product. ${ }^{1} \mathrm{H} \mathrm{NMR}\left(\mathrm{CDCl}_{3}\right): \delta=0.55\left(\mathrm{t}, J=7.2 \mathrm{~Hz}, 9 \mathrm{H}, \mathrm{CH}_{2} \mathrm{CH}_{3}\right), 0.57(\mathrm{t}, J=7.2 \mathrm{~Hz}, 9 \mathrm{H}$, $\mathrm{CH}_{2} \mathrm{CH}_{3}$ ), 1.13 (s, $18 \mathrm{H}, \mathrm{CH}_{3}$ ), 1.35 (s, $18 \mathrm{H}, \mathrm{CH}_{3}$ ) $), 1.47$ (q, $J=7.5 \mathrm{~Hz}, 6 \mathrm{H}, \mathrm{CH}_{2} \mathrm{CH}_{3}$ ), 1.73 (q, $J=7.5 \mathrm{~Hz}, 6 \mathrm{H}, \mathrm{CH}_{2} \mathrm{CH}_{3}$ ), 2.47 (s, $9 \mathrm{H}, \mathrm{NCH}_{3}$ ), 2.43 (b t, $6 \mathrm{H}, \mathrm{N}_{-}-\mathrm{CH}_{2} \mathrm{CH}_{2}-\mathrm{O}$ ), 3.65 (t, $J=5.7$ $\left.\mathrm{Hz}, 6 \mathrm{H}, \mathrm{N}-\mathrm{CH}_{2} \mathrm{CH}_{2}-\mathrm{O}\right), 6.36$ (s, $\left.1 \mathrm{H}, \mathrm{CH}\right), 6.99$ (b, $\left.3 \mathrm{H}, \mathrm{Ar}-\mathrm{H}\right), 7.05$ (b, $\left.3 \mathrm{H}, \mathrm{Ar}-\mathrm{H}\right) .{ }^{13} \mathrm{C} \mathrm{NMR}$ $\left(\mathrm{CDCl}_{3}\right): \delta=9.3,9.7,28.8,29.7,35.35,36.9,37.1,37.8,39.3$ (aliphatic); $52.2\left(\mathrm{~N}^{\left.-\mathrm{CH}_{2}\right)}\right) 71.7(\mathrm{O}-$ $\left.\mathrm{CH}_{2}\right) ; 124.9,127.9,138.0,139.8,142.6,153.4$ (aromatic). LSI MS: $\mathrm{m} / \mathrm{z}=884.76[\mathrm{M}+\mathrm{H}]^{+}$.

Methyl amine-2. To a stirring solution of Ester amine-2 (7.0 g, $0.0069 \mathrm{~mol})$ in tetrahydrofuran $(500 \mathrm{~mL})$ at ice cold condition, lithium aluminium hydride (2.8 g, 0.074 moles) was slowly added. The reaction mixture was stirred at room temperature for 6 days. The reaction mixture was cooled to ice cold temperature and $1 \mathrm{M} \mathrm{NaOH}(50 \mathrm{~mL})$ was added and the stirring was continued for 15 minutes. Then water $(100 \mathrm{~mL})$ was added and the content was transferred to separating funnel and extracted with diethyl ether $(4 \times 50 \mathrm{~mL})$. The organic phase was washed with brine $(5 \times 20 \mathrm{~mL})$, dried over $\mathrm{MgSO}_{4}$ and evaporated to give $5.04 \mathrm{~g}(87 \%)$ of pure product. ${ }^{1} \mathrm{H} \mathrm{NMR}\left(\mathrm{CDCl}_{3}\right): \delta=1.18\left(\mathrm{~s}, \mathrm{CH}_{3}, 27 \mathrm{H}\right), 1.34\left(\mathrm{~s}, \mathrm{CH}_{3}, 27 \mathrm{H}\right), 1.95(\mathrm{t}, J=7.35 \mathrm{~Hz}, 6 \mathrm{H}, \mathrm{N}-$ $\mathrm{CH}_{2} \mathrm{CH}_{2} \mathrm{CH}_{2}-\mathrm{O}$ ), 2.43 (s, $9 \mathrm{H}, \mathrm{CH}_{3}$ ), 2.73 (t, $J=7.35 \mathrm{~Hz}, 6 \mathrm{H}, \mathrm{N}-\mathrm{CH}_{2} \mathrm{CH}_{2} \mathrm{CH}_{2}-\mathrm{O}$ ), 3.54 (t, $J=$ $\left.6.30 \mathrm{~Hz}, 6 \mathrm{H}, \mathrm{N}-\mathrm{CH}_{2} \mathrm{CH}_{2} \mathrm{CH}_{2}-\mathrm{O}\right), 6.36(\mathrm{~s}, 1 \mathrm{H}, \mathrm{CH}), 7.12-7.26(\mathrm{~m}, 6 \mathrm{H}, \mathrm{Ar}-\mathrm{H}) .{ }^{13} \mathrm{C} \mathrm{NMR}$ $\left(\mathrm{CDCl}_{3}\right): \delta=30.8$ 31.6, 31.7, 34.6, 35.6, 36.6, 38.8 (aliphatic); $49.3\left(\mathrm{~N}-\mathrm{CH}_{3}\right) ; 71.0\left(\mathrm{O}_{-} \mathrm{CH}_{2}\right)$; 122.6, 127.3, 138.0, 141.8, 144.3, 147.4, 153.9 (aromatic). FAB MS: $\mathrm{m} / \mathrm{z}=842.71[\mathrm{M}+\mathrm{H}]^{+}$.

Chlor amine-1. To a solution of the Methyl amine-1 (2.42 g, $2.74 \mathrm{mmol})$ and $\mathrm{K}_{2} \mathrm{CO}_{3}(4.50 \mathrm{~g}$, $32.56 \mathrm{mmol})$ in $\mathrm{CH}_{2} \mathrm{Cl}_{2}$ was added chloroacetyl chloride $(1.40 \mathrm{~mL}, 17.60 \mathrm{mmol})$, and the reaction mixture was refluxed for $18 \mathrm{~h}$. A second portion of chloroacetyl chloride $(0.70 \mathrm{ml}$, $8.80 \mathrm{mmol}$ ) was added and refluxed for an additional $20 \mathrm{~h}$. Subsequently, the solution was cooled down, and washed with $2 \mathrm{~N} \mathrm{NaOH}, \mathrm{H}_{2} \mathrm{O}$ and dried over $\mathrm{MgSO}_{4}$. The solvent was remover in vacuo, and the crude white solid was recrystallized from 
dichloromethane/hexamethyl-disiloxane to give $2.70(88 \%) \mathrm{g}$ of pure product. ${ }^{1} \mathrm{H}$ NMR $\left(\mathrm{CDCl}_{3}\right)$ as well as ${ }^{13} \mathrm{C}$ NMR $\left(\mathrm{CDCl}_{3}\right)$ spectra are very complicated. ${ }^{1} \mathrm{H}$ NMR $\left(\mathrm{CDCl}_{3}\right): \delta=0.51-0.60$ (m, $18 \mathrm{H}, \mathrm{CH}_{2} \mathrm{CH}_{3}$ ), 1.12 (b, $18 \mathrm{H}, \mathrm{CH}_{3}$ ), 1.30 (b, $18 \mathrm{H}, \mathrm{CH}_{3}$ ), 1.44 - 1.73 (b m, $12 \mathrm{H}$,

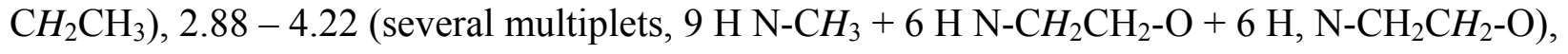
$4.06\left(\mathrm{~s}, 6 \mathrm{H}, \mathrm{CH}_{2}-\mathrm{Cl}\right), 6.33,6.38,6.43(\mathrm{~s}, 1 \mathrm{H}, \mathrm{CH}), 6.82-7.11(\mathrm{~m}, 6 \mathrm{H}, \mathrm{Ar}-\mathrm{H})$. LSI MS: m/z = $1112.67[\mathrm{M}+\mathrm{H}]^{+}$.

Chlor amine-2. To a solution of the Methyl amine-2 (3.00 g, $3.60 \mathrm{mmol})$ and $\mathrm{K}_{2} \mathrm{CO}_{3}(6.00 \mathrm{~g}$, $43.40 \mathrm{mmol})$ in $\mathrm{CH}_{2} \mathrm{Cl}_{2}(20 \mathrm{ml})$ was added chloroacetyl chloride (2.08 $\left.\mathrm{mL}, 26.15 \mathrm{mmol}\right)$, and the reaction mixture was heated at $45^{\circ} \mathrm{C}$ for $12 \mathrm{~h}$. A second portion of chloroacetyl chloride (1.04 $\mathrm{ml}, 13.07 \mathrm{mmol}$ ) was added and stirred for an additional $20 \mathrm{~h}$ at $45^{\circ} \mathrm{C}$. Subsequently, the solution was cooled down, and washed with $2 \mathrm{~N} \mathrm{NaOH}, \mathrm{H}_{2} \mathrm{O}$ and dried over $\mathrm{MgSO}_{4}$. The solvent was remover in vacuo to give $2.50 \mathrm{~g}(66 \%)$ of pure product. ${ }^{1} \mathrm{H}$ NMR $\left(\mathrm{CDCl}_{3}\right): \delta=1.18$ (s, $27 \mathrm{H}, \mathrm{CH}_{3}$ ), $1.36\left(\mathrm{~s}, 27 \mathrm{H}, \mathrm{CH}_{3}\right.$ ) $), 1.84-1.95\left(\mathrm{~m}, 6 \mathrm{H} \mathrm{O}-\mathrm{CH}_{2} \mathrm{CH}_{2} \mathrm{CH}_{2}-\mathrm{N}\right), 2.86-3.04$ (m, 9 $\left.\mathrm{H}, \mathrm{N}-\mathrm{CH}_{3}\right), 3.37-3.65$ (b m, $\left.6 \mathrm{H}, \mathrm{O}-\mathrm{CH}_{2} \mathrm{CH}_{2} \mathrm{CH}_{2}-\mathrm{N}+6 \mathrm{H}, \mathrm{CH}_{2}-\mathrm{Cl}\right), 4.04-4.10$ (m, $6 \mathrm{H}, \mathrm{O}-$ $\left.\mathrm{CH}_{2} \mathrm{CH}_{2} \mathrm{CH}_{2}-\mathrm{N}\right), 6.33(\mathrm{~s}, 1 \mathrm{H}, \mathrm{CH}), 7.20-7.11(\mathrm{~m}, 6 \mathrm{H}, \mathrm{Ar}-\mathrm{H}) .{ }^{13} \mathrm{C} \mathrm{NMR}\left(\mathrm{CDCl}_{3}\right): \delta=27.9$, 29.3, 31.6, 33.7, 34.6, 35.7, 39.1, 41.1, 41.8, 46.347 .9 (aliphatic); $70.4\left(\mathrm{OCH}_{2}\right) ; 122.6,127.5$, 137.9, 141.8, 144.9, 153.5 (aromatic) $166.2(\mathrm{C}=\mathrm{O})$. Anal. Calcd. for $\mathrm{C}_{61} \mathrm{H}_{94} \mathrm{Cl}_{3} \mathrm{~N}_{3} \mathrm{O}_{6}: \mathrm{C}, 68.36$; H, 8.84; N, 3.92; Found: C, 68.58; H, 8.31; N, 3.71. EI MS m/z $=1071.61[\mathrm{M}+\mathrm{H}]^{+}$.

Compound 11. Method A. The $2.50 \mathrm{~g}, 2.24 \mathrm{mmol}$ of starting material (Chlor amine-1) was dissolved in $9.00 \mathrm{ml}$ of ethyl diphenylphosphinite $(9.59 \mathrm{~g}, 41.65 \mathrm{mmol})$ while the temperature was gradually increased from 100 to $150^{\circ} \mathrm{C}$, and the mixture was stirred for $40 \mathrm{~h}$. Subsequently, the reaction mixture was cooled down to rt, and the diisopropyl ether was added till a white precipitate was formed. The solid was filtered and washed with diisopropyl ether to afford 3.08 g $(85 \%)$ of pure product. ${ }^{1} \mathrm{H}$ NMR $\left(\mathrm{CDCl}_{3}\right)$ as well as ${ }^{13} \mathrm{C}$ NMR $\left(\mathrm{CDCl}_{3}\right)$ spectra are very complicated. ${ }^{1} \mathrm{H} \mathrm{NMR}\left(\mathrm{CDCl}_{3}\right): \delta=0.44-0.53\left(\mathrm{~m}, 18 \mathrm{H}, \mathrm{CH}_{2} \mathrm{CH}_{3}\right), 1.04\left(\mathrm{~s}, 9 \mathrm{H}, \mathrm{CH}_{3},\right), 1.09$ (s, $9 \mathrm{H}, \mathrm{CH}_{3}$ ), [these two singlets merge into one $\delta=1.8$ at $55 \mathrm{C}$ ], $1.21\left(\mathrm{~s}, 9 \mathrm{H}, \mathrm{CH}_{3},\right), 1.27(\mathrm{~s}, 9 \mathrm{H}$, $\mathrm{CH}_{3}$ ), [these two singlets merge into one $\delta=1.25$ at $55 \mathrm{C}$ ], $1.42\left(\mathrm{~b} \mathrm{~m}, 6 \mathrm{H}, \mathrm{CH}_{3}\right.$,), $1.62(\mathrm{~b} \mathrm{~m}, 6$ $\mathrm{H}, \mathrm{CH}_{3}$,), $2.66-3.69$ (several multiplets, $9 \mathrm{H}, \mathrm{N}-\mathrm{CH}_{3}+6 \mathrm{H} \mathrm{N}-\mathrm{CH}_{2} \mathrm{CH}_{2}-\mathrm{O}+6 \mathrm{H}, \mathrm{N}-\mathrm{CH}_{2} \mathrm{CH}_{2}-\mathrm{O}$ ), 6.21, 6.26, 6.32 (s, 1 H, CH), 6.83 - 7.02 (m, 6 H, Ar-H), 7.44 - 7.53 (m, 18 H, P-Ar H), 7.84 - 
$7.90(\mathrm{~m}, 18 \mathrm{H}, \mathrm{P}-\mathrm{Ar} H)$. ESI FT -ICR MS m/z $=827.94[\mathrm{M}+2 \mathrm{Na}]^{2+}, \mathrm{m} / \mathrm{z}=1632.89[\mathrm{M}+\mathrm{Na}]^{+}$. Anal. Calcd. for $\mathrm{C}_{100} \mathrm{H}_{130} \mathrm{~N}_{3} \mathrm{O}_{9} \mathrm{P}_{3}$ : C, 74.55; H, 8.13; N, 2.61; Found: C, 74.34; H, 8.44; N, 2.61 . Slow diffusion of pentane into solution of $\mathbf{1 1}$ in diethyl ether/dichloromethane afforded crystals suitable for X-ray analysis. Method B. A solution of secondary amine $(0.47 \mathrm{~g}, 0.53 \mathrm{mmol})$ and p-nitrophenyl (diphenylphosphoryl)acetate $(1.10 \mathrm{~g}, 2.88 \mathrm{mmol})$ in dichloromethane, was stirred for 2 weeks at room temperature. Subsequently solution was treated with $1 \mathrm{M} \mathrm{NaOH}$ and stirred for additional 2 hours. The p-nitrophenol salt was extracted from organic phase using 5\% sodium carbonate. Organic phase was dried over $\mathrm{MgSO}_{4}$, filtered and the solvent removed in vacuo. The crude product was criticized by diffusion of pentane into solution of product in diethyl ether/dichloromethane; yield $0.60 \mathrm{~g}(70 \%)$.

Compound 12 Method A. The $0.50 \mathrm{~g}, 0.47 \mathrm{mmol}$ of starting material (Chlor amine-2) was suspended in $1.00 \mathrm{ml}$ of ethyl diphenylphosphinite $(4.20 \mathrm{mmol})$ while the temperature was gradually increased from 100 to $150{ }^{\circ} \mathrm{C}$. Within first $3 \mathrm{~h}$ of reaction, every 20 minutes the mixture was exposed for few seconds to the vacuum. The reaction mixture was stirred at $150{ }^{\circ} \mathrm{C}$ for additional $20 \mathrm{~h}$. Subsequently it was cooled down to room temperature and the diethyl ether was added till a white precipitate was formed. The solid was filtered and redissolved in diisopropyl ether to give pure product upon crystallization. Yield $0.42 \mathrm{~g}(57 \%)$. ${ }^{1} \mathrm{H}$ NMR $\left(\mathrm{CDCl}_{3}\right)$ as well as ${ }^{13} \mathrm{C} \mathrm{NMR}\left(\mathrm{CDCl}_{3}\right)$ spectra are very complicated. ${ }^{1} \mathrm{H} \mathrm{NMR}\left(\mathrm{CDCl}_{3}\right): \delta=1.15$ (s, $27 \mathrm{H}, \mathrm{CH}_{3}$,), 1.27 (s, $27 \mathrm{H}, \mathrm{CH}_{3}$,), $1.78-1.95$ (m, $\left.6 \mathrm{H}, \mathrm{N}-\mathrm{CH}_{2} \mathrm{CH}_{2} \mathrm{CH}_{2}-\mathrm{O}\right), 2.66-3.55$ (several multiplets, $27 \mathrm{H}: 9 \mathrm{H} \mathrm{N}-\mathrm{CH}_{3}+6 \mathrm{H} \mathrm{N}-\mathrm{CH}_{2} \mathrm{CH}_{2} \mathrm{CH}_{2}-\mathrm{O}+6 \mathrm{H}, \mathrm{N}_{-} \mathrm{CH}_{2} \mathrm{CH}_{2} \mathrm{CH}_{2}-\mathrm{O}$ ), 6.24 (b s, 1 H, CH), 6.93 (b s, 2 H, Ar-H), 7.06 (b s, 2 H, Ar-H), 7.38 (m, 18 H, P-Ar H), 7.74 (m, 12 H, P-Ar H). ${ }^{13} \mathrm{C} \mathrm{NMR}\left(\mathrm{CDCl}_{3}\right) \delta=27.9,29.4,31.5,33.9,34.5,35.5,36.9,37.7,38.6,38.9,46.0$, 48.3 (aliphatic); $70.6\left(\mathrm{O}-\mathrm{CH}_{2}\right) ; 122.3,127.2$, 128.6, 128.7, 131.2, 131.3, 132.1, 133.3, 137.7 , 141.7, 144.5, 144.7, 153.5 (aromatic); $164.8(\mathrm{C}=\mathrm{O})$. ${ }^{31} \mathrm{P} \mathrm{NMR}\left(\mathrm{CDCl}_{3}\right) \delta=29.4,29.3$. EI MS $\mathrm{m} / \mathrm{z}=1567.86[\mathrm{M}+\mathrm{H}]^{+}$. Method B. A solution of secondary amine (2.00 g, $\left.2.40 \mathrm{mmol}\right)$, pnitrophenyl (diphenylphosphoryl)acetate $\left(4.50 \mathrm{~g}, 11.80 \mathrm{mmol}\right.$ ) and $1 \mathrm{ml} \mathrm{of} \mathrm{Et}_{3} \mathrm{~N}$ in chloroform, was stirred for 5 days at $45-50^{\circ} \mathrm{C}$. After cooling down to the rt solution was treated with $1 \mathrm{M}$ $\mathrm{NaOH}$ and stirred for additional 2 hours. The p-nitrophenol salt was extracted from organic phase using 5\% sodium carbonate. Organic phase was dried over $\mathrm{MgSO}_{4}$, filtered and the 
solvent removed in vacuo. The crude product was washed with diethyl ether and dried yielding $2.50 \mathrm{~g}(67 \%)$ of clean product.

Tb-complex of 8a $\left[\mathbf{8 a} \cdot \mathrm{TbNO}_{3}\right]\left(\mathrm{NO}_{3}\right)_{2}$ To a solution of $\mathbf{8 a}(0.200 \mathrm{~g}, 0.127 \mathrm{mmol})$ in acetonitrile (8mL), $\mathrm{Tb}\left(\mathrm{NO}_{3}\right)_{3} \cdot 6 \mathrm{H}_{2} \mathrm{O}(0.058 \mathrm{~g}, 0.128 \mathrm{mmol})$ in methylene chloride $(4.5 \mathrm{~mL})$ was added and reaction mixture was stirred overnight at room temperature resulting in a white solid. The complex was isolated by filtration, washed with acetonitrile and dried. Yield $0.180 \mathrm{~g} \mathrm{(74 \% ).}$ Anal. Calcd for $\mathrm{C}_{97} \mathrm{H}_{124} \mathrm{~N}_{6} \mathrm{O}_{18} \mathrm{P}_{3} \mathrm{~Tb}$ : C, 60.87; H, 6.53; N, 4.39. Found: C, 60.91; H, 6.66; N, 4.27. Slow diffusion of ether into a concentrated solution of the complex in methanol, afforded crystals suitable for structural analysis.

Tb-complex of $11\left[11 \cdot \mathrm{TbNO}_{3}\right]\left(\mathrm{NO}_{3}\right)_{2}$ A solution of $\mathrm{Tb}\left(\mathrm{NO}_{3}\right)_{3} \cdot 6 \mathrm{H} 2 \mathrm{O}(0.028 \mathrm{~g}, 0.062 \mathrm{mmol})$ in 1 $\mathrm{ml}$ of methanol was added to a solution of $16 \mathbf{a}(0.100 \mathrm{~g}, 0.062 \mathrm{mmol})$ in methanol $(1 \mathrm{~mL})$, and reaction mixture was stirred for one hour at room temperature. A white precipitate formed within minutes, and the product was collected by filtration, washed with cold methanol, and dried to obtain $0.080 \mathrm{~g}(62 \%)$ of product. ESI FT -ICR MS m/z $=915.40\left[\mathbf{1 6 a} \cdot \mathrm{TbNO}_{3}\right]^{2+}$. Slow diffusion of ether into a concentrated solution of the complex in mixture of methanol and dichloromethane afforded crystals suitable for structural analysis.

Bi-complex of 8c $\left[\mathbf{8 c} \cdot \mathrm{BiNO}_{3}\right]\left(\mathrm{NO}_{3}\right)_{2}$ A solution of $\mathrm{Bi}\left(\mathrm{NO}_{3}\right)_{3} \cdot 5 \mathrm{H}_{2} \mathrm{O}(0.058 \mathrm{~g}, 0.12 \mathrm{mmol})$ in $8 \mathrm{~mL}$ of 1:1 mixture of acetonitrile and methanol was added to a solution of $8 \mathrm{c}(0.08 \mathrm{~g}, 0.06 \mathrm{mmol})$ in $2 \mathrm{~mL}$ of methanol, and the mixture was stirred for 1 hour. Part of solvent was evaporated in-

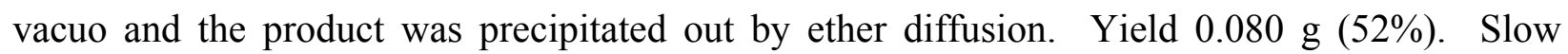
diffusion of ether into a saturated acetonitrile/methanol solution of $\left[\mathbf{8 c} \cdot \mathrm{Bi}\left(\mathrm{NO}_{3}\right)\right]\left(\mathrm{NO}_{3}\right)_{2}$ afforded crystals suitable for structural analysis. ${ }^{1} \mathrm{H}$ NMR $\left(\mathrm{CD}_{3} \mathrm{CD}\right), 55^{\circ} \mathrm{C}: \mathrm{\delta}=1.15$ (s, $27 \mathrm{H}$; Ar$\left.\mathrm{C}\left(\mathrm{CH}_{3}\right)_{3}\right), 2.14$ (s, $\left.9 \mathrm{H} ; \mathrm{Ar}-\mathrm{CH}_{3}\right), 3.17$ (b, 12H; 3.96 Ar-O-CH$\left.{ }_{2} \mathrm{CH}_{2}\right), 6.74$ (s, $\left.1 \mathrm{H} ; \mathrm{C}-\mathrm{H}\right), 7.00$ (d, $J=2.05 \mathrm{~Hz}, 3 \mathrm{H} ; \operatorname{Ar} H), 7.10(\mathrm{~d}, J=2.56 \mathrm{~Hz}, 3 \mathrm{H} ; \operatorname{Ar} H), 7.49$ (m, $12 \mathrm{H}$; P-Ar H), 7.62 (m, $6 \mathrm{H}$; P-Ar H), 7.74 (m, 12 H; P-Ar H), 7.86 (s, $3 \mathrm{H} ; \mathrm{N}-\mathrm{H}) .{ }^{31} \mathrm{P}$ NMR $\left(\mathrm{CDCl}_{3}\right)$ : = 39.66. HR ESI-ICR MS (sample injected as solution in $1 \% \mathrm{HNO}_{3} / \mathrm{MeOH}$ ): $\mathrm{m} / \mathrm{z}=814.29\left[\mathbf{8 c} \cdot \mathrm{Bi}\left(\mathrm{NO}_{3}\right)\right]^{2+}$ and $\mathrm{m} / \mathrm{z}$ $=1691.56 \quad\left[\mathbf{8 c} \cdot \mathrm{Bi}\left(\mathrm{NO}_{3}\right)_{2}\right]^{+} . \quad$ Anal. Cald for $\left\{\left[\mathbf{8 c} \cdot \mathrm{Bi}\left(\mathrm{NO}_{3}\right) \quad \cdot \mathrm{MeOH} \cdot 2 \mathrm{H}_{2} \mathrm{O}\right]\left[\mathrm{NO}_{3}\right]_{2}\right\}$ $\mathrm{C}_{83} \mathrm{H}_{102} \mathrm{BiN}_{6} \mathrm{O}_{21} \mathrm{P}_{3}$ : C 54.73; H 5.64; N 4.61; Found: C, 54.54; H, 5.32; N, 4.92. 
Diamide Ligands 15-19

(I) 1,4-dioxane, pyridine

(II) $\mathrm{X}=\mathrm{S}$, O: PyBOP, diisopropylethylamine, DMF
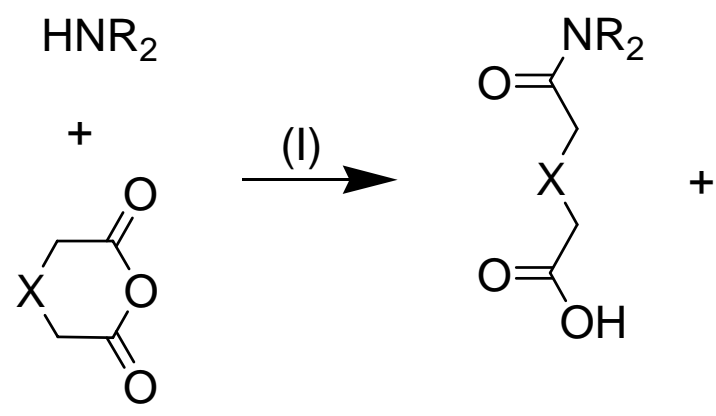

$$
\begin{array}{ll}
\text { L2 } X=O, R={ }^{\mathrm{i} P r} & \\
\text { L3 } X=O, R=\mathrm{Bu} & \text { Pa } \mathrm{n}=1 \\
\text { L4 X }=\mathrm{S}, \mathrm{R}=\mathrm{i}^{\mathrm{P} P} & \text { Pb } \mathrm{n}=2
\end{array}
$$<smiles>[X]CC([R20])=O</smiles>

(II)

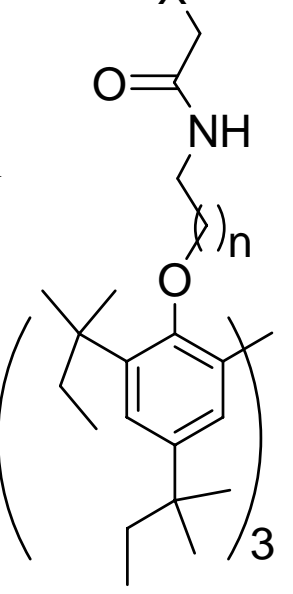

$15 \mathrm{R}={ }^{\mathrm{i}} \mathrm{Pr}, \mathrm{X}=\mathrm{O}, \mathrm{n}=1$

$17 \mathrm{R}={ }^{\mathrm{i}} \mathrm{Pr}, \mathrm{X}=\mathrm{O}, \mathrm{n}=2$

$18 \mathrm{R}=\mathrm{Bu}, \mathrm{X}=\mathrm{O}, \mathrm{n}=1$

$19 \mathrm{R}={ }^{\mathrm{i}} \mathrm{Pr}, \mathrm{X}=\mathrm{S}, \mathrm{n}=1$

The lanthanide and actinide salts were used as received. The solutions were prepared from $18 \mathrm{M} \Omega$ Millipore deionized water, TraceMetal grade $\mathrm{HNO}_{3}$ (Fisher Scientific), and freshly distilled organic solvents. A Varian Cary $50 \mathrm{UV} / \mathrm{Vis}$ spectrophotometer was used for the Arsenazo(III) assays. Elemental analyses were performed at the in-house facility of Department of Chemistry at University of Florida. The ${ }^{1} \mathrm{H},{ }^{13} \mathrm{C}$, and spectra were recorded on a Varian VXR300 or Mercury-300 spectrometer at 299.95 and $75.4 \mathrm{MHz}$ for the proton and carbon channels respectively. Mass spectrometry samples were analyzed on a Bruker Apex II 4.7T Fourier transform ion cyclotron resonance mass spectrometer.

\section{${ }^{1}$ H NMR experiment}

Equal volumes of $10^{-2} \mathrm{M}$ solutions of $\mathrm{Lu}\left(\mathrm{NO}_{3}\right)_{3}$ in $1 \mathrm{M}$ nitric acid and Tris-DGA (15) in D2-dichloromethane were mixed for $2 \mathrm{~h}$. The second portion of the same $10^{-2} \mathrm{M}$ solution of $\mathbf{1 5}$ in D2-dichloromethane was mixed with $1 \mathrm{M}$ nitric acid. After phase separation, the organic layers were analyzed in the ${ }^{1} \mathrm{H}$ NMR experiment. Another NMR sample of the $\mathrm{Lu}(\mathrm{III})$ complex with 
15 was synthesized directly in the deuterated solvent. The $10^{-5}$ mol of $\mathrm{Lu}\left(\mathrm{NO}_{3}\right)_{3} \cdot 5 \mathrm{H}_{2} \mathrm{O}$ salt was stirred with $1 \mathrm{ml}$ of the $10^{-2} \mathrm{M}$ solution of $\mathbf{1 5}$ in D2-dichloromethane for $2 \mathrm{~h}$. Even though the complex partially precipitated from the solution, the concentration of the sample was sufficient for the NMR analysis.

\section{Extractions conditions}

The extraction experiments were performed on a series of eleven lanthanides, ${ }^{152} \mathrm{Eu}$, and ${ }^{241} \mathrm{Am}$ radioisotopes. Solutions of $10^{-4} \mathrm{M}$ metal nitrates in $1 \mathrm{M}$ nitric acid were mixed with equal volumes of $10^{-3}$ and $10^{-4} \mathrm{M}$ organic solutions for approximately $20 \mathrm{~h}$. The concentration of lanthanide ions in the aqueous phase before and after the extraction were determined spectrophotometrically $(\lambda=655 \mathrm{~nm})$, or in the case of ${ }^{241} \mathrm{Am}$ and ${ }^{152} \mathrm{Eu}$, they were measured by a Canberra GammaTrac 1185 with $\mathrm{Ge}(\mathrm{Li})$ detector and AccuSpec-B multi-channel analyzer. Extraction efficiencies were calculated using the formula: $\% \mathrm{E}=100 \%\left(\mathrm{~A}_{1}-\mathrm{A}\right) /\left(\mathrm{A}_{1}-\mathrm{A}_{0}\right)$, where $\mathrm{A}$ is the absorbance of the extracted aqueous phase with the Arsenazo(III) indicator, $\mathrm{A}_{1}$ is the absorbance of the aqueous phase before extraction with the indicator, and $A_{0}$ is the absorbance of metal-free $1 \mathrm{M}$ nitric acid and the indicator. The errors, based on the precision of the spectrophotometer and the standard deviation from the mean of at least three measurements, were in most cases no higher than two percent. The extraction percentage was further converted into distribution ratios of the total metal ion concentration in the organic phase against the total metal ion concentration in the aqueous phase $\left(D=\Sigma\left[\mathrm{M}_{\mathrm{org}}\right] / \Sigma\left[\mathrm{M}_{\mathrm{aq}}\right]\right)$ and in view of the errors associated with the spectrophotometric technique, the maximum value that could be measured for the extraction percentage and distribution ratio was 99 .

\section{Synthetic Procedures}

The tris-thio/diglycolamides (15, 17 and 19) have been prepared by the reaction of primary amines $\mathbf{P a}$ or $\mathbf{P b}$ with mono-substituted oxa/thio-pentaneamides (L2, L3 or L4) and with the coupling agent benzotriazole-1-yl-oxy-trispyrrolidinophosphonium hexafluorophosphate (PyBOP) as illustrated in Scheme 1. All final products have been obtained in high yields and purity with relatively small synthetic effort. The synthetic procedures for $\mathbf{L 2}$, L3 and $\mathbf{L} \mathbf{4}$ have been prepared following literature methods. ${ }^{53,65,83}$ 
[(Diisopropylcarbamoyl)-methoxy]-acetic acid L2. A mixture of $6.09 \mathrm{ml}(0.043 \mathrm{~mol})$ of diisopropyl amine and $3.50 \mathrm{ml}(0.043)$ of pyridine was slowly added to a solution of $5.15 \mathrm{~g}$ ( $0.043 \mathrm{~mol})$ of diglycolic anhydride in $40 \mathrm{ml}$ of 1, 4-dioxane, under an ice bath condition. After stirring the reaction mixture for approximately $20 \mathrm{~h}$ at room temperature, solvent was evaporated under reduced pressure, and $6 \mathrm{M}$ hydrochloric acid was added. The organic phase was further extracted with dichloromethane, dried over magnesium sulfate, and partially evaporated. Clean product crystallized upon slow solvent evaporation. Yield: $4.5 \mathrm{~g}(48 \%)$. ${ }^{1} \mathrm{H} \mathrm{NMR}\left(\mathrm{CDCl}_{3}\right): \delta=$ $1.26\left(\mathrm{~d}, J=6.7 \mathrm{~Hz}, 6 \mathrm{H} ; \mathrm{NCHCH}_{3}\right.$ ), 1.38 (d, $J=6.9 \mathrm{~Hz}, 6 \mathrm{H} ; \mathrm{NCHCH}_{3}$ ), $3.40-3.63$ (two multiplets, $2 \mathrm{H} ; \mathrm{NCHCH}_{3}$ ), 4.10 (s, $\left.2 \mathrm{H} ; \mathrm{CH}_{2} \mathrm{CON}\right), 4.30$ (s, $\left.2 \mathrm{H} ; \mathrm{CH}_{2} \mathrm{COOH}\right) .{ }^{13} \mathrm{C} \mathrm{NMR}\left(\mathrm{CDCl}_{3}\right)$ :

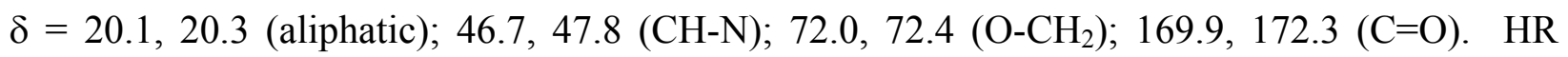
LSIMS $[\mathrm{M}+\mathrm{H}]^{+}=218.1392$, (Theoretical $\left.[\mathrm{M}+\mathrm{H}]^{+}=218.1392\right)$.

\section{2-[(Diisopropylcarbamoyl)-methoxy]-N,N-diisopropyl-acetamiden $16 . \quad$ A cold} solution of mono-substituted amide $(2.0 \mathrm{~g}, 9.20 \mathrm{mmol})$ in $40 \mathrm{ml}$ of dry dichloromethane was gradually treated with oxalyl chloride $(1.46 \mathrm{ml}, 18.40 \mathrm{mmol})$. After $4 \mathrm{~h}$ solvent was evaporated and the orange sticky residue was dissolved in $20 \mathrm{ml}$ of dioxane. Subsequently, $6.45 \mathrm{ml}$ (0.046 mol) of diisopropyl amine was slowly added to the solution, and stirred overnight at room temperature. The solvent was evaporated, and the residue was dissolved in a mixture of diethyl ether and pentane, extracted with $1 \mathrm{M}$ hydrochloric acid followed by the extraction with $1 \mathrm{M}$ sodium hydroxide, and died over magnesium sulfide. Pure product crystallized upon slow evaporation of solvent in $43 \%$ yield $(1.10 \mathrm{~g}) .{ }^{1} \mathrm{H} \mathrm{NMR}\left(\mathrm{CDCl}_{3}\right): \delta=1.18(\mathrm{~d}, J=6.4 \mathrm{~Hz}, 12 \mathrm{H}$; $\left.\mathrm{NCHCH}_{3}\right), 1.40$ (d, $\left.J=5.4 \mathrm{~Hz}, 12 \mathrm{H} ; \mathrm{NCHCH}_{3}\right), 3.44\left(\mathrm{~m}, 2 \mathrm{H} ; \mathrm{NCHCH}_{3}\right), 3.90(\mathrm{~m}, 2 \mathrm{H}$; $\left.\mathrm{NCHCH}_{3}\right), 4.22\left(\mathrm{~s}, 4 \mathrm{H} ; \mathrm{OCH}_{2}\right) .{ }^{13} \mathrm{C} \mathrm{NMR}\left(\mathrm{CDCl}_{3}\right): \delta=20.2,20.5\left(\mathrm{CH}_{3}\right) ; 46.0,48.0(\mathrm{CH}-\mathrm{NH})$; $70.4\left(\mathrm{O}-\mathrm{CH}_{2}\right) ; 168.1(\mathrm{C}=\mathrm{O})$. HR LSIMS m/z $[\mathrm{M}+\mathrm{H}]^{+}=301.2487$, (Theoretical m/z $[\mathrm{M}+\mathrm{H}]^{+}=$ 301.2491).

Compound 15. Method I. To a mixture of $0.85 \mathrm{~g}(7.12 \mathrm{mmol})$ of 2-mercaptothiazoline, DCC $(1.47 \mathrm{~g}, 7.12 \mathrm{mmol})$ and DMAP $(0.11,0.89 \mathrm{mmol})$ in $60 \mathrm{ml}$ of dichloromethane (DCM), $1.55 \mathrm{~g}(7.12 \mathrm{mmol})$ of mono-substituted oxa-pentaneamide $\mathbf{L} 2$ was added and stirred for $5 \mathrm{~h}$. Subsequently, $1.50 \mathrm{~g}$ ( $1.78 \mathrm{mmol})$ of amine Pa dissolved in $10 \mathrm{ml}$ of DCM was added dropwise, and the solution was stirred for $48 \mathrm{~h}$. White precipitate was filtered away, and solvent was 
evaporated in vacuo. The residue was treated with diethyl ether followed by addition of pentane. The crashed out solid was filtered away and remaining solution of product was evaporated. The crude material was dissolved in mixture of DCM and hexamethyldisiloxane and left for crystallization. Yield: $1.50 \mathrm{~g}(59 \%)$. ${ }^{1} \mathrm{H} \mathrm{NMR}\left(\mathrm{CDCl}_{3}\right): \delta=0.52\left(\mathrm{~m}, 18 \mathrm{H} ; \mathrm{CH}_{2} \mathrm{CH}_{3}\right), 1.13$ (s, $\left.18 \mathrm{H} ; \mathrm{CCH}_{3}\right), 1.20$ (d, $\left.J=5.9 \mathrm{~Hz}, 18 \mathrm{H} ; \mathrm{NCHCH}_{3}\right), 1.31$ (s, $\left.18 \mathrm{H} ; \mathrm{CCH}_{3}\right), 1.39$ (d, $J=6.1 \mathrm{~Hz}$, $18 \mathrm{H} ; \mathrm{NCHCH}_{3}$ ), $1.20-1.70$ (two broad multiplets, $6 \mathrm{H}+6 \mathrm{H} ; \mathrm{CH}_{2} \mathrm{CH}_{3}$ ), $3.20-3.90$ (broad multiplets: $\left.6 \mathrm{H}, \mathrm{CH}_{2} \mathrm{CH}_{2}-\mathrm{NH}_{2} ; 6 \mathrm{H}, \mathrm{NCHCH}_{3} ; 6 \mathrm{H}, \mathrm{O}-\mathrm{CH}_{2} \mathrm{CH}_{2}\right), 4.10$ (s, $\left.6 \mathrm{H} ; \mathrm{OCH}_{2}\right), 4.22(\mathrm{~s}, 6 \mathrm{H}$;

$\mathrm{OCH}_{2}$ ), 6.43 (s, 1H; CH), 7.02 (s, $\left.3 \mathrm{H} ; \mathrm{Ar}-\mathrm{H}\right), 7.11$ (s, $\left.3 \mathrm{H} ; \mathrm{Ar}-\mathrm{H}\right), 7.89$ (bt, $\left.3 \mathrm{H} ; \mathrm{N}-\mathrm{H}\right) .{ }^{13} \mathrm{C}$ NMR $\left(\mathrm{CDCl}_{3}\right): \delta=9.2,9.7,20.6,21.0,28.9,29.7,35.4,37.0,37.7,38.6,39.3,39.5,46.2,47.8$ (aliphatic); 70.2, $71.1\left(\mathrm{O}_{-} \mathrm{CH}_{2}\right) ; 125.0,127.9,137.8,139.9,142.9,153.0$ (aromatic); 167.6, 170.2 $(\mathrm{C}=\mathrm{O})$. HR ESI-ICR MS $[\mathrm{M}+\mathrm{K}+\mathrm{H}]^{2+}=739.5151$, (Theoretical $\left.\mathrm{m} / \mathrm{z}[\mathrm{M}+\mathrm{K}+\mathrm{H}]^{2+}=739.5200\right)$. Anal. Found: $\mathrm{C}, 71.3 ; \mathrm{H}, 10.2 ; \mathrm{N}, 5.7$. Calc. for $\mathrm{C}_{85} \mathrm{H}_{142} \mathrm{~N}_{6} \mathrm{O}_{12}$ : C, 70.9; H, 9.9; N, $5.8 \%$.

\section{General procedure for preparation of compounds 15 and 17. Method II.}

A mixture of 1.0 equivalent of mono-substituted amide (L2), 2.0 eq. of ethyl-diisopropylamine, and 1.1 eq. PyBOP (Benzotriazole-1-yl-oxy-trispyrrolidinophosphonium hexafluorophosphate) was stirred in DMF for approximately $30 \mathrm{~min}$. Subsequently, 0.3 eq. of amine (Pa or $\mathbf{P b}$ ) was added and stirred for 48h. Upon following treatment with $10 \%$ hydrochloric acid, white solid crashed out of solution. A precipitate was extracted with diethyl ether, and the organic solution was further washed with $0.5 \mathrm{M}$ sodium hydroxide, and dried over magnesium sulfide. A solvent was evaporated under reduced pressure leaving clean light yellowish product in $73 \%$ yield for both compounds.

N,N-diisopropyl-2-(2-oxoethylthio)acetamide (L4). The methodology for the preparation of $\mathbf{L} \mathbf{4}$ followed the synthetic pathways reported for $\mathbf{L} 2$ and $\mathbf{L} 3$. A mixture of $3.54 \mathrm{ml}$ $(0.025 \mathrm{~mol})$ of diisopropyl amine and $1.00 \mathrm{ml}(0.180 \mathrm{~mol})$ of pyridine was slowly added to a solution of $3.00 \mathrm{~g}(0.023 \mathrm{~mol})$ of 1,4-oxathiane-2,6-dione in $40 \mathrm{ml}$ of 1, 4-dioxane, under an ice bath condition. After stirring the reaction mixture for approximately $20 \mathrm{~h}$ at room temperature, the solvent was evaporated under reduced pressure, and $3 \mathrm{M}$ hydrochloric acid was added. The organic phase was further extracted with chloroform, dried over magnesium sulfate, and partially evaporated. The product crystallized upon slow evaporation of the solvent to afford $1.50 \mathrm{~g}$ (30\%) of product. ${ }^{1} \mathrm{H} \mathrm{NMR}\left(\mathrm{CDCl}_{3}\right): \delta=1.12\left(\mathrm{~d}, J=6.7 \mathrm{~Hz}, 6 \mathrm{H} ; \mathrm{NCHCH}_{3}\right), 1.26(\mathrm{~d}, J=6.9 \mathrm{~Hz}$, 
$\left.6 \mathrm{H} ; \mathrm{NCHCH}_{3}\right), 3.25$ (s, $2 \mathrm{H} ; \mathrm{CH}_{2} \mathrm{CON}$ ), 3.37 (m, $\left.1 \mathrm{H} ; \mathrm{NCHCH}_{3}\right), 3.42$ (s, $\left.2 \mathrm{H} ; \mathrm{CH}_{2} \mathrm{COOH}\right), 3.89$ $\left(\mathrm{m}, 1 \mathrm{H} ; \mathrm{NCHCH}_{3}\right) .{ }^{13} \mathrm{C} \mathrm{NMR}\left(\mathrm{CDCl}_{3}\right): \delta=20.1,20.4,33.5,34.5,46.4,50.1$ (aliphatic); 168.8, $171.6(\mathrm{C}=\mathrm{O})$. HR LSIMS $[\mathrm{M}+\mathrm{H}]^{+}=234.1172$, (Theoretical LSIMS $\left.[\mathrm{M}+\mathrm{H}]^{+}=234.1143\right)$.

Compound 18. A mixture of mono-substituted amide (L3) (1.46 g, 5.95 mmol), ethyldiisopropyl-amine (1.96 ml, $11.84 \mathrm{mmol}$ ), and PyBOP (3.90 g, $7.49 \mathrm{mmol})$ was stirred in $40 \mathrm{ml}$ of DMF for approximately $30 \mathrm{~min}$. Subsequently, $1.50 \mathrm{~g}(1.78 \mathrm{mmol})$ of amine $(\mathbf{P a})$ was added and stirred for $48 \mathrm{~h}$. Upon treatment with 10\% hydrochloric acid, a white solid of precipitated from the solution. The solid was extracted with diethyl ether, and the organic solution was further washed with $0.5 \mathrm{M}$ sodium hydroxide, and dried over magnesium sulfate. The solvent was evaporated under reduced pressure to yield $2.00 \mathrm{~g}(74 \%)$ of product. ${ }^{1} \mathrm{H} \mathrm{NMR}\left(\mathrm{CDCl}_{3}\right): \delta=$ 0.47 (m, $18 \mathrm{H} ; \mathrm{CH}_{2} \mathrm{CH}_{3}$ ), $0.80-1.70$ (signals: $18 \mathrm{H}, \mathrm{NCH}_{2} \mathrm{CH}_{2} \mathrm{CH}_{2} \mathrm{CH}_{3} ; 18 \mathrm{H}+18 \mathrm{H}, \mathrm{CCH}_{3} ; 12 \mathrm{H}$, $\left.\mathrm{NCH}_{2} \mathrm{CH}_{2} \mathrm{CH}_{2} \mathrm{CH}_{3} ; 12 \mathrm{H}, \mathrm{NCH}_{2} \mathrm{CH}_{2} \mathrm{CH}_{2} \mathrm{CH}_{3} ; 6 \mathrm{H}+6 \mathrm{H}, \mathrm{CH}_{2} \mathrm{CH}_{3}\right), 3.12$ (t, $J=7.4 \mathrm{~Hz}, 6 \mathrm{H}$, $\mathrm{NCH}_{2} \mathrm{CH}_{2} \mathrm{CH}_{2} \mathrm{CH}_{3}$ ), 3.27 (t: $J=7.2 \mathrm{~Hz}, 6 \mathrm{H}, \mathrm{NCH}_{2} \mathrm{CH}_{2} \mathrm{CH}_{2} \mathrm{CH}_{3}$ ), $3.10-3.80$ (broad signals: $6 \mathrm{H}$, $\left.\mathrm{CH}_{2} \mathrm{CH}_{2}-\mathrm{NH}_{2} ; 6 \mathrm{H}, \mathrm{O}-\mathrm{CH}_{2} \mathrm{CH}_{2}\right), 4.06\left(\mathrm{~s}, 6 \mathrm{H} ; \mathrm{OCH}_{2}\right), 4.24\left(\mathrm{~s}, 6 \mathrm{H} ; \mathrm{OCH}_{2}\right), 6.37(\mathrm{~s}, 1 \mathrm{H} ; \mathrm{CH}), 6.98$ (s, $3 \mathrm{H}$; Ar- $H$ ), 7.06 (s, $3 \mathrm{H}$; Ar- $H$ ), $7.86(\mathrm{t}, J=5.7 \mathrm{~Hz}, 3 \mathrm{H} ; \mathrm{N}-H) .{ }^{13} \mathrm{C} \mathrm{NMR}\left(\mathrm{CDCl}_{3}\right): \delta=9.3$, 9.7, 13.9, 14.0, 20.2, 20.4, 29.7, 29.9, 31.2, 35.4, 37.0, 37.8, 38.6, 39.2, 39.5 (aliphatic); 45.8, 46.7, 69.8, $70.3\left(\mathrm{O}-\mathrm{CH}_{2}-\mathrm{CO}\right) ; 71.4\left(\mathrm{O}-\mathrm{CH}_{2}\right) ; 124.9,127.8,137.8,139.9,142.8,153.1$ (aromatic),

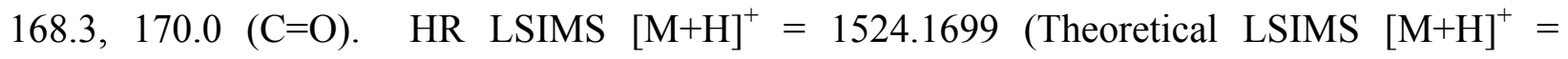
1524.1703). Anal. Calcd for $\mathrm{C}_{91} \mathrm{H}_{154} \mathrm{~N}_{6} \mathrm{O}_{12}: \mathrm{C}, 71.71 ; \mathrm{H}, 10.18 ; \mathrm{N}, 5.51$. Found: $\mathrm{C}, 71.99 ; \mathrm{H}$, $10.35 ; \mathrm{N}, 5.45$

Compound 17. A mixture of mono-substituted amide L2 (1.27 g, $5.87 \mathrm{mmol})$, ethyldiisopropyl-amine (1.94 ml, 11.730mmol), and PyBOP (4.35 g, 6.45mmol) was stirred in $40 \mathrm{ml}$ of DMF for approximately $30 \mathrm{~min}$. A $1.56 \mathrm{~g}(1.76 \mathrm{mmol})$ portion of amine $\mathbf{P b}$ was added and stirred for $48 \mathrm{~h}$. Upon treatment with $10 \%$ hydrochloric acid, a yellow solid precipitated from the solution. The solid was extracted with diethyl ether, and the organic solution was further washed with $0.5 \mathrm{M}$ sodium hydroxide, and dried over magnesium sulfate. The solvent was evaporated under reduced pressure leaving $1.90 \mathrm{~g}$ (73\%) of clean, light yellow product. ${ }^{1} \mathrm{H}$ NMR $\left(\mathrm{CDCl}_{3}\right): \delta=0.51\left(\mathrm{~m}, 18 \mathrm{H} ; \mathrm{CH}_{2} \mathrm{CH}_{3}\right), 1.12\left(\mathrm{~s}, 18 \mathrm{H} ; \mathrm{CCH}_{3}\right), 1.19\left(\mathrm{~d}, J=6.7 \mathrm{~Hz}, 18 \mathrm{H} ; \mathrm{NCHCH}_{3}\right)$, $1.30\left(\mathrm{~s}, 18 \mathrm{H} ; \mathrm{CCH}_{3}\right), 1.38$ (d, $\left.J=6.7 \mathrm{~Hz}, 18 \mathrm{H} ; \mathrm{NCHCH}_{3}\right), 1.67$ (q, $J=7.6 \mathrm{~Hz}, 6 \mathrm{H} ; \mathrm{CH}_{2} \mathrm{CH}_{3}$ ), 
2,00 (b, $6 \mathrm{H} ; \mathrm{CH}_{2} \mathrm{CH}_{2} \mathrm{CH}_{2}$ ), 3.47 (broad multiplet: $18 \mathrm{H} ; \mathrm{O}_{-} \mathrm{CH}_{2} \mathrm{CH}_{2} \mathrm{CH}_{2}-\mathrm{NHCO}, 3 \mathrm{H} ; \mathrm{NCHCH}_{3}$ ), $3.77\left(\mathrm{~m}, 3 \mathrm{H} ; \mathrm{NCHCH}_{3}\right), 4.07$ (s, 6H; $\left.\mathrm{OCH}_{2}\right), 4.20$ (s, 6H; $\left.\mathrm{OCH}_{2}\right), 6.34$ (s, 1H; $\left.\mathrm{CH}\right), 6.99$ (d, J= $2.0 \mathrm{~Hz}, 3 \mathrm{H}$; Ar-H), 7.04 (d, J=2.0 Hz, $3 \mathrm{H} ; \mathrm{Ar}-H), 7.84$ (bt, $3 \mathrm{H} ; \mathrm{N}-H) .{ }^{13} \mathrm{C} \mathrm{NMR}\left(\mathrm{CDCl}_{3}\right): \delta=$ 9.2, 9.7, 20.6, 20.8, 28.7, 29.6, 30.5, 35.2, 36.8, 37.0, 37.7, 38.9, 39.2, 46.1, 47.7, 70.0, 70.9, 71.1 (aliphatic); 124.7, 127.9, 138.0, 139.7, 142.4, 153.4 (aromatic); 167.6, $169.9(\mathrm{C}=\mathrm{O})$. HR ESIICR MS m/z $[\mathrm{M}+\mathrm{H}+\mathrm{K}]^{2+}=760.5481$, (Theoretical $\mathrm{m} / \mathrm{z}[\mathrm{M}+\mathrm{H}+\mathrm{K}]^{2+}=760.5430$ ). Anal. Calcd for $\mathrm{C}_{88} \mathrm{H}_{148} \mathrm{~N}_{6} \mathrm{O}_{12}: \mathrm{C}, 71.31 ; \mathrm{H}, 10.06 ; \mathrm{N}, 5.67$. Found: C, 71.68; H, 10.30; N, 5.61.

Compound 19. A mixture of mono-substituted amide L4 (1.79 g, $7.67 \mathrm{mmol})$, ethyldiisopropyl-amine (2.54 ml, $15.37 \mathrm{mmol})$, and PyBOP (4.40 g, $8.46 \mathrm{mmol})$ was stirred in $40 \mathrm{ml}$ of DMF for approximately $30 \mathrm{~min}$. Subsequently, $1.95 \mathrm{~g}(2.31 \mathrm{mmol})$ of amine $(\mathbf{P a})$ was added and stirred for $48 \mathrm{~h}$. Upon treatment with $10 \%$ hydrochloric acid, a white solid precipitated from the solution. A solid was collected, extracted with diethyl ether, and the organic solution was further washed with $0.5 \mathrm{M}$ sodium hydroxide, and dried over magnesium sulfide. The solvent was evaporated under reduced pressure leaving $2.90 \mathrm{~g}(84 \%)$ of light yellow product. ${ }^{1} \mathrm{H}$ NMR $\left(\mathrm{CDCl}_{3}\right): \delta=0.51\left(\mathrm{~m}, 18 \mathrm{H} ; \mathrm{CH}_{2} \mathrm{CH}_{3}\right), 1.12\left(\mathrm{~s}, 18 \mathrm{H} ; \mathrm{CCH}_{3}\right), 1.21\left(\mathrm{~d}, J=6.4 \mathrm{~Hz}, 18 \mathrm{H} ; \mathrm{NCHCH}_{3}\right)$, $1.31\left(\mathrm{~s}, 18 \mathrm{H} ; \mathrm{CCH}_{3}\right), 1.37$ (d, $J=6.2 \mathrm{~Hz}, 18 \mathrm{H} ; \mathrm{NCHCH}_{3}$ ), $1.20-1.70$ (two broad multiplets, $6 \mathrm{H}$ $+6 \mathrm{H} ; \mathrm{CH}_{2} \mathrm{CH}_{3}$ ), $3.27-4.10$ (signals: $6 \mathrm{H}, \mathrm{O}-\mathrm{CH}_{2} \mathrm{CH}_{2} ; 6 \mathrm{H}, \mathrm{OCH}_{2} ; 6 \mathrm{H}, \mathrm{OCH}_{2} ; 6 \mathrm{H}, \mathrm{CH}_{2} \mathrm{CH}_{2}-\mathrm{NH}_{2}$; 6H, $\mathrm{NCHCH}_{3}$ ), 6.43 (s, 1H; CH), 7.01 (s, $\left.3 \mathrm{H} ; \mathrm{Ar}-H\right), 7.07$ (s, $\left.3 \mathrm{H} ; \mathrm{Ar}-H\right), 7.94$ (bt, $\left.3 \mathrm{H} ; \mathrm{N}-H\right)$. ${ }^{13} \mathrm{C}$ NMR $\left(\mathrm{CDCl}_{3}\right): \delta=9.3,9.7,20.6,20.9,28.7,29.7,35.3,35.5,36.1,37.0,38.7,39.3,40.2$, 46.2, 49, 7, 49, 9 (aliphatic); 70.3 $\left(\mathrm{O}-\mathrm{CH}_{2}\right) ; 125.0,127.9,137.8,140.0,142.9,153.2$ (aromatic); 167.7, $169.7(\mathrm{C}=\mathrm{O})$. HR ESI-ICR MS m/z $[\mathrm{M}+\mathrm{Na}]^{+}=1509.9872\left(\right.$ Theoretical $\mathrm{m} / \mathrm{z}[\mathrm{M}+\mathrm{Na}]^{+}=$ 1509.9893). Anal. Calcd for $\mathrm{C}_{85} \mathrm{H}_{142} \mathrm{~N}_{6} \mathrm{O}_{9} \mathrm{~S}_{3}$ : C, 68.60; H, 9.62; N, 5.65, Found: C, 68.94; H, 9.99; N, 5.51. 
NERI Final Report

\section{Advanced Extraction Methods for Actinide/Lanthanide Separations}

Grant No. DE-FG07-02SF22614, SF 269A

Project Number 02-098

Final Report

September 2002 - September 2005

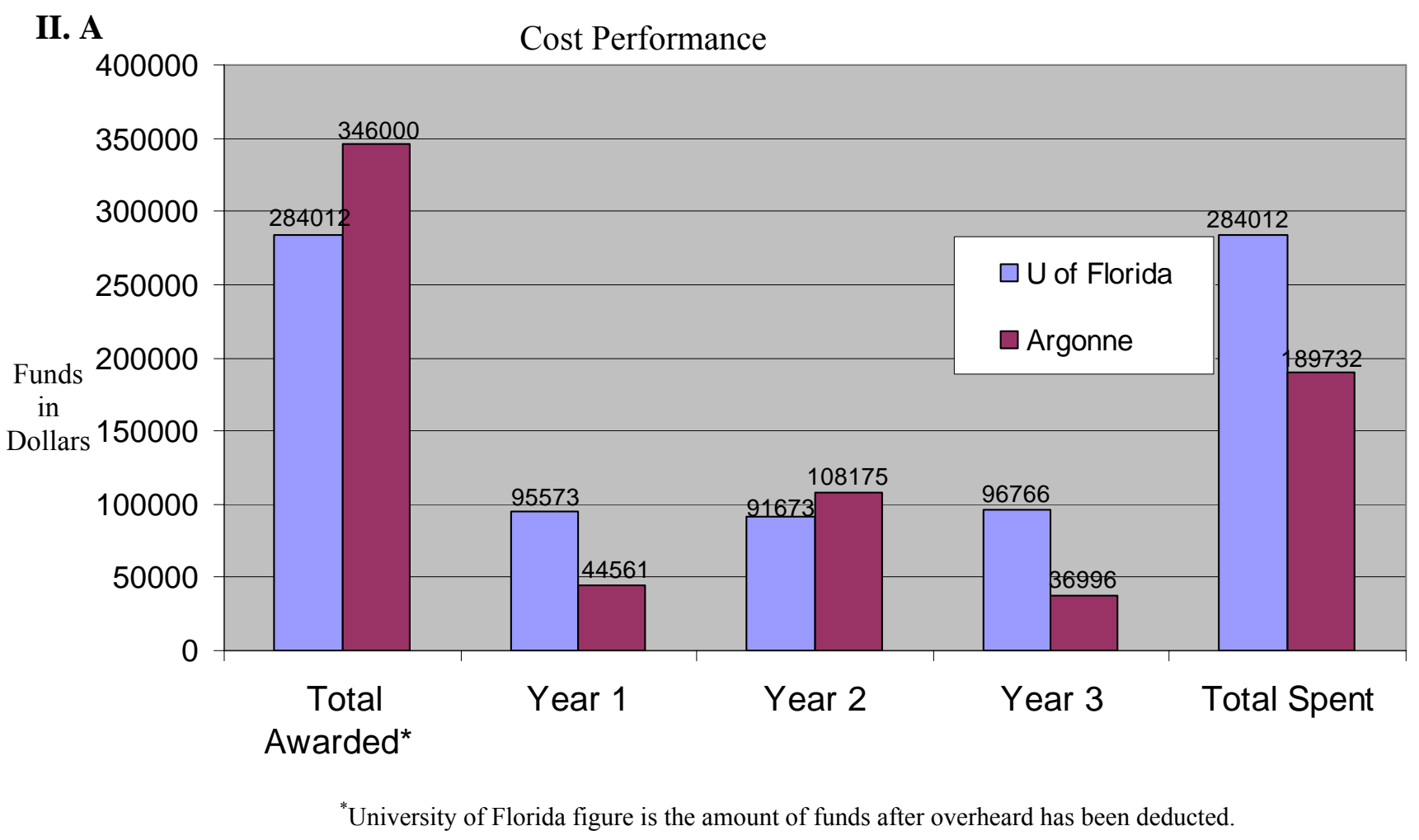


NERI Final Report

\section{Advanced Extraction Methods for Actinide/Lanthanide Separations \\ Grant No. DE-FG07-02SF22614, SF 269A \\ Project Number 02-098 \\ Final Report \\ September 2002 - September 2005}

Status Summary of NERI Tasks - Years 1-3

\begin{tabular}{|c|c|c|c|}
\hline $\begin{array}{c}\text { Milestone/Task } \\
\text { Description }\end{array}$ & $\begin{array}{c}\text { Planned } \\
\text { Completion } \\
\text { Date }\end{array}$ & $\begin{array}{c}\text { Actual Completion } \\
\text { Date }\end{array}$ & Percent Complete \\
\hline $\begin{array}{c}\text { Analysis of Binding } \\
\text { Properties of 8a with Am } \\
\text { Argonne }\end{array}$ & $12 / 30 / 02$ & $3 / 30 / 02$ & $100 \%$ \\
\hline $\begin{array}{c}\text { Full Screening of Binding } \\
\text { Properties of 8d at Florida }\end{array}$ & $3 / 30 / 02$ & $3 / 15 / 02$ & $100 \%$ \\
\hline $\begin{array}{c}\text { Full Screening of Binding } \\
\text { Propertis of 5 at UF. }\end{array}$ & $5 / 30 / 03$ & $5 / 30 / 03$ & $100 \%$ \\
\hline $\begin{array}{c}\text { Extraction Testing of 8a at } \\
\text { Argonne with Pu }\end{array}$ & $5 / 30 / 03$ & $5 / 30 / 03$ & $100 \%$ \\
\hline $\begin{array}{c}\text { Preparation of more soluble } \\
\text { derivative of 8a }\end{array}$ & $6 / 30 / 03$ & $8 / 30 / 03$ & $100 \%$ \\
\hline $\begin{array}{c}\text { Submission of 5 to Argonne } \\
\text { for testing }\end{array}$ & $6 / 30 / 03$ & $\mathrm{NA}$ & $100 \%$ \\
\hline $\begin{array}{c}\text { Extraction Testing at Argonne } \\
\text { with 8a at high Nitrate salt } \\
\text { concentration }\end{array}$ & $6 / 30 / 03$ & $5 / 30 / 03$ & $100 \%$ \\
\hline $\begin{array}{c}\text { Design, isolation, and testing } \\
\text { of CMPS ligands with } \\
\text { enhanced solubility at UF }\end{array}$ & $7 / 30 / 03$ & $8 / 30 / 03$ & $100 \%$ \\
\hline $\begin{array}{c}\text { Testing of binding properties } \\
\text { of new CMPS and new } \\
\text { CMPO ligands at Argonne }\end{array}$ & $10 / 1 / 03$ & $12 / 15 / 03$ & $100 \%$ \\
\hline $\begin{array}{c}\text { Prep/screening (UF) of } \\
\text { CMPO ligands with long arms }\end{array}$ & $8 / 07 / 03$ & $9 / 15 / 03$ & \\
\hline $\begin{array}{c}\text { Preparation/ screening of } \\
\text { CMPS ligands with longer } \\
\text { linker arms }\end{array}$ & $8 / 07 / 03$ & $9 / 15 / 03$ & \\
\hline $\begin{array}{c}\text { Alkylation of nitrogen in } \\
\text { CMPO derivatives }\end{array}$ & $9 / 30 / 03$ & & \\
\hline & & & \\
\hline
\end{tabular}




\begin{tabular}{|c|c|c|c|}
\hline $\begin{array}{l}\text { Scale up and Testing of } \\
\text { Alkylated CMPO derivative }\end{array}$ & $12 / 1 / 03$ & $5 / 15 / 04$ & $100 \%$ \\
\hline $\begin{array}{l}\text { Alkylation of nitrogen in } \\
\text { CMPS derivatives }\end{array}$ & $12 / 30 / 03$ & discontinued & $0 \%$ \\
\hline $\begin{array}{l}\text { Preparation of asymmetric } \\
\text { ligands at UF }\end{array}$ & $4 / 15 / 04$ & discontinued & $75 \%$ \\
\hline $\begin{array}{l}\text { Characterization N-oxide } \\
\text { Ligands Binding }\end{array}$ & $9 / 1 / 04$ & $8 / 15 / 04$ & $100 \%$ \\
\hline $\begin{array}{c}\text { Testing of Alkylated CMPO } \\
\text { derivatives at Argonne }\end{array}$ & $3 / 30 / 04$ & $8 / 30 / 04$ & $100 \%$ \\
\hline $\begin{array}{l}\text { EXAFS Measurements of } \\
\mathrm{Pu}(\mathrm{IV}) \text { species }\end{array}$ & $6 / 30 / 04$ & $11 / 30 / 04$ & $100 \%$ \\
\hline Analysis of EXAFS data & $9 / 30 / 04$ & $\begin{array}{c}1 / 30 / 05 \\
\text { discontinued }\end{array}$ & $50 \%$ \\
\hline $\begin{array}{l}\text { Preparation of new diamide } \\
\text { ligands at UF }\end{array}$ & $10 / 15 / 04$ & $8 / 15 / 04$ & $100 \%$ \\
\hline $\begin{array}{l}\text { Complete Analysis of binding } \\
\text { properties of } 15 \text { in } 1 \mathrm{M} \mathrm{HNO}_{3}\end{array}$ & $11 / 15 / 04$ & $11 / 15 / 04$ & $100 \%$ \\
\hline $\begin{array}{l}\text { Preparation and analysis of } \\
\text { sulfur diamide ligands }\end{array}$ & $11 / 15 / 04$ & $12 / 31 / 04$ & $100 \%$ \\
\hline $\begin{array}{l}\text { Synthesis and Extraction } \\
\text { studies of thiophene ligands }\end{array}$ & $1 / 31 / 05$ & $3 / 15 / 05$ & $100 \%$ \\
\hline $\begin{array}{c}\text { Preliminary Analysis of } \\
\text { binding properties of diamide } \\
\text { ligands at Argonne }\end{array}$ & $12 / 1 / 04$ & $2 / 28 / 05$ & $100 \%$ \\
\hline $\begin{array}{l}\text { Analysis of Sulfur Diamide } \\
\text { ligands at Argonne }\end{array}$ & $1 / 30 / 05$ & $3 / 15 / 05$ & $100 \%$ \\
\hline $\begin{array}{l}\text { Preparation of pyridine } \\
\text { diamide ligands }\end{array}$ & $3 / 31 / 05$ & $3 / 15 / 05$ & $100 \%$ \\
\hline $\begin{array}{c}\text { Complete analysis of } \mathbf{1 5} \text { and } \\
\mathbf{1 7} \text { at Argonne }\end{array}$ & $7 / 15 / 05$ & $5 / 30 / 05$ & $100 \%$ \\
\hline $\begin{array}{l}\text { Submission of Diamide } \\
\text { Manuscript to J. Chem. Soc. } \\
\text { Dalton Transactions }\end{array}$ & $7 / 15 / 05$ & $\begin{array}{c}\text { 6/30/05 } \\
\text { Accepted 10/4/05 }\end{array}$ & $100 \%$ \\
\hline $\begin{array}{c}\text { Submission of CMPO } \\
\text { Mansuscript to Inorganic } \\
\text { Chemistry }\end{array}$ & $8 / 1 / 05$ & $8 / 28 / 05$ & $100 \%$ \\
\hline $\begin{array}{l}\text { Submission of Full Paper on } \\
\text { Diamide Complexes to }\end{array}$ & $10 / 15 / 05$ & $10 / 15 / 05$ & $100 \%$ \\
\hline
\end{tabular}




\begin{tabular}{|c|c|c|c|}
\hline $\begin{array}{c}\text { Solvent Extraction and Ion } \\
\text { Exchange }\end{array}$ & & \\
\hline $\begin{array}{c}\text { Submission of CMPS } \\
\text { Mansuscript to Inorganic } \\
\text { Chemistry }\end{array}$ & $10 / 1 / 05$ & & $50 \%$ \\
\hline
\end{tabular}




\section{References}

(1) Gonzalez, V. L. "U.S. Weapons-Useable Plutonium Disposition Policy: Implementation of the MOX Fuel Option," Amarillo National Resource Center for Plutonium, 1998.

(2) Choppin, G. R.; Nash, K. L. Radiochimica Acta 1995, 70-1, 225-236.

(3) Cecille, L.; Casarci, M.; Pietrelli, L. In New Separation Chemistry Techniques for Radioactive Waste and other Specific Applications; Elsevier Applied Science: New York, 1991.

(4) Madic, C.; Bourges, J.; J.F., D. In International Conference on Accelerator-Driven Transmutation Technology and Applications: Las Vegas, 1994.

(5) Tommasi, J.; Delpech, M.; Grouiller, J. P.; Zaetta, A. Nuclear Technology 1995, 111, 133-148.

(6) Salvatores, M.; Zaetta, A.; Girard, C.; Delpech, M.; Slessarev, I.; Tommasi, J. Applied Radiation and Isotopes 1995, 46, 681-687.

(7) Nash, K. L. Solvent Extraction and Ion Exchange 1993, 11, 729-768.

(8) Ozawa, M.; Nemoto, S.; Nomura, K.; Korea, Y.; Togashi, A. In International Information Exchange Program on Actinide and Fission Product Separation and Transmutation: Argonne, Illinois, 1992.

(9) Bond, W. D.; Leuze, R. E. "Feasibility Studies of the Partitioning of Commercial HighLevel Wastes Generated in Spent Fuel Reprocessing: Anual Progress Report for FY1974," U. S. Atomic Energy Commission, 1975.

(10) Schulz, W. W.; McIsaac, L. D. In International Solvent Extraction Conference: Toronto, Canada, 1979; Vol. 2, p 619.

(11) Schulz, W. W.; Navratil, J. D. In Recent Developement in Separation Science; Li, N. N., Ed.; CRC Press, Inc.: Boca Raton, Florida, 1981; Vol. VII, p 31.

(12) McIsaac, L. D.; Baker, J. D.; Krupa, J. F.; Meikrantz, D. H.; Schroeder, N. C. In Actinide Separation; Navratil, J. D., Schulz, W. W., Eds.; American Chemical Society: Washington D. C., 1980, p 395.

(13) Bond, E. M.; Leuze, R. E. In Actinide Separation; Schulz, W. W., Ed.; American Chemical Society: Washington D. C., 1980, p 441.

(14) Liljenzin, J. O.; Rydberg, J.; Skarnemark, G. Separation Science and Technology 1980, $15,799-824$.

(15) Cecille, L.; Dworschak, H.; Girardi, F.; Hunt, B. A.; Mannone, F.; Mousty, F. In Actinide Separation; Navratil, J. D., Schulz, W. W., Eds.; American Chemical Society: Washington D. C., 1980, p 427.

(16) Koch, G. In Actinide Separation; Navratil, J. D., Schulz, W. W., Eds.; American Chemical Society: Washington D. C., 1980, p 411.

(17) Ishimori, T. In Actinide Separation; Navratil, J. D., Schulz, W. W., Eds.; American Chemical Society: Washington D. C., 1980, p 343. 
(18) Horwitz, E. P.; Delphin, W. H.; Mason, G. W.; Steindler, M. "Recovery Alternatives Applicable to Waste Streams in Actinide Partitioning and Transmutation Program Process," U. S. Department of Energy, 1978.

(19) Navratil, J. D.; Martella, L. L. In Actinide Recovery from Waste and Low-Grade Sources; navratil, J. D., Schulz, W. W., Eds.; Harwood Academic Publisher: New York, 1982, p 27.

(20) Horwitz, E. P.; Diamond, H.; Kalina, D. G. In Plutonium Chemistry; Carnall, W. C., Choppin, G. R., Eds.; American Chemical Society: Washington D. C., 1983, p 433.

(21) Zhu, Y. J.; Jiao, R.; Wang, S.; Fan, S.; Liu, B.; Zheng, H.; Zhou, S.; Chen, S. In International Solvent Extraction Conference (ISEC'83): Denver, Colorado, 1983.

(22) Horwitz, E. P.; Diamond, H.; Kalina, D. G.; Kaplan, L.; Mason, G. W. In International Solvent Extraction Conference (ISEC'83): Denver, Colorado, 1983.

(23) O'Laughlin, J. W. Progress in Nuclear Energy.; Pergamon Press.: New York, 1966; Vol. 6.

(24) Kalina, D. G.; Horwitz, E. P.; Kaplan, L.; Muscatello, A. C. Separation Science and Technology 1981, 16, 1127-1145.

(25) McKay, H. A. C.; Miles, J. H.; Swanson, J. L. In Science and Technology of Tributyl Phosphate; Schulz, W. W., Navratil, J. D., Eds.; CRS Press: Boca Raton, 1984, p 1.

(26) Miles, J. H. In Science and Technology of Tributyl Phosphate; Schulz, W. W., Navratil, J. D., Eds.; CRS Press: Boca Raton, 1984, p 11.

(27) Horwitz, E. P.; Kalina, D. G.; Diamond, H.; Vandegrift, G. F.; Schulz, W. W. Solvent Extraction and Ion Exchange 1985, 3, 75-109.

(28) Chamberlain, D. B.; Leonard, R. A.; Hoh, J. C.; Gay, E. C.; Kalina, D. G.; Vandegrift, G. F. "TRUEX Hot Demonstration: Final Report," 1990.

(29) Horwitz, E. P.; Kalina, D. G.; Kaplan, L.; Mason, G. W.; Diamond, H. Separation Science and Technology 1982, 17, 1261-1279.

(30) Martin, K. A.; Horwitz, E. P.; Ferraro, J. R. Solvent Extraction and Ion Exchange 1986, 4, 1149-1169.

(31) Baker, J. D.; Mincher, B. J.; Meikrantz, D. H.; Berreth, J. R. Solvent Extraction and Ion Exchange 1988, 6, 1049-1065.

(32) ArnaudNeu, F.; Bohmer, V.; Dozol, J. F.; Gruttner, C.; Jakobi, R. A.; Kraft, D.; Mauprivez, O.; Rouquette, H.; SchwingWeill, M. J.; Simon, N.; Vogt, W. J. Chem. Soc., Perkin Trans. 2 1996, 1175-1182.

(33) Matthews, S. E.; Saadioui, M.; Bohmer, V.; Barboso, S.; Arnaud-Neu, F.; SchwingWeill, M. J.; Carrera, A. G.; Dozol, J. F. Journal Fur Praktische Chemie-ChemikerZeitung 1999, 341, 264-273.

(34) Barboso, S.; Carrera, A. G.; Matthews, S. E.; Arnaud-Neu, F.; Bohmer, V.; Dozol, J. F.; Rouquette, H.; Schwing-Weill, M. J. J. Chem. Soc., Perkin Trans. 2 1999, 719-723. 
(35) Delmau, L. H.; Simon, N.; Schwing-Weill, M. J.; Arnaud-Neu, F.; Dozol, J. F.; Eymard, S.; Tournois, B.; Gruttner, C.; Musigmann, C.; Tunayar, A.; Bohmer, V. Separation Science and Technology 1999, 34, 863-876.

(36) Arduini, A.; Bohmer, V.; Delmau, L.; Desreux, J. F.; Dozol, J. F.; Carrera, M. A. G.; Lambert, B.; Musigmann, C.; Pochini, A.; Shivanyuk, A.; Ugozzoli, F. Chemistry-a European Journal 2000, 6, 2135-2144.

(37) Peters, M. W.; Werner, E. J.; Scott, M. J. Inorganic Chemistry 2002, 41, 1707-1716.

(38) Dinger, M. B.; Scott, M. J. European Journal of Organic Chemistry 2000, 2467-2478.

(39) Xu, J.; Kullgren, B.; Durbin, P. W.; Raymond, K. N. Journal of Medicinal Chemistry 1995, 38, 2606-2614.

(40) Ozawa, M.; Nemoto, S.; Nomura, K.; Korea, Y.; Togashi, A. In OECD/NEA Meeting ANL, 1992.

(41) Diamond, R. M.; Street, K.; Seaborg, G. T. Journal of the American Chemical Society 1954, 76, 1461-1469.

(42) Kandil, A. T.; Aly, H. F.; Raieh, M.; Choppin, G. R. Journal of Inorganic \& Nuclear Chemistry 1975, 37, 229-232.

(43) Musicas, C. In Actinide/Lanthanide Separation; World Scientific Publishing: Honolulu, Hawaii, 1984, p 19.

(44) Smith, B. F.; Jarvinen, G. D.; Jones, M. M.; Hay, P. J. Solvent Extraction and Ion Exchange 1989, 7, 749-765.

(45) Ensor, D. D.; Jarvinen, G. D.; Smith, B. F. Solvent Extraction and Ion Exchange 1988, 6, 439-445.

(46) Chen, J.; Zhu, Y. J.; Jiao, R. Z. Separation Science and Technology 1996, 31, 2723-2731.

(47) Cossy, C.; Helm, L.; Merbach, A. E. Inorganic Chemistry 1988, 27, 1973-1979.

(48) Abbasi, A.; Lindqvist-Reis, P.; Eriksson, L.; Sandstrom, D.; Lidin, S.; Persson, I.; Sandstrom, M. Chemistry-a European Journal 2005, 11, 4065-4077.

(49) Floris, F. M.; Tani, A. Journal of Chemical Physics 2001, 115, 4750-4765.

(50) Stephan, H.; Gloe, K.; Beger, J.; Muhl, P. Solvent Extraction and Ion Exchange 1991, 9, 459-469.

(51) Yao, J.; Wharf, R. M.; Choppin, G. R. In Separation of F-Elements; Nash, K. L., Choppin, G. R., Eds.; plenum Press: New York, 1995, 1995, pp 31-42.

(52) Sasaki, Y.; Choppin, G. R. JOURNAL OF RADIOANALYTICAL AND NUCLEAR CHEMISTRY-ARTICLES 1996, 207, 383-394.

(53) Sasaki, Y. I.; Choppin, G. R. ANALYTICAL SCIENCES 1996, 12, 225-230.

(54) Sasaki, Y.; Tachimori, S. Solvent Extraction and Ion Exchange 2002, 20, 21-34.

(55) Narita, H.; Yaita, T.; Tamura, K.; Tachimori, S. Radiochimica Acta 1998, 81, 223-226. 
(56) Sasaki, Y.; Sugo, Y.; Suzuki, S.; Tachimori, S. Solvent Extraction and Ion Exchange 2001, 19, 91-103.

(57) Sasaki, Y.; Sugo, Y.; Tachimori, S. In International Conference ATALANTE 2000: Avignon, France, 2000.

(58) Zhu, Z. X.; Sasaki, Y.; Suzuki, H.; Suzuki, S.; Kimura, T. Analytica Chimica Acta 2004, 527, 163-168.

(59) Narita, H.; Yaita, T.; Tachimori, S. In ISEC'99: Barcelona, Spain, 1999, pp 693-696.

(60) Shannon, R. D. Acta Crystallographica Section A 1976, 32, 751-767.

(61) Zhang, Y.; Liu, W.; Wang, Y.; Tang, N.; Tan, M.; Yu, K. Journal of Coordination Chemistry 2002, 55, 1293-1299.

(62) Spjuth, L.; Liljenzin, J.; Skalberg, M.; Hudson, M.; Chan, G.; Drew, M.; Feaviour, M.; Iveson, P.; Madic, C. RADIOCHIMICA ACTA 1997, 78, 39-46.

(63) Matloka, K.; Sah, A. K.; Peters, M. W.; Srinivasan, P.; Gelis, A.; Regalbuto, M.; Vandegrift, G. F.; Scott, M. J. Inorganic Chemistry.

(64) Matloka, K. ; Scott, M. J. Unpublished data.

(65) Matloka, K.; Gelis, A.; Regalbuto, M.; Vandegrift, G. F.; Scott, M. J. Dalton Transactions 2005.

(66) Sasaki, Y.; Choppin, G. R. Journal of Radioanalytical and Nuclear Chemistry 1997, 222, 271-274.

(67) Sasaki, Y.; Adachi, T.; Choppin, G. R. Journal of Alloys and Compounds 1998, 271, 799802.

(68) Sasaki, Y.; Choppin, G. R. Journal of Radioanalytical and Nuclear Chemistry 2000, 246, 267-273.

(69) Herbst, R. S.; Law, J. D.; Todd, T. A.; Romanovskiy, V. N.; Smirnov, I. V.; Babain, V. A.; Esimantovskiy, V. N.; Zaitsev, B. N. In The 14th Symposium

on Separation Science and Technology for Energy Applications: Gatlinburg, TN, 2005.

(70) Reinoso-Garcia, M. M.; Verboom, W.; Reinhoudt, D. N.; Brisach, F.; Arnaud-Neu, F.; Liger, K. 2005, 23, 425-437.

(71) Gruner, B.; Mikulasek, L.; Cisarova, I.; Bohmer, V.; Danila, C.; Reinoso-Garcia, M. M.; Verboom, W.; Reinhoudt, D. N.; Casnati, A.; Ungaro, R. 2005, 2022-2039.

(72) Herbst, R. S.; Law, J. D.; Todd, T. A.; Romanovskiy, V. N.; Smirnov, I. V.; Babain, V. A.; Esimantovskiy, V. N.; Zaitsev, B. N. 2003, 38, 2685-2708.

(73) Smirnov, I. V.; Babain, V. A.; Shadrin, A. Y.; Efremova, T. I.; Bondarenko, N. A.; Herbst, R. S.; Peterman, D. R.; Todd, T. A. 2005, 23, 1-21.

(74) Coupez, B.; Wipff, G. 2004, 7, 1153-1164.

(75) Law, J. D.; Herbst, R. S.; Peterman, D. R.; Tillotson, R. D.; Todd, T. A. 2004, 147, $284-$ 290. 
(76) Smirnov, I. V.; Stoyanov, E. S.; Vorob'eva, T. P. 2003, 53, A501-A508.

(77) Herbst, R. S.; Law, J. D.; Todd, T. A.; Romanovskiy, V. N.; Babain, V. A.; Esimantovskiy, V. M.; Smirnov, I. V.; Zaitsev, B. N. 2002, 20, 429-445.

(78) Reinoso-Garcia, M. M.; Dijkman, A.; Verboom, W.; Reinhoudt, D. N.; Malinowska, E.; Wojciechowska, D.; Pietrzak, M.; Selucky, P. 2005, 2131-2138.

(79) Marczenko, Z. Separation and spectrophotometric determination of elements; E. Horwood; Halsted Press: Chichester New York, 1986.

(80) Cleveland, J. M. The Chemistry of Plutonium; Gordon and Breach Science: New York, 1969.

(81) Peters, M. W.; University of Florida: Gainesville, Florida, 2002.

(82) Fieser, L. F.; Fieser, M. Reagents for organic synthesis; Wiley: New York, 1967.

(83) Ping, Z.; Jing, C.; Chunyu, L.; Guoxin, T. Chemical Journal on Internet 2003, 5, 52. 